Universidade de São Paulo

Instituto de Física

\title{
Estudo da sintonia das emissões ópticas de pontos quânticos de InAs/GaAs nas regiões de
} $1,3 \mu \mathrm{m} \mathrm{e} 1,5 \mu \mathrm{m}$

\section{Marcelo Jacob da Silva}

Orientador: Alain André Quivy

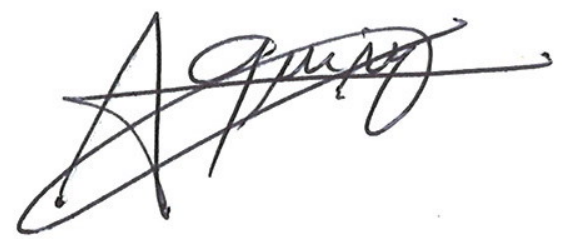

INSTITUTO DE FÍSICA

Serviço de Biblioteca e Informação

Tombo: $3961 \mathrm{ex} .1$

Comissão Examinadora

Prof. Dr. Alain André Quivy (IFUSP)

Profa. Dra. Maria Cecília B. S. Salvadori (IFUSP)

Prof. Dr. Fernando Iikawa (UNICAMP)

Prof. Dr. Wagner Nunes Rodrigues (UFMG)

Profa. Dra. Patrícia Lustoza de Souza (PUC-Rio)

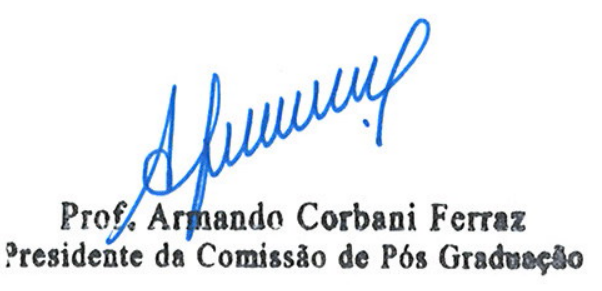

São Paulo

-2003-

SBI-IFUSP

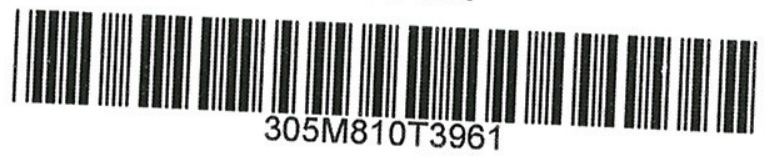


FICHA CATALOGRÁFICA

Preparada pelo Serviço de Biblioteca e Informação do Instituto de Física da Universidade de São Paulo

Silva, Marcelo Jacob da

Estudo da Sintonia das Emissões Ópticas de Pontos Quânticos de InAs/GaAs nas Regiões de $1,3 \mu \mathrm{m}$ e 1,5 $\mu \mathrm{m}$. São Paulo, 2003

Tese (Doutoramento) Universidade de São Paulo Instituto de Física - Depto. de Física dos Materiais e Mecânica

Orientador: Prof. Dr. Alain André Quivy Área de Concentração: Física da Matéria Condensada

Unitermos: 1. Semicondutores;

2. Pontos Quânticos;

3. Epitaxia por feixe molecular;

4. Fotoluminescência;

5. Microscopia de força atômica. 


\section{Agradecimentos}

Durante os quatro anos de execução dessa tese, tive a grande sorte de compartilhar do trabalho de pessoas que foram para mim muito mais do que colaboradores competentes. Foram amigos, com os quais dividi as alegrias e excitações da descoberta cientifica e também as frustrações comuns do dia-a-dia de qualquer pessoa. Com meus colegas de MBE, Sandro e Tomás, vivi os melhores momentos de minha carreira como estudante.

Sendo um trabalho de doutorado uma atividade longa e que envolve interações com um grande número de pessoas, certamente serei injusto em meus agradecimentos com pelo menos uma dezena de colegas. Não posso, no entanto, deixar de agradecer a turma do LNMS: Geraldo, Américo, Cássio, Celso, Paulinho, Ivan, Odile, Rafael, Márcia, Ângela, Júlio, Lara, Mônica, Profa. Euzi e Prof. J. R. Leite. Agradeço os colegas da UnB: Profa. Maria, Prof. Sebastião, Prof. Junio, Dr. Ádamo e Dr. Frank; os colegas da USP-São Carlos, Prof. Euclydes e Dr. Pedro; os colegas da Unicamp, Prof. Eliermes e Prof. Fernando; do LNLS, Prof. D. Ugarte e Pulinho; e do IFUSP, Profa. Cecília Salvadori. Meu trabalho só foi possível graças à colaboração e interação com essas pessoas, com quem tive importantes lições. Impossível também deixar de mencionar os colegas da USC (University of Southern California) com os quais tive o privilégio de trabalhar por quase um ano durante meu estágio nos EUA: Prof. A. Madhukar, Prof. O. Schimidt, Dr. Chen, Dr. Kim, Max, Syiuan Lu, Hooman e o adorável casal Mary e Barret Shiff. Agradeço os colegas Eng. Caio W. Kramer, Eng. Egídio Faria e César Souza, por me oferecerem a chance de uma continuidade promissora de minha carreira como pesquisador

Agradeço do fundo do coração às pessoas mais importantes da minha vida: meu irmão Marcos, meus pais Antonio e Vilma, e minha avó Maria.

E finalmente, agradeço à FAPESP e a Voith Siemens Hydro Power Generation, sem as quais essa página de agradecimentos, e as outras 100 páginas a seguir não existiriam. 


\section{Índice}

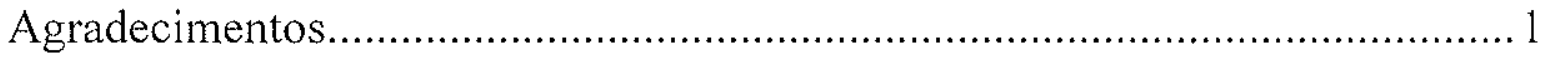

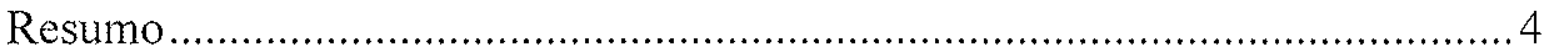

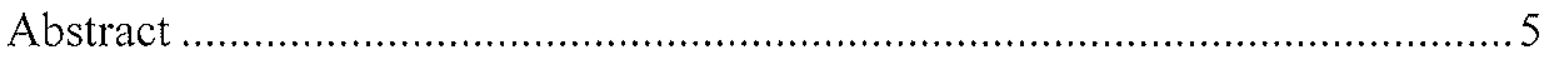

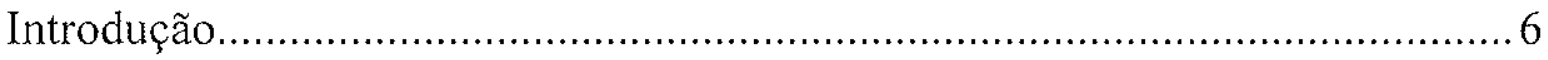

Capítulo 1 - Aspectos conceituais de MBE ……....................................... 13

1.1 - A técnica MBE

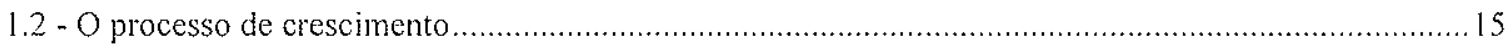

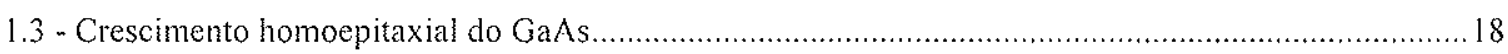

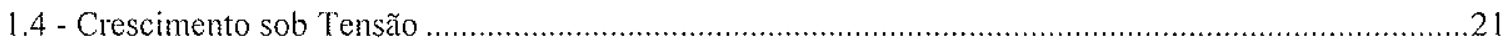

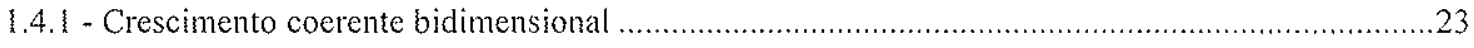

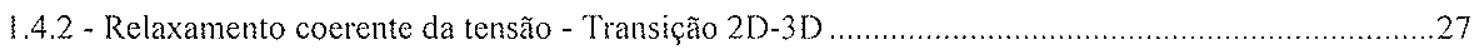

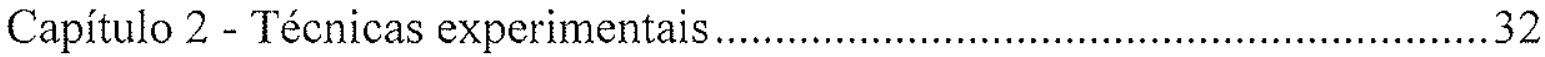

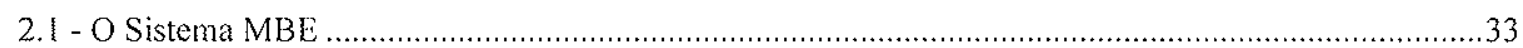

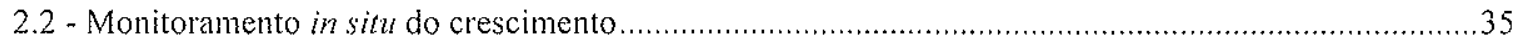

2.3 - Aplicação do RHEED no crescimento de pontos quânticos ................................................................. 39

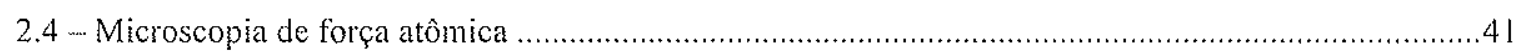

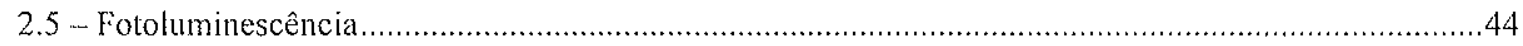

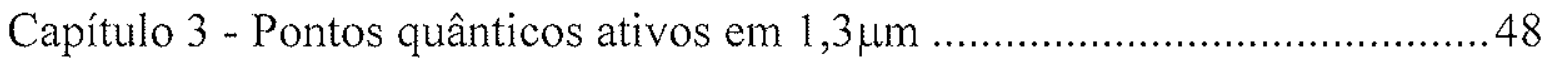

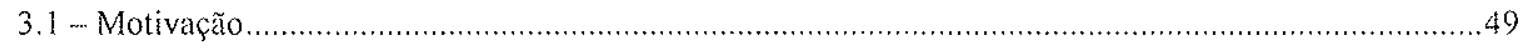

3.2 - Aspectos gerais do crescimento de pontos quânticos ativos em $1,3 \mu \mathrm{m} \ldots \ldots \ldots \ldots \ldots \ldots \ldots \ldots \ldots \ldots \ldots \ldots \ldots \ldots \ldots \ldots . . .54$

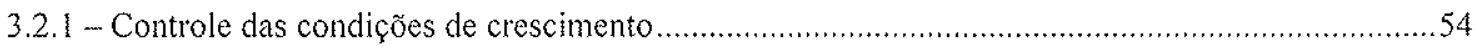

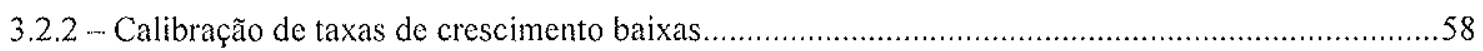

3.2.3 -..-Nossa receita para o crescimento e caracterização de pontos quânticos ativos em $1,3 \mu m$.............59

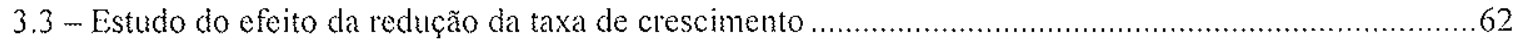

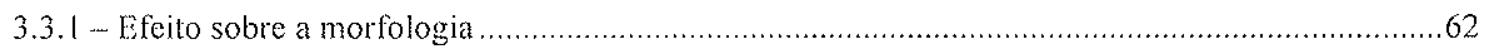

3.3.2 - Efeito sobre as propriedades ópticas * sintonia da emissão em $1,3 \mu m \ldots \ldots \ldots \ldots \ldots \ldots \ldots \ldots \ldots \ldots \ldots \ldots \ldots . . .67$ 
3.4 -- Evolução dos pontos quânticos em função da quantidade de InAs depositado ...............................81

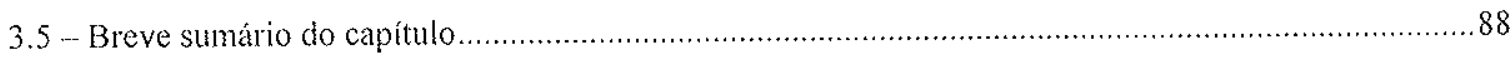

\section{Capítulo 4 - Manipulação das condições de crescimento para atividade óptica}

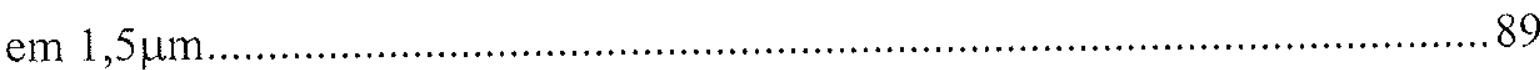

4.1 - Extensão do grau de manipulação das propriedades de pontos quânticos de InAs/GaAs .................90

4.1.1 - Comb́nação de baixa taxa de crescimento com alta temperatura do substrato .........................90

4.2 .... Propriedades ópticas de pontos quânticos ativos em 1,4-1,5 Hm .........................................95

Capítulo 5 - Considerações finais e conclusão …...................................... 103

5.1 ... Acoplamento vertical vs. baixa taxa de crescimento ............................................................ 104

5.2 ... Controle da densidade de pontos quânticos crescidos em baixa taxa ....................................... 106

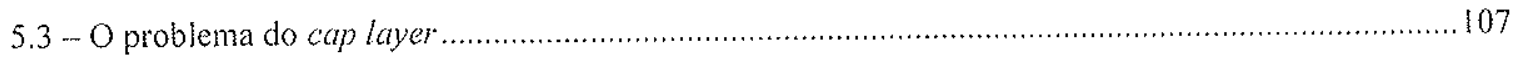

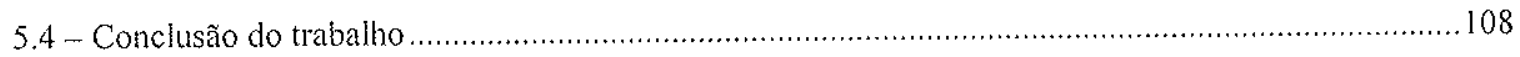

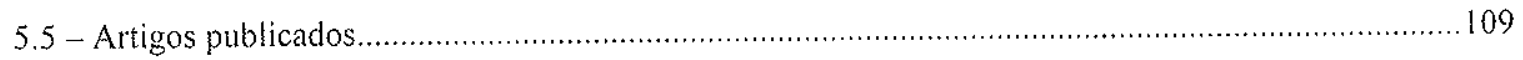

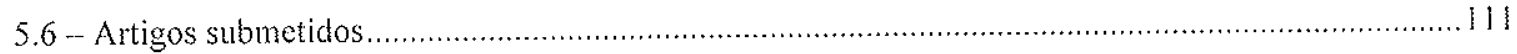

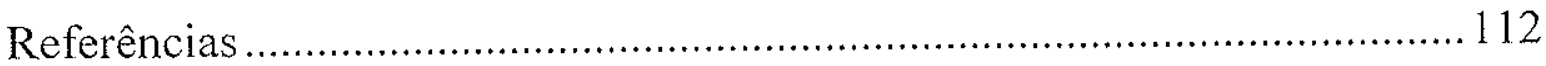




\section{Resumo}

Nesse trabalho, estudamos o crescimento epitaxial por feixe molecular de pontos quânticos de InAs/GaAs, bem como suas propriedades ópticas e morfológicas. O método de crescimento em baixa taxa foi usado para a fabricação de estruturas de pontos quânticos com alturas médias suficientes para a obtenção de resposta óptica nas faixas de $1,3 \mu \mathrm{m}$ e $1,5 \mu \mathrm{m}$ em temperatura ambiente. O interesse na manufatura desse tipo de amostra decorre do fato de serem estes os comprimento de onda de mínima atenuação de sinal em redes de transmissão por fibras ópticas. O estudo sistemático das etapas envolvidas na evolução de pontos quânticos de superfície no regime de baixa taxa de deposição permitiu entender como tais estruturas, com alturas médias bem maiores que as normalmente obtidas na literatura, puderam ser alcançadas. As condições de crescimento foram otimizadas para a produção de emissões estreitas nas faixas de comprimento de onda de interesse. 


\section{Abstract}

In this work, we studied the molecular-beam epitaxy of InAs/GaAs quantum dots as well as their optical and morphological properties. The low growth rate approach allowed the manufacture of quantum dots large enough to provide an optical response in the vicinities of $1,3 \mu \mathrm{m}$ and $1,5 \mu \mathrm{m}$ at room temperature. The interest in this kind of structure lays on the fact that such wavelength windows represent the regions of minimal signal attenuation in optical-fiber communication systems. The systematic investigation of the steps involved in the evolution of surface quantum dots grown under low rate allowed us to understand how such structures, with an average size much larger than that normally obtained in the literature, could be achieved. The growth conditions were optimized to produce samples with narrow optical emissions tuned around the interesting wavelength ranges. 


\section{Introdução}

Do final do século XIX até as primeiras décadas do século XX, uma grande parte da pesquisa realizada em Física foi voltada para o estudo dos átomos. Naquele período, descobertas como a da existência de séries regulares nas emissões espectrais do átomo de hidrogênio (séries de Lyman, Balmer, Paschen, etc.) e sua posterior interpretação teórica através de modelos semi-clásssicos (Rutherford, Bohr) demonstraram que os valores de energia de elétrons ligados ao núcleo atômico poderiam assumir apenas valores discretos e bem determinados (dentro dos limites das relações de incerteza de Heisenberg). Associados aos possiveis valores de energia que um elétron pode possuir quando ligado ao átomo, estão os níveis de energia do sistema núcleo-elétron. Um elétron devidamente excitado a partir da absorção de uma quantidade específica de energia pode saltar para um dos níveis superiores e, de modo oposto, tende a emitir uma porção determinada de energia (fóton) ao relaxar para um nível de energia menor.

Em 1928, com a introdução do conceito de estrutura de bandas de energia em sólidos cristalinos, Bloch [1] criou uma importante ramificação na pesquisa das propriedades atômicas que até então dedicava-se ao estudo dos espectros atômicos discretos obtidos através de descargas elétricas em gases rarefeitos. Em contraste com os gases, os átomos em um cristal são fortemente ligados entre si e arranjam-se em altíssima densidade. De fato, é justamente essa alta densidade de átomos a principal responsável pela imensa gama de aplicações dos materiais sólidos em dispositivos eletrônicos e optoeletrônicos modernos. A disposição concentrada de átomos permite, por exemplo, que um detector de material semicondutor tenha uma alta absorção, criando uma densidade elevada de portadores que podem fluir através do cristal, fornecendo uma corrente de detecção facilmente mensurável. De modo semelhante, a inversão de população em um laser de material cristalino é facilitada pelo alto ganho do meio denso. Um laser moderno de material semicondutor com um comprimento de cerca de $1 \mathrm{~mm}$ e seção transversal da ordem de apenas $10^{-4} \mathrm{~mm}^{2}$ pode emitir luz continuamente com uma potência que excede 1 
W, enquanto um laser ativado a partir de um gás deve possuir um comprimento da ordem de $1 \mathrm{~m}$ para essa mesma finalidade.

A pequena separação entre os átomos que compõem o sólido cristalino torna possível uma sensível interação entre os elétrons dos átomos que o compõem. É essa interação a responsável pela formação das faixas de valores permitidos de energias (bandas de energia) propostas por Bloch, em oposição a valores discretos de energia observados nos espectros de átomos individuais. As regiões entre as bandas de energia representam estados proibidos de ocupação de portadores e são denominadas gaps* de energia. Um portador (elétron ou buraco) que venha a ocupar um estado de energia no interior dessas bandas comporta-se como se fosse uma partícula livre, possuindo uma total delocalização de sua função de onda. Nessa situação, o portador pode mover-se ao longo do meio cristalino em qualquer direção do espaço tridimensional real, semelhante ao que faria se estivesse no vácuo. A analogia com o movimento no vácuo é quase total quando as interações da carga do portador em movimento com o ambiente do cristal são levadas em conta através de uma modificação na massa do portador em relação àquela que teria se estivesse de fato no vácuo. Como essa massa efetiva do portador depende de sua interação com o ambiente no interior do cristal, ela varia entre os materiais. Para os materiais III-V (GaAs, InAs, etc.) as massas efetivas dos elétrons variam entre $1 \%$ e $10 \%$ da massa do elétron no vácuo.

Um ponto central na teoria de Bloch a respeito das bandas de energia é o fato do cristal ser considerado como um meio de dimensões infinitas em todas as direções. Na prática, basta que as dimensões do cristal sejam muito maiores que o comprimento de onda de de Broglie do portador para que este se comporte como uma partícula livre no interior do material. Uma ruptura total desse comportamento surge quando a dimensão do cristal em uma direção qualquer é reduzida ao nível do comprimento de onda de de Broglie do portador. Nesse caso, a limitação do movimento em uma dimensão leva à manifestação de efeitos de quantização, eliminando o caráter contínuo das bandas de energia. $O$ comprimento de onda de de Broglie $(\lambda)$ depende da massa efetiva do portador do seguinte modo:

\footnotetext{
* Ao longo desse trabalho procuraremos, sempre que possível, usar palavras em português. Existem, no entanto, determinados termos como gap, bulk, ataque quimico etc., que estão tão fortemente enraizados no jargão da física de semicondutores que optamos por manter os mesmos em inglês. Quando for esse o caso, essas palavras estarão escritas em itálico.
} 


$$
\lambda=\frac{h}{\mathrm{p}}=\frac{\mathrm{h}}{\sqrt{3 \mathrm{~m}_{\mathrm{cr}} \mathrm{kT}}}
$$

onde h é a constante de Planck $\left(6,63 \times 10^{-34} \mathrm{~J} . \mathrm{s}\right)$, p representa o momento do portador, $\mathrm{m}_{\mathrm{ef}}$ é a massa efetiva, $\mathrm{k}$ é a constante de Boltzman $\left(1,38 \times 10^{-23} \mathrm{~J} . \mathrm{K}^{-1}\right)$ e T a temperatura do cristal em Kelvin. Sendo a massa efetiva muitas vezes menor que a massa do portador no vácuo, os efeitos de quantização devem tornar-se presentes em cristais com espessuras da ordem de centenas de vezes o parâmetro de rede do material. O fato de uma espessura dessa ordem ser grande em comparação com as dimensões atômicas típicas estimulou a idéia de se produzir na prática estruturas cristalinas com pelo menos uma das dimensões reduzidas a esse nível para a investigação dos efeitos de quantização. Trabalhos com essa finalidade iniciaram-se no final dos anos 50 e início dos anos 60. As dificuldades tecnológicas para a confecção de filmes cristalinos muito finos e de boa qualidade limitaram a maior parte da pesquisa desenvolvida nessa época a trabalhos puramente teóricos [2,3]. Uma grande mudança ocorreu no início da década de 70 com o surgimento das técnicas epitaxiais, sobretudo a epitaxia por feixe molecular (ou simplesmente MBE, de molecular beam epitaxy). Esse método tornou possível a inserção de camadas com espessura de apenas algumas monocamadas atômicas de um cristal semicondutor no interior de um volume cristalino de um segundo material semicondutor com um gap de energia maior que o primeiro, criando uma estrutura de poço de potencial (QW, quantum well) bidimensional onde o movimento dos portadores é restringido em uma das direções. Em 1974, Dingle et al. [4] mediram o espectro de absorção em um $\mathrm{QW}$ de $\mathrm{Al}_{x} \mathrm{Ga} a_{-x} \mathrm{As} / \mathrm{GaAs}$ crescido epitaxialmente e observaram a forma de uma função degrau, esperada para uma estrutura dessa natureza com efeitos de confinamento em uma direção. Uma diminuição da espessura do filme de GaAs que compunha o poço era acompanhada de um deslocamento da posição dos degraus do espectro para altas energias, evidenciando o efeito da redução da dimensão sobre os estados de energia do sistema. Uma avalanche de trabalhos experimentais e teóricos decorreu da difusão das técnicas epitaxiais, e no final dos anos 80 a maior parte das propriedades dos QWs já era bem compreendida. O controle dos níveis de energia através de variações da espessura dos filmes, assim como a possibilidade de se estender esse grau de manipulação através da combinação de diferentes materiais, permitiram que as técnicas 
epitaxiais produzissem diversos tipos de dispositivos eletrônicos e optoeletrônicos usados na sociedade moderna. Em particular, a redução da dimensionalidade de cristais semicondutores favorece as aplicações que envolvem processos sobre comprimentos de onda (ou energia) específicos, como laseres (emissão de luz num comprimento de onda bem determinado) e fotodetectores (deteç̧ão de uma radiação específica). Em um material semicondutor de volume macroscópico (bulk*), portadores injetados no material distribuem-se preenchendo o continuum das bandas de energia, sendo susceptíveis aos diversos mecanismos de espalhamento de elétrons e buracos. Nessa situação, as distribuições de portadores próximos ao fundo da banda de condução e topo da banda de valência alargam-se facilmente com a temperatura. Esse alargamento é uma característica indesejada em um dispositivo como um laser onde a performance é maximizada se os portadores puderem ser concentrados na vizinhança de um comprimento de onda específico de operação do dispositivo. Se, por outro lado, utilizar-se um sistema que permite o confinamento dos portadores, mesmo que em uma única direção como num $\mathrm{QW}$, então, o problema é minimizado já que a quantização das bandas de energia na direção de confinamento impede a distribuição contínua dos portadores. Algo análogo ocorre com os detectores de comprimento de onda específico, sendo esse mais um bom exemplo dos benefícios da redução da dimensionalidade para aplicações tecnológicas.

O ganho no desempenho desse tipo de dispositivo através da redução da dimensionalidade em uma direção motivou o passo seguinte no desenvolvimento de estruturas semicondutores mesoscópicas baseado na redução progressiva das dimensões do cristal nas outras direções. A redução definitiva da dimensionalidade, permitindo o confinamento de portadores nas três direções espaciais do cristal, leva ao que hoje se convencionou chamar de pontos quânticos (QDs, quantum dots). Um QD é, portanto, um volume de material semicondutor pequeno o bastante para apresentar efeitos de quantização e ainda grande o suficiente para conter um número elevado de átomos $\left(>10^{4}\right)$. A quantização da energia nas três direções aniquila a formação de bandas contínuas no interior da estrutura, tornando seu espectro de energia totalmente discreto, de modo semelhante ao encontrado em átomos individuais. É muito interessante notar a rota cíclica

\footnotetext{
* Usaremos a palavra bulk quando nos referirmos a um volume de determinado material semicondutor com dimensões muito maiores que o comprimento de onda de de Broglie dos portadores, onde as bandas de energia são contínuas, não havendo efeitos de confinamento.
} 
percorrida nessa área da física onde o foco partiu do estudo de espectros discretos de átomos em gases rarefeitos, passando para os sistemas sólidos com bandas contínuas de energia capazes de permitir o movimento livre de portadores, e finalmente convergindo para a redução da dimensionalidade, recuperando nos QDs o caráter discreto dos níveis de energia inicialmente encontrados apenas nos átomos.

As primeiras tentativas de se produzir QDs envolveram a inserção de materiais semicondutores, como $\mathrm{ZnS}, \mathrm{ZnSe}$ ou CdSe, em uma matriz vítrea [5]. A dificuldade no controle dos tamanhos e formas das nanoestruturas e o fato delas serem imersas em um meio isolante não permitiram que esse tipo de técnica se desenvolvesse ao ponto de visar qualquer aplicação na confecção de dispositivos eletrônicos ou optoeletrônicos. A corrida para a produção de pontos quânticos realmente promissores para aplicações tecnológicas iniciou-se de fato em meados da década de 80 através do uso de técnicas litográficas no processamento de QWs crescidos por MBE. Com esse método, pontos quânticos de GaAs com dimensões da ordem de 10-50 nm imersos numa matriz de $\mathrm{Al}_{x} \mathrm{Ga}_{1 . x}$ As puderam ser fabricados de maneira sistemática [6]. As imperfeições criadas nas estruturas durante o processamento, que basicamente consiste na remoção de parte do filme semicondutor através de ataque químico químico, diminuíram no entanto, as perspectivas da aplicação prática desse tipo de técnica. Um progresso significativo nessa área ocorreu no início dos anos 90 com a observação de que QDs com total perfeição cristalina poderiam ser produzidos in situ através de um processo de auto-organização do material depositado durante o crescimento $\mathrm{MBE}$ de fillmes sob tensão [7,8]. Os processos de auto organização dizem respeito a efeitos de ordenação espontânea (sem intervenção externa ao sistema, como por exemplo a ação do homem) e estão presentes de diversas formas na natureza, desde a formação de dunas de areia no deserto até a pigmentação da pele de alguns animais. Pontos quânticos assim formados possuem a grande vantagem de dispensarem qualquer tipo de processamento pós-crescimento o que lhes permite a manutenção da qualidade cristalina. Além disso, já os primeiros resultados [9] com esse método mostraram ser possível a obtenção de estruturas em altíssimas densidades $\left(\sim 10^{11} \mathrm{~cm}^{-2}\right)$, algo extremamente positivo para aplicações como laseres e sistemas de detecção. Esse processo de formação de estruturas totalmente espontâneo traz consigo, além dessas vantagens, algumas desvantagens relevantes. Talvez a maior delas diga respeito à limitação quanto ao grau de 
manipulação da forma e composição química das estruturas, algo que é indispensável para permitir a versatilidade e, consequentemente, competitividade necessárias aos dispositivos que venham a ser fabricados a partir de QDs. Essa tese se insere justamente no contexto da manipulação estrutural dos QDs (tamanho, forma, etc.) e no impacto dessa manipulação sobre sua resposta óptica.

O objetivo central desse trabalho é investigar os efeitos da redução extrema da taxa de crescimento sobre as características dos pontos quânticos de In $\mathrm{As} / \mathrm{GaAs}$ crescidos por MBE no regime de auto-organização. Estamos interessados sobretudo em abordar a possibilidade de se estender a faixa de emissão luminosa desse sistema para a chamada região de longo comprimento de onda, visando atingir as janelas ópticas em $1.31 \mu \mathrm{m}$ e 1.55 $\mu \mathrm{m}$. Esses valores de comprimento de onda correspondem aos mínimos de atenuação em fibras ópticas convencionais de sílica usadas em sistemas de comunicação de média e longa distância. Do ponto de vista tecnológico e comercial, a confecção de pontos quânticos crescidos sobre substratos de GaAs para operação nessa região do espectro é um objetivo extremamente perseguido. Os resultados esperados de baixa densidade de corrente de limiar (threshold current ${ }^{*}$ ) vêm sendo progressivamente alcançados $[10,11]$ através da obtenção de laseres de QDs de InAs introduzidos em uma matriz de InGaAs crescida sobre substratos de GaAs (100). Essa configuração, geralmente chamada de DWELL (dot in the well) já está sendo usada atualmente por empresas americanas e européias que garantem estar na iminência de apresentar os primeiros laseres comerciais operando en $1.3 \mu \mathrm{m}$. Apesar das baixas correntes de limiar exibidas por essas estruturas, a esperada insensibilidade térmica dos dispositivos de QDs não pôde ainda ser totalmente explorada para esses laseres. O fato da camada ativa de QDs de InAs ser inserida num poço quântico de InGaAs (com concentrações de In em torno de $20 \%$ para operação em $1.3 \mu \mathrm{m}$ ) ao invés de diretamente na matriz de GaAs torna a fuga de portadores dos QDs para o poço quântico um problema ainda significativo para a otimização da performance do dispositivo. Além disso, como o sistema é mantido sob tensão em razão do desacordo entre os parâmetros de rede das ligas envolvidas, espera-se que a densidade de defeitos pontuais atuando como centros de recombinação não radiativa atue negativamente sobre a performance dos dispositivos. Em

\footnotetext{
* Corrente de threshold é a corrente mínima necessária para fornecer um número de portadores suficiente para compensar as perdas na estrutura e realizar a inversão de população no laser.
} 
nossa investigação do crescimento de QDs usando baixas taxas de deposição, procuramos maximizar o tamanho e a concentração de In das estruturas afim de eliminar a necessidade de sua inserção no interior do poço de InGaAs, ou ao menos reduzir a concentração de In necessária no poço. Mostraremos ao longo desse trabalho que QDs de InAs imersos numa matriz de GaAs podem ser aplicados em tais dispositivos para operação na região de 1.3 $\mu \mathrm{m}$. Além disso, apresentaremos resultados que mostram que o grau de manipulação na produção dos QDs através da redução da taxa de crescimento abaixo de $0,01 \mathrm{MC} / \mathrm{s}^{*}$ nos permite estender a faixa de emissão óptica dessas estruturas para $1.4 \mu \mathrm{m}$ e $1.5 \mu \mathrm{m}$, superando algumas expectativas recentemente apresentadas para esse sistema [12].

Essa tese está organizada do seguinte modo. No capítulo 1, apresentaremos uma breve discussão a respeito dos conceitos básicos envolvidos no crescimento MBE e sobretudo no crescimento sob tensão, que é justamente o caso para o sistema In(Ga)As/GaAs que usaremos para a produção de QDs. No capítulo 2, descreveremos as técnicas experimentais usadas no trabalho. Além de uma descrição do sistema MBE, forneceremos detalhes da instrumentação utilizada na caracterização estrutural e óptica das amostras. A apresentação dos resultados inicia-se no capítulo 3, onde estudaremos o crescimento de QDs com resposta óptica na região de $1.3 \mu \mathrm{m}$. No capítulo 4, investigaremos a possibilidade de se manipular o sistema afim de obter emissões na importante região de $1.5 \mu \mathrm{m}$. Finalmente, no capítulo 5 apresentaremos as conclusões e contribuições da tese para esse campo de estudo, bem como perspetivas de aprimoramento das estruturas ora estudadas.

\footnotetext{
* Monocamadas por segundo
} 


\section{Capítulo 1}

\section{Aspectos conceituais de MBE}

Nesse capítulo, abordaremos as idéias básicas relacionadas com a técnica MBE e sua utilização no crescimento de filmes finos. Analisaremos qualitativamente os principais mecanismos cinéticos presentes na trajetória de um átomo desde sua emissão a partir das células de efusão até a incorporação definitiva no meio cristalino. Discutiremos o crescimento homoepitaxial do GaAs sob uma ótica histórica, e alguns dos conceitos teóricos pertinentes ao crescimento sob tensão serão vistos em detalhe. Um exemplo simples ao final do capítulo irá ilustrar como a transição morfológica da frente de crescimento pode ser capaz de acomodar de uma maneira coerente (i. e. sem deslocações) a energia elástica devida à tensão. 


\section{1 - A técnica MBE}

A técnica MBE, abreviatura de molecular beam epitaxy, refere-se a um método de crescimento de filmes finos que envolve a reação de dois ou mais feixes moleculares com a superfície cristalina de um substrato, sob condições de ultra-alto vácuo (pressão abaixo de $10^{-9}$ Torr). A palavra epitaxy refere-se ao fato de que cada camada cristalina em crescimento tende a seguir a orientação cristalográfica da camada imediatamente anterior. O ambiente de ultra-alto vácuo assegura a integridade dos feixes incidentes durante o crescimento e limita os níveis de impurezas não intencionais que eventualmente possam ser incorporadas nas amostras durante o processo de formação do filme. Com essas características, a técnica MBE é capaz de produzir camadas monocristalinas com precisão atômica, permitindo a confecção de nanoestruturas semicondutoras tais como super-redes e poços quânticos capazes de suprir as demandas tecnológicas dos dispositivos microeletrônicos e optoeletrônicos modernos. A produção e o desenvolvimento desses dispositivos motivou a utilização do $\mathrm{MBE}$ no crescimento dos mais variados tipos de compostos cristalinos. Entre os semicondutores, os principais são os das famílias III-V, IIVI e IV-IV. Ao longo dessa tese, as discussões serão focalizadas no crescimento dos elementos III (gálio e índio, principalmente) e V (arsênio).

A primeira tentativa de se produzir estruturas de compostos semicondutores III-V em meados da década de 50 empregou o método da evaporação, onde a estrutura era obtida a partir da evaporação dos próprios compostos III-V que a integxariam. Por exemplo, uma interface GaAs-AlAs era obtida através da evaporação do composto GaAs seguida da evaporação do composto AlAs. No entanto, nas temperaturas onde a evaporação produz um transporte de massa suficiente para o crescimento, a pressão de vapor dos elementos $\mathrm{V}$ é muito maior que a dos elementos III e, consequentemente, a temperatura de evaporação do GaAs adequada para a produção do feixe de arsênio (As) é, em geral, insuficiente para a produção do feixe de gálio $(\mathrm{Ga})$ num crescimento estequiométrico. A primeira tentativa bem sucedida de se obter feixes de As e Ga adequados ao crescimento estequiométrico do composto GaAs foi realizada por Günther [13] em 1958. No método de Günther, os feixes 
de As e Ga não eram obtidos a partir do composto GaAs, mas sim a partir de cargas individuais de As e Ga puros. Assim, no crescimento do GaAs, a carga de As era mantida em uma temperatura $T_{1}$, a carga de Ga em uma temperatura $T_{2}$ e o substrato em uma temperatura intermediária $T_{3}$, criando uma maneira eficiente de se obter a razão de fluxos V/III adequada. A técnica criada por Günther é freqüientemente chamada de método das três temperaturas. Com essa técnica, ele foi capaz de obter o crescimento estequiométrico de uma série de compostos III-V binários e ternários. Porém, como os filmes foram depositados sobre substratos de vidro, as camadas crescidas tornaram-se policristalinas. $\mathrm{O}$ crescimento de compostos III-V monocristalinos pelo método das três temperaturas só foi obtido em 1968 por Davey e Pankey [14], após uma grande evolução das condições de vácuo do crescimento e da produção de substratos monocristalinos de GaAs. Assim, o método de Günther, aperfeiçoado pelo desenvolvimento das condições de vácuo, pela fabricação de substratos monocristalinos e pela produção de feixes puros e uniformes, deu origem à técnica que hoje denomina-se MBE.

\section{2 - O processo de crescimento}

No processo de crescimento, o substrato e todas as espécies químicas ( $\mathrm{As}_{4}, \mathrm{Ga}, \mathrm{In}$, etc.) dirigidas à sua superfície estão em diferentes temperaturas. Poder-se-ia, portanto, esperar que a formação de um filme sempre ocorra muito fora do equilíbrio térmico. Por outro lado, apesar das diferenças iniciais de temperatura, a formação do material cristalino é precedida por um imenso número de processos cinéticos de superfície que podem promover a acomodação térmica das espécies, ou seja, os átomos e moléculas adsorvidos sobre o substrato podem trocar energia entre si, e com a superfície, aproximando o sistema do equilíbrio termodinâmico, e só então serem incorporados. Estima-se [15] que, para uma taxa de crescimento típica de uma monocamada por segundo ( $1 \mathrm{MC} / \mathrm{s}$ ), um átomo de $\mathrm{Ga}$ sobre um substrato de GaAs a $600^{\circ} \mathrm{C}$ possa realizar aproximadamente um milhão de trocas entre sítios antes de ser incorporado definitivamente no cristal, o que proporciona uma oportunidade adequada para que o sistema se aproxime de um estado isotérmico de mais baixa energia. Assim, a diferença entre um filme em crescimento alcançar um estado 
próximo ao equilíbrio ou permanecer estático muito longe do equilíbrio está relacionada com a habilidade dos átomos incidentes sobre o substrato em alcançar os sítios energeticamente mais favoráveis para sua incorporação. A eficiência com a qual os processos cinéticos (adsorções física e química, dissociação de espécies moleculares, migração, etc.) podem aproximar o sistema do equilíbrio dentro da escala de tempo do crescimento de uma monocamada $(\sim 1 \mathrm{~s})$ depende das condições de crescimento (fluxos incidentes, temperatura do substrato) e da natureza do sistema (tipo de substrato, orientação do substrato, acordo de parâmetro de rede entre o substrato e o filme crescido, etc.). Crescimentos sob condições muito diferentes implicam em diferenças relevantes nas taxas dos processos cinéticos envolvidos e, desse modo, tendem a resultar em diferenças significativas (quanto à topografia, composição química, etc.) no filme crescido. Dentro desse contexto, pode-se estabelecer as seguintes etapas para uma descrição da cinética envolvida no crescimento MBE [16]:

1 - Incidência aleatória de átomos e/ou moléculas sobre o substrato;

2 - Adsorção física das espécies;

3 - Migração sobre a superfície das espécies adsorvidas;

3 - Possível evaporação (desadsorção) de parte do material adsorvido;

4 - Adsorção química;

5 - Migração sobre a superfície de espécies quimisorvidas;

6 - Possível evaporação (desadsorção);

7 - Incorporação no cristal.

A figura 1.1 ilustra esquematicamente tais processos. Ao alcançar a superfície do substrato, um átomo (ou molécula) incidente tende a perder parte de sua energia através de excitações térmicas ou eletrônicas dos átomos da superfície do cristal. Se uma quantidade suficiente de energia é perdida o átomo pode acomodar-se à superfície atingindo o estágio de adsorção física. Nesse caso, o átomo encontra-se ligado à superfície através de forças fracas do tipo van der Waals causadas pela atração Coulombiana do átomo adsorvido com os átomos da superfície. O tipo de potencial de interação ao qual o átomo incidente está sujeito ao aproximar-se da superfície esta ilustrado na figura $1.1 \mathrm{~b}$, onde $\mathrm{E}_{\mathrm{a}}$ representa a 
energia de adsorção. A fraca interação do estado fisisorvido permite uma grande mobilidade das espécies sobre a superfície. Difundindo sobre o substrato, o átomo adsorvido pode interagir basicamente de duas maneiras: (a) receber energia de outras espécies móveis e eventualmente desligar-se da superfície (desadsorção) ou (b) perder ainda mais energia ligando-se quimicamente à superfície. No último caso, o estágio de adsorção química é atingido e o átomo passa a estar ligado à superfície através de uma energia bem maior que a presente no estado fisisorvido. Um átomo quimisorvido ainda pode migrar sobre a superfície porém, o movimento agora é afetado pelo estado da superfície (composição química, reconstrução, orientação, etc.) e pela disposição dos sítios de incorporação (presença de degraus, defeitos, etc.). As chances de um átomo adsorvido quimicamente desadsorver-se é menor por causa de sua maior energia de ligação e, portanto, a maior parte das espécies nesse estágio tende a ser definitivamente incorporada ao final do crescimento de uma monocamada completa. Essa representação conceitual do crescimento é bastante genérica e delineia os principais processos cinéticos envolvidos na cristalização de materiais a partir do estado gasoso sobre a superfície de um sólido, sendo válida para muitos materiais e sistemas. A seguir, discutiremos como tais processos agem em um caso especifico: o crescimento de um filme de GaAs sobre um substrato de GaAs (crescimento homoepitaxial).

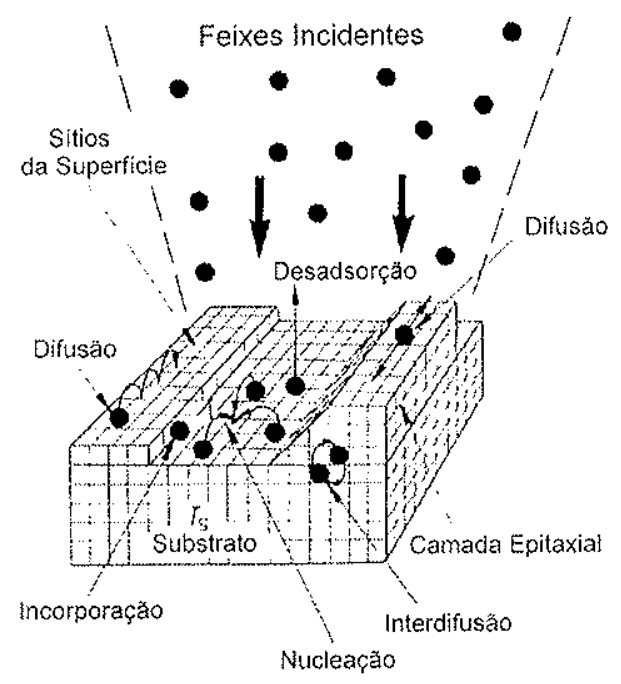

(a)

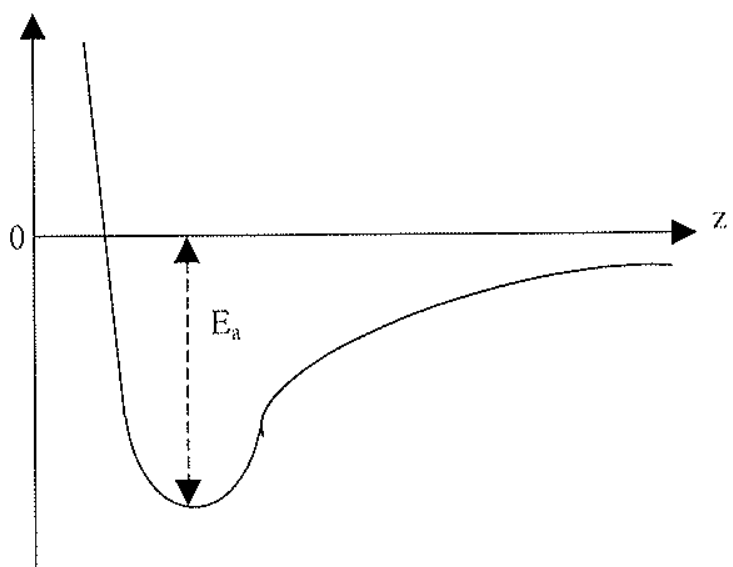

(b)

Figura 1.1 - (a) Hlustração esquemática dos principais processos cinéticos presentes durante o crescimento epitaxial. (b) Potencial de Van der Waals ao qual se submete um átomo ou molécula que a tinge a superficie do substrato. 


\section{3 - Crescimento homoepitaxial do GaAs}

O estudo dos processos envolvidos na formação de camadas cristalinas de compostos III-V iniciou-se com os trabalhos de J. R. Arthur [17]. Suas investigações procuravam determinar o quanto do material ( $\mathrm{Ga}$ e As 2$)$ incidente sobre um substrato de GaAs (100) era de fato incorporado no cristal e sob quais condições se dava essa incorporação. Os experimentos baseavam-se na incidência dos feixes de $\mathrm{Ga}$ e $\mathrm{As}_{2}$ sobre a superfície e na detecção do fluxo de desadsorção. Quantitativamente, a parcela das espécies incidentes que aderem à superfície foi acessada através da introdução de uma quantidade definida como coeficiente de fixação $\beta$ (sticking coefficient):

$$
\beta=\frac{N_{a d}}{F}
$$

onde $\mathrm{N}_{\text {ad }}$ é o número de átomos ou moléculas adsorvidas e F é o fluxo total incidente de determinada espécie. Incidindo fluxos de $\mathrm{Ga}$ e $\mathrm{As}_{2}$ (alternadamente) sobre a superfície cristalina do GaAs, Arthur observou os seguintes resultados:

I - O coeficiente $\beta$ para o Ga $\left(\beta_{\mathrm{Ga}}\right)$ é sempre maior que zero e torna-se igual a um abaixo de $480^{\circ} \mathrm{C}$

II - O coeficiente $\beta$ para o $\mathrm{As}_{2}\left(\beta_{\mathrm{As} 2}\right)$ só é significativo em dois casos:

a-quando é feita uma deposição prévia de Ga sobre a superfície; b- quando o substrato é aquecido acima de $500^{\circ} \mathrm{C}$.

A observação I indica que o Ga tende a condensar-se sobre a superfície do GaAs quando é mantido um fluxo incidente. Se a temperatura está abaixo de $480^{\circ} \mathrm{C}$ a adsorção do fluxo incidente é total $\left(\beta_{\mathrm{Ga}}=1\right)$, mas mesmo em temperaturas mais elevadas essa adsorção é 
significativa. De maneira oposta, a observação II mostra que o As 2 incidindo sobre o GaAs não tende a condensar-se, sendo refletido (desadsorvido) pela superfície. Exceto, porém, quando a superfície está coberta com Ga (observação Il-a), pois nesse caso o As que atinge substrato reage com a população de Ga existente, produzindo o composto GaAs, e sua desadsorção diminui bruscamente. Segundo Arthur, a magnitude da redução da desadsorção (aumento da adsorção) de $\mathrm{As}_{2}$ depende da dosagem de $\mathrm{Ga}$, e para uma quantidade da ordem de uma monocamada (1MC) a adsorção é completa $\left(\beta_{\mathrm{As} 2}=1\right)$. Diante disso, é correto afirmar que a fixação de moléculas de $\mathrm{As}_{2}$ sobre o GaAs ocorre na presença de átomos de Ga sobre a superfície. Nessa direção, Arthur interpretou a observação II-b, de que o $\mathrm{As}_{2}$ é também fixado se a temperatura do substrato for maior que $500^{\circ} \mathrm{C}$, como resultado da existência de uma população de Ga na superfície, deixada pela evaporação do As nativo do substrato, já que nesse caso observou-se a fixação do $A s_{2}\left(\beta_{A s 2}>0\right)$ sem qualquer recobrimento prévio da superfície com átomos de Ga. Assim, com base nesses resultados, Arthur aponta o seguinte raciocínio para se chegar à condição adequada ao crescimento estequiométrico do GaAs: no composto binário GaAs, há um átomo de Ga para cada um de As. Portanto, na ausência de quaisquer perdas (desadsorção), a estequiometria exata é obtida quando o fluxo atômico de $\mathrm{Ga}\left(\mathrm{J}_{\mathrm{Ga}}\right)$ for igual ao dobro do fluxo molecular de $\mathrm{As}_{2}$ $\left(\mathrm{J}_{\mathrm{As} 2}\right)$. Na prática, no entanto, a desadsorção está sempre presente, sobretudo a do $\mathrm{As} 2$, que possui duas partes: uma devida à dissociação do GaAs em altas temperaturas (conforme IIb) e outra devida às moléculas incidentes que deixam a superfície antes de serem incorporadas. Sendo assim, com o objetivo de se repor tais perdas de As, a relação $\mathrm{J}_{\mathrm{Ga}}<2 \mathrm{~J}_{\mathrm{As} 2}$ deve ser mantida, sendo que qualquer excesso de $\mathrm{As}_{2}$ é naturalmente reevaporado (conforme II). Com base em seus resultados, Arthur propôs um modelo de crescimento para o GaAs que envolve as seguintes reações:

$$
\begin{aligned}
\mathrm{As}_{2(\mathrm{~g})} & \leftrightarrow \mathrm{As}_{2}{ }^{*} \\
\mathrm{As}_{2}{ }^{*}+2 \mathrm{~V}^{*}(\mathrm{As}) & \leftrightarrow 2 \mathrm{As}^{*}(\mathrm{As}) \\
\mathrm{As} \mathrm{s}_{(\text {volume })} & \rightarrow \mathrm{As}^{*}(\mathrm{As})
\end{aligned}
$$

\footnotetext{
- Os valores absolutos de temperatura expressos em livros e artigos não devem ser aceitos como referências exatas, já que o valor encontrado para essa grandeza é fortemente dependente da instrumentação usada para sua medida. Isso torna-se mais crítico quando se observa que os experimentos de Arthur foram realizados há cerca de 25 anos.
} 
$\mathrm{As}_{2(\mathrm{~g})}$ indica o arsênio incidente na fase gasosa, e $\mathrm{A} \mathrm{s}_{(\mathrm{volume})}$ diz respeito ao arsênio presente no volume cristalino abaixo da superfície. $\mathrm{O}$ asterisco denota as espécies da superfície: $\mathrm{As}_{2}{ }^{*}$ indica moléculas adsorvidas na superfície, $V^{*}{ }_{(A s)}$ diz respeito aos sítios vagos de As na superfície e As* (As) representa os sítios de As ocupados. As flechas de duplo sentido indicam a possibilidade de reações inversas, como a desadsorção do $\mathrm{As}_{2}$ (i) e a formação de $\mathrm{As}_{2}$ a partir de dois átomos de As já incorporados (ii).

Com os trabalhos posteriores de Foxon e Joyce [18,19], o modelo de Arthur sofreu algumas alterações, como por exemplo a inclusão da possibilidade de formação da espécie tetramérica $\mathrm{As}_{4}$ antes da desadsorção do arsênio em baixas temperaturas $\left(\sim 330^{\circ} \mathrm{C}\right)$. No entanto, talvez a maior contribuição de Foxon e Joyce nesse tópico do crescimento MBE tenha sido dada através da modelação do sistema Ga-As 4 -GaAs. Apesar de Arthur ter lidado apenas com fluxos de arsênio dimérico $\left(\mathrm{As}_{2}\right)$, é possível, e na verdade até mais comum atualmente, o uso de feixes tetraméricos $\left(\mathrm{As}_{4}\right)$. A figura 1.2 ilustra os processos envolvidos no crescimento do GaAs a partir de um feixe tetramérico de arsênio. Segundo esse modelo, a dissociação das moléculas de $\mathrm{As}_{4}$ ocorre através de uma aproximação de duas dessas moléculas na vizinhança de átomos de Ga. Assim, a partir de duas moléculas de $\mathrm{As}_{4}$ (totalizando oito átomos de As), quatro são incorporados na rede cristalina do GaAs e os quatro restantes desadsorvem-se na forma de $A s_{4}$. Isto é consistente com a observação de que o valor máximo do coeficiente de fixação para o $\mathrm{As}_{4}$ é 0,5 .

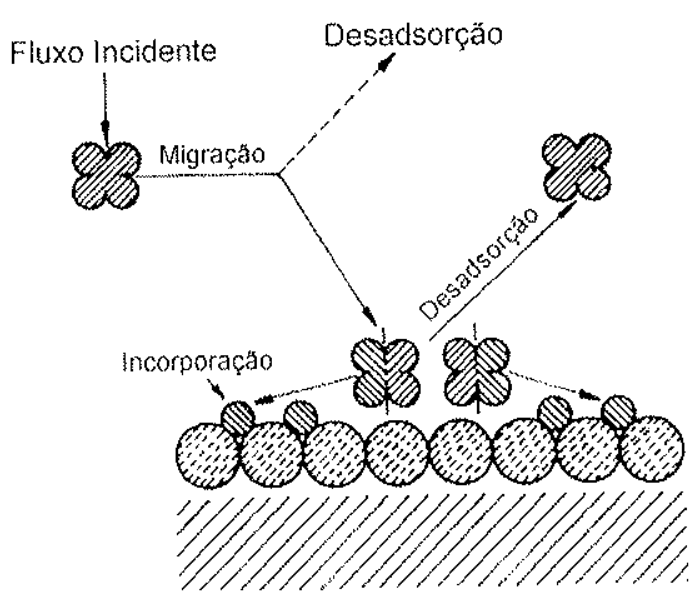

Figura 1.2 - Modelo para incorporação de moléculas tetraméricas de arsênio $\left(\mathrm{As}_{4}\right)$ em uma superfície de GaAs na presença de átomos de Ga. 


\section{4 - Crescimento sob Tensão}

Os átomos de gálio e arsênio num filme cristalino puro de GaAs estão dispostos em uma rede do tipo zincblende, onde cada átomo de As da rede realiza ligações químicas covalentes com os quatro átomos de Ga que são seus vizinhos mais próximos (e de modo análogo, cada átomo de Ga realiza ligações com os quatro átomos de As de sua vizinhança). O comprimento das ligações As-Ga estabelece o espaçamento interatômico de equilíbrio do cristal e o comprimento da aresta da célula convencional, denominado parâmetro de rede, é utilizado como unidade para expressar-se as distâncias interatômicas e interplanares da estrutura. Por exemplo, a distância entre dois planos sucessivos de átomos da mesma espécie, denominada monocamada (MC), é $a / 2$, onde $a$ é o parâmetro de rede. A figura 1.3 mostra esquematicamente a disposição dos átomos de As e Ga na célula convencional do GaAs, destacando as distâncias correspondentes ao parâmetro de rede e à monocamada.

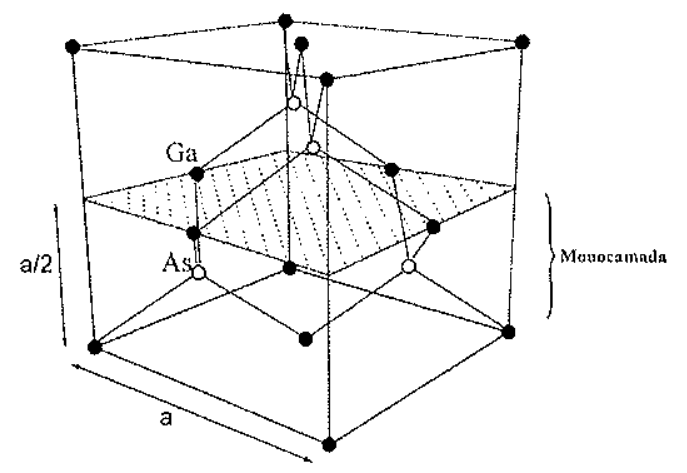

Figura 1.3. - Célula convencional da rede zincblende do composto binário GaAs. Na figura estão indicadas as distâncias referentes ao parâmetro de rede e à monocamada (MC).

O cristal de InAs é totalmente análogo ao de GaAs, possuindo o mesmo tipo de estrutura cristalina. Porém, como o comprimento das ligações As-ln é maior que o das ligações As-Ga, o espaçamento interatômico de equilíbrio na rede do InAs é maior que aquele do GaAs. 
A técnica de crescimento MBE permite a deposição sucessiva de diferentes ligas (GaAs, AlAs, $\mathrm{Al}_{\mathrm{x}} \mathrm{Ga}_{\mathrm{I}_{-} \mathrm{A}} \mathrm{As}$, InAs, $\operatorname{In}_{x} \mathrm{Ga}_{1-x} \mathrm{As}$, etc.) para a produção de heteroestruturas como QWs e super-redes. Quando o crescimento é tal que o filme depositado e o substrato sobre o qual ele é crescido possuem a mesma estrutura cristalina e parâmetros de rede iguais ou muito próximos $\left(\mathrm{Al}_{\mathrm{x}} \mathrm{Ga}_{1-x} \mathrm{As}\right.$ sobre GaAs, por exemplo), há um acordo total no arranjo dos átomos dos dois meios materiais e a camada em crescimento reproduz a disposição de átomos do substrato. Nessa situação, há um emparelhamento perfeito entre os átomos dos dois meios em sua interface comum e o crescimento se diz coerente. Em grande parte das situações, no entanto, o interesse pode estar justamente na combinação de materiais que diferem sensivelmente $(\sim 10 \%)$ quanto ao parâmetro de rede. Mesmo assim há a possibilidade do crescimento ocorrer no regime coerente, sobretudo em seus estágios iniciais. Para tanto, é preciso que os átomos da camada em crescimento disponham-se segundo o parâmetro de rede do substrato, rearranjando seus átomos através de deformações das posições naturais. Essa deformação permite a manutenção da coerência entre os meios e implica necessariamente num acúmulo de energia elástica no filme em crescimento. O fato dessa energia crescer com o aumento da espessura do filme (como veremos em maior detalhe a seguir) pode conduzir a uma situação onde as diferenças estruturais dos dois materiais não podem mais ser acomodadas através do crescimento bidimensional coerente. Uma possibilidade para o alívio da tensão consiste na criação de regiões de desacordo entre os meios, onde cada um adota seu parâmetro de rede natural. Nessas regiões, chamadas de deslocações, o filme torna-se incoerente. A formação desse tipo de defeito está invariavelmente associada à criação de centros de recombinação não radiativa que degradam as propriedades ópticas do material. As deslocações são portanto, indesejadas em filmes destinados à confecção de dispositivos optoeletrônicos. Há cerca de dez anos, um mecanismo alternativo, baseado na transição morfológica da frente de crescimento de um caráter bidimensional (2D) para tridimensional (3D) foi identificado em diversos sistemas $[20,21]$. Nesse caso, as estruturas 3D formadas aliviam a tensão sem a perda da coerência (i.e. sem deslocações) o que as torna extremamente atrativas para o emprego em dispositivos. Nas próximas duas seções, analisaremos de forma mais minuciosa o crescimento bidimensional coerente sob tensão e, através de um exemplo 
simples (analítico), veremos como a transição morfológica para o crescimento 3D pode aliviar a energia elástica acumulada.

\subsection{1 - Crescimento coerente bidimensional}

O tratamento das deformações elásticas presentes no crescimento coerente de heteroestruturas sob tensão pode ser abordado considerando-se um exemplo onde uma fina camada bidimensional de um determinado material é depositada epitaxialmente sobre um substrato espesso de material diferente. Como ilustrado na figura 1.4, na ausência de uma interface comum entre os meios, ambos estão livres de deformação e, portanto, adotam seus respectivos parâmetros de rede naturais (bulk): $a_{e p i}$ e $a_{s u b}$. Se o parâmetro de rede de bulk da camada epitaxial for maior que o do substrato, como é o caso ilustrado pela figura 1.4 (análogo, ao crescimento de InAs sobre GaAs), então a camada deve deformar-se no sentido de reduzir seu parâmetro de rede lateral para que se estabeleça uma interface coerente com o substrato. Como o substrato é muito mais espesso que a camada epitaxial, a tensão média sobre sua superfície tende a ser muito menor que aquela sobre a camada em crescimento, e como a tensão é proporcional à deformação do meio, então o substrato deve se deformar muito menos que a camada epitaxial. Assim, considera-se como uma boa aproximação que, durante o crescimento, todo o desacordo (descasamento) de parâmetro de rede entre os dois meios esteja acomodado por deformações na camada epitaxial, ao invés de deformações compartilhadas entre a camada e o substrato. Em razão disso, pode-se assumir que toda a energia devida à deformação (responsável pela coerência) armazena-se na rede cristalina da camada epitaxial. Esta é uma situação análoga ao caso de duas molas acopladas onde, após a aplicação de uma força de tensão, a maior parte da energia se armazena na mola que mais facilmente se deforma. 


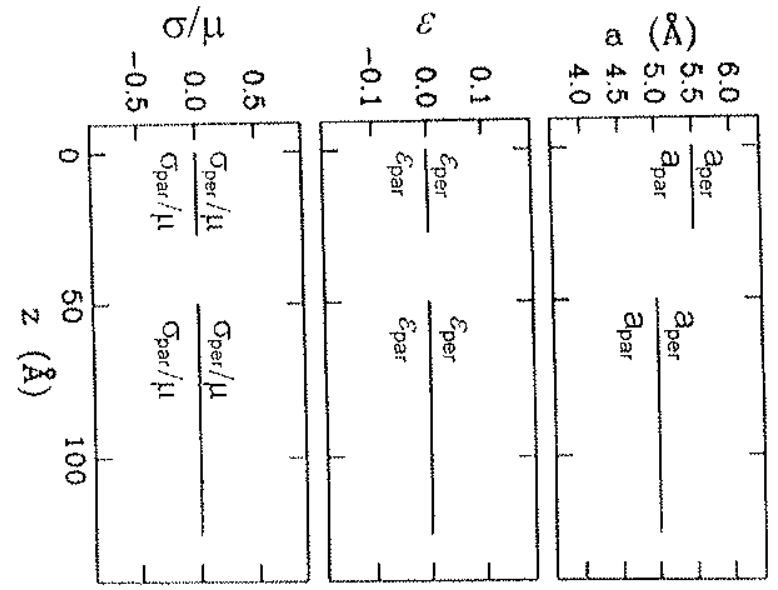

(a)
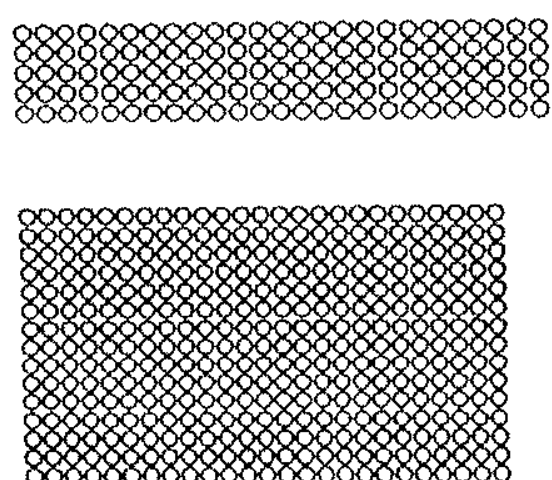

(b)

Figura 1.4 - Situação hipotética onde uma camada epitaxial com parâmetro de rede natural de $5,5 \AA$ e um substrato com parâmetro de rede de $5 \AA$ não estão conectados por uma interface comum. Da esquerda para a direita, o primeiro gráfico mostra que as tensões paralela $\left(\sigma_{p u r}\right)$ e perpendicular $\left(\sigma_{p e r}\right)$ à superfície são nulas (nos dois meios) na ausência de interação. De acordo com o segundo gráfico, também são nulas as deformações paralela $\left(\varepsilon_{p u r}\right)$ e perpendicular $\left(\varepsilon_{p u r}\right)$. O terceiro gráfico ilustra o fato de cada meio adotar seu próprio parâmetro de rede.

Para estimar as deformações e energias associadas ao estabelecimento da coerência no crescimento bidimensional de heteroestruturas sob tensão, emprega-se a lei de Hooke generalizada para cristais cúbicos [22]:

$$
\left(\begin{array}{l}
\varepsilon_{x} \\
\varepsilon_{y} \\
\varepsilon_{z} \\
\gamma_{x y} \\
\gamma_{y z} \\
\gamma_{z x}
\end{array}\right)=\left(\begin{array}{cccccc}
C_{11} & C_{12} & C_{12} & 0 & 0 & 0 \\
C_{12} & C_{11} & C_{12} & 0 & 0 & 0 \\
C_{12} & C_{12} & C_{11} & 0 & 0 & 0 \\
0 & 0 & 0 & C_{44} & 0 & 0 \\
0 & 0 & 0 & 0 & C_{44} & 0 \\
0 & 0 & 0 & 0 & 0 & C_{44}
\end{array}\right)\left(\begin{array}{c}
\sigma_{x} \\
\sigma_{y} \\
\sigma_{z} \\
\tau_{x y} \\
\tau_{y z} \\
\tau_{z x}
\end{array}\right)
$$

onde os $\varepsilon_{i}(i=x, y, z)$ são as deformações longitudinais, os $\gamma_{i}$ são as deformações de cisalhamento, os $\sigma_{i}$ são as tensões longitudinais, os $\tau_{i}$ são as tensões de cisalhamento e os $C_{i j}(i, j=x, y, z)$ são os coeficientes de elasticidade do meio. Usualmente, os coeficientes $C_{i j}$ para materiais de simetria cúbica são escritos em termos da razão de Poisson, $v$, e do módulo de cisalhamento, $\mu$, que são constantes que dependem apenas do meio cristalino. 
Excluindo os termos de cisalhamento (pois em nosso caso só há tensão longitudinal) e empregando $v$ e $\mu$, a equação 1.2 pode ter a forma:

$$
\left(\begin{array}{c}
\varepsilon_{x} \\
\varepsilon_{y} \\
\varepsilon_{z}
\end{array}\right)=\frac{1}{2 \mu(1+v)}\left(\begin{array}{ccc}
1 & -v & -v \\
-v & 1 & -v \\
-v & -v & 1
\end{array}\right)\left(\begin{array}{l}
\sigma_{x} \\
\sigma_{y} \\
\sigma_{z}
\end{array}\right)
$$

As relações entre os coeficientes de elasticidade $C_{i j}, \nu$ e $\mu$ são:

$$
\begin{aligned}
& C_{11}=2 \mu\left(\frac{1-v}{1-2 v}\right) \\
& C_{12}=2 \mu\left(\frac{v}{1-2 v}\right)
\end{aligned}
$$

Se realizarmos mais uma simplificação, considerando as tensões e deformações paralelas ao plano de crescimento $\left(\varepsilon_{x}, \varepsilon_{y}, \sigma_{x}\right.$ e $\left.\sigma_{y}\right)$ simétricas, pode-se simplificar a notação fazendo:

$$
\begin{aligned}
& \varepsilon_{x}=\varepsilon_{y}=\varepsilon_{/ /} \\
& \sigma_{x}=\sigma_{y}=\sigma_{/ /} \\
& \varepsilon_{z}=\varepsilon_{\perp} \\
& \sigma_{z}=\sigma_{\perp}
\end{aligned}
$$

Então, a equação 1.3 torna-se:

$$
\left(\begin{array}{c}
\varepsilon_{/ /} \\
\varepsilon_{1}
\end{array}\right)=\frac{1}{2 \mu(1+v)}\left(\begin{array}{cc}
1-v & -v \\
-2 v & 1
\end{array}\right)\left(\begin{array}{l}
\sigma_{/ /} \\
\sigma_{1}
\end{array}\right)
$$


A equação 1.6 contém dois parâmetros conhecidos e dois desconhecidos. O primeiro parâmetro conhecido é a deformação paralela, $\varepsilon_{/ /}$, que é determinada pelo desacordo entre os parâmetros de rede (descasamento):

$$
\varepsilon_{/ /}=\frac{a_{s u b}-a_{e p i}}{a_{s u b}}
$$

onde os a são os parâmetros de rede de bulk do substrato e da camada epitaxial. O segundo parâmetro conhecido é a tensão perpendicular, $\sigma_{-l}$, que é nula, já que a camada é livre para se expandir verticalmente. Assim, a equação 1.6 permite escrever as duas quantidades desconhecidas (a tensão paralela, $\sigma_{/ /}$, e a deformação perpendicular, $\varepsilon_{\perp}$ ) em termos de $\varepsilon_{/ /}$, como:

$$
\begin{aligned}
& \sigma_{/ \prime}=2 \mu\left(\frac{1+v}{1-v}\right) \varepsilon_{l /} \\
& \varepsilon_{1}=\frac{-2 v}{1-v} \varepsilon_{/ /}
\end{aligned}
$$

Como expressado na primeira das equações 1.8 e ilustrado na figura 1.5 , se a camada epitaxial for deformada na direção paralela à interface de tal maneira que o parâmetro de rede paralelo se ajuste àquele do substrato, haverá a introdução de tensão $\left(\sigma_{/ /}\right)$ no plano da interface entre os meios. $\mathrm{E}$ de acordo com a segunda das equações 1.8, uma deformação perpendicular $\left(\varepsilon_{\perp}\right)$ também estará presente em resposta à deformação paralela que estabelece a coerência. É interessante mencionar que para a maioria dos materiais, a razão de Poisson vé tal $(0,25-0,35)$ que as deformações paralelas e perpendiculares alteram a camada epitaxial de um modo particular, no qual o volume da célula unitária do cristal, antes e depois da deformação, é aproximadamente o mesmo. 

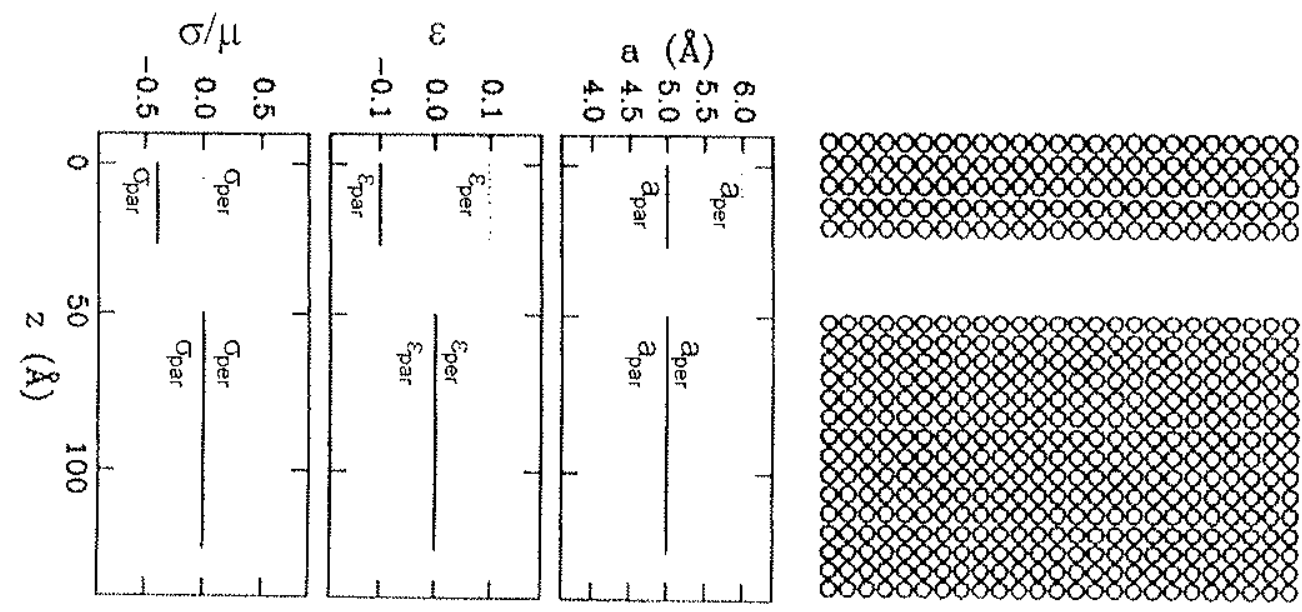

Figura 1.5 - Situação hipotética onde uma camada epitaxial com parâmetro de rede natural de $5,5 \AA$ foi deformada para ajustar'se a um substrato com parâmetro de rede de $5 \AA$, analogamente ao que ocorre na produção de uma interface coerente entre dois meios cristalinos. Da esquerda para a direita, o primeiro diagrama ilustra a tensão não nula imposta à camada epitaxial na direção paralela $\left(\sigma_{p(n)}\right)$. O segundo diagrama atenta para o fato da tensão lateral provocar deformações nas duas direções (paralela, $\varepsilon_{\text {ker }}$, e perpendicular, $\varepsilon_{p e r}$ ) na camada epitaxial. O terceiro diagrama mostra a mudança do parâmetro de rede da epicamada para adequar-se àquele do substrato. As linhas pontilhadas referem-se à tensão, deformação e parâmetro de rede da camada epitaxial perpendiculares à diref̧ão de crescimento.

\subsection{2 - Relaxamento coerente da tensão - Transição 2D-3D}

A energia elástica por unidade de área associada à tensão em um crescimento epitaxial bidimensional coerente pode então ser obtida através das equações 1.8 [23]:

$$
u=\frac{1}{2} h\left(2 \sigma_{/ /} \varepsilon_{/ /}+\sigma_{\perp} \varepsilon_{1}\right)=2 \mu\left(\frac{1+v}{1-v}\right) h \varepsilon_{/ /}{ }^{2}
$$

O aumento linear da energia com a espessura do filme, $h$, pode conduzir o sistema a situações onde a acomodação do filme epitaxial acontece através da quebra do pseudomorfismo com a formação de uma frente de crescimento 3D. As estruturas 3D permitem o relaxamento do sistema através da introdução de uma grande densidade de degraus nos quais a deformação do filme pode ser maior que aquela possível no crescimento 2D [24] discutida na seção anterior. Como já mencionado, essa via de acomodação da tensão não é a única nem a mais comum, porém será discutida com maiores 
detalhes em razão de ser o mecanismo responsável pela formação de pontos quânticos. Para ilustrar como o desenvolvimento de uma frente de crescimento rugosa (3D) pode ser favorável do ponto de vista energético em comparação com o crescimento 2D, vamos imaginar o seguinte exemplo. Consideremos duas estruturas como as mostradas nas figuras 1.6. A figura 1.6a representa um filme bidimensional de espessura $h$ crescido sob tensão sobre um substrato cristalino e a fígura $1.6 \mathrm{~b}$ mostra uma situação onde o filme desenvolve uma rugosidade unidimensional regular na forma de uma sucessão de triângulos de altura $2 A$ e base $2 B$.
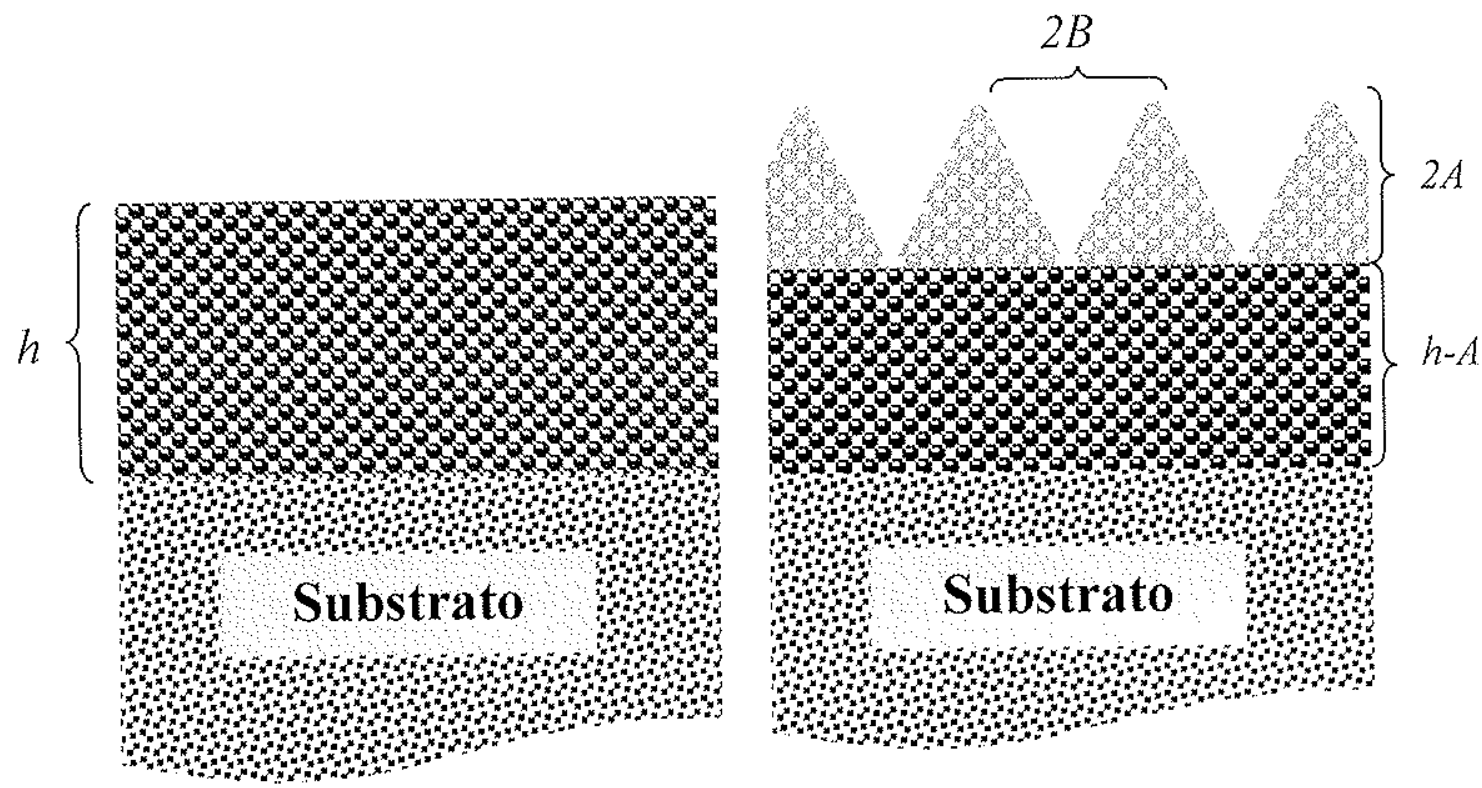

Figura 1.6 - (a) Exemplo de um filme 2D de espessura $h$ mantido sob tensão e (b) da criação de uma rugosidade hipotética (região mais clara) para alívio da energia elástica do sistema.

Em cada um dos casos, a energia total do sistema possui duas componentes. Uma devida ao volume cristalino sob tensão (dada pela equação 1.9) e outra devida à superfície, de modo que: $E_{\text {Tot }}=E_{\text {vol. }}+E_{\text {sup. }}$. Vamos supor que no filme rugoso as deformações microscópicas sejam capazes de aliviar completamente a tensão no volume cristalino da região mais clara da figura $1.6 \mathrm{~b}$, mantendo o restante do filme sob tensão. Se tomarmos a energia de superfície por unidade de área y e a área total como $\sigma$, então podemos escrever a energia total para cada caso como: 
Filme plano: $\quad \mathrm{E}^{(\mathrm{I})}=\gamma \alpha+2 \mu\left(\frac{1+v}{1-v}\right) h \varepsilon_{/ /}{ }^{2}$

Filme rugoso: $\quad \mathrm{E}^{(\mathrm{Il})}=2 \mu\left(\frac{1+v}{1-v}\right)(\mathrm{h}-\mathrm{A}) \varepsilon_{/ /}{ }^{2}+\gamma \alpha\left(1+\frac{4 \mathrm{~A}^{2}}{\mathrm{~B}^{2}}\right)^{1 / 2}$

O primeiro termo da direita na equação 1.11 mostra que a formação da rugosidade reduz a espessura do filme sob tensão para $(\mathrm{h}-\mathrm{A})$, reduzindo assim a primeira componente da energia. Por outro lado, a mudança da topografia do filme aumenta a área da superfície por um fator $\left(1+4 \mathrm{~A}^{2} / \mathrm{B}^{2}\right)^{1 / 2}$, elevando a componente superficial da energia. Podemos agora investigar sob quais condições o decréscimo da energia elástica coerente causado pela rugosidade compensa o aumento da energia de superfície a ponto de tornar a transição 2D-3D favorável. Para isso vamos considerar o comportamento da razão entre as energias totais nos casos de filme rugoso, $\mathrm{E}^{(11)}$ e liso, $\mathrm{E}^{(1)}$. Uma simplificação que não altera qualitativamente os resultados consiste em fazer $2 \mu(1+v / 1-v) \varepsilon_{\| \prime}{ }^{2}=$ constante $=1$. Assim obtemos a razão:

$$
\frac{E^{(I)}}{E^{(I)}}=\frac{(h-A)+\gamma \sigma\left(1+4 A^{2} / B^{2}\right)^{1 / 2}}{h+\gamma \sigma}
$$

A figura 1.7 mostra os resultados do comportamento da razão em 1.12 em função da amplitude da rugosidade (A), mantendo fixas a espessura do filme (h=10000 unidades) e a base dos triângulos ( $B=100$ unidades). Cada curva foi tomada para um valor diferente da densidade de energia de superfície $\gamma$, conforme indicado.

Algumas observações relevantes podem ser feitas a partir desses resultados. Consideremos a curva de linha cheia para a qual $y \sigma=100$. Nota-se que inicialmente para uma amplitude muito pequena a razão é próxima de 1 já que nesse caso é pequena a diferença entre as superfícies rugosa e lisa. A medida que a amplitude da rugosidade aumenta, a razão entre as 
energias diminui, indicando que é favorável ao sistema (do ponto de vista energético)

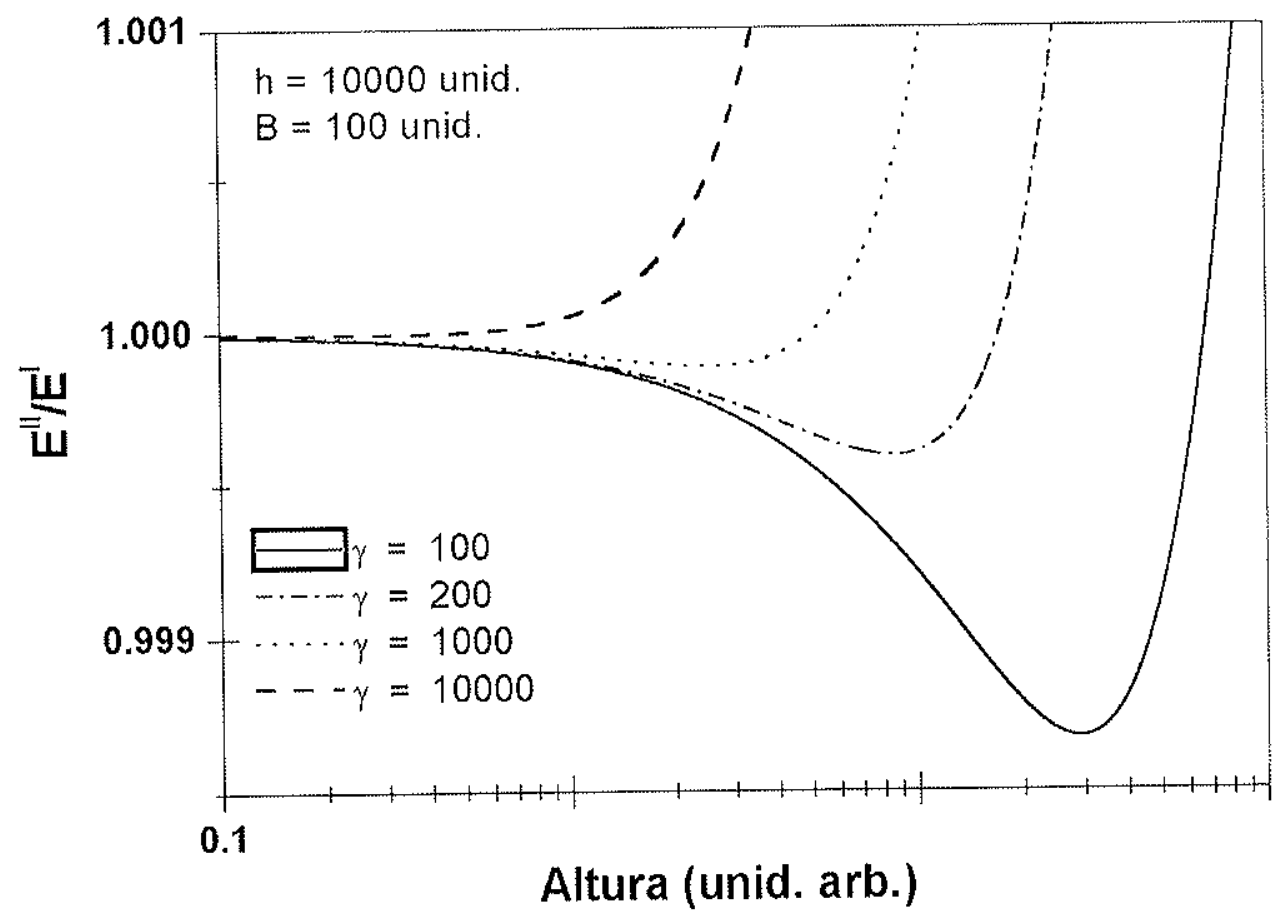

Figura 1.7 - Comportamento da razão entre as energias totais para os casos de crescimento 3D e 2D. Para valores baixos da densidade de energia de superfície existe uma forma ótima para a topografia 3D do filme que minimiza a energia total. Os valores de $h, \mathrm{~A}, \mathrm{~B}$ e $\gamma$ foram tomados em unidades arbitrarias.

romper o pseudomorfismo e assumir um caráter 3D. Apesar de haver uma faixa larga de valores de amplitude da rugosidade para os quais $\mathrm{E}^{(\mathrm{II})}<\mathrm{E}^{(1)}$, há uma amplitude ótima $(\sim 30$ unidades) que minimiza a energia de superfície estabelecendo as faces mais estáveis para a transição. Para amplitudes que excedem o valor ótimo, a componente superficial da energia tende a crescer mais rapidamente que o decréscimo da componente volumétrica, e a razão entre as energias do filme rugoso e liso aumenta monotonicamente até exceder 1 , onde a morfologia rugosa deixa de ser favorável em relação a uma topografia plana. Notemos agora como as curvas comportam-se em função da densidade de energia de superfície. A medida que $\gamma$ aumenta, a amplitude da rugosidade ótima diminui e as curvas tornam-se menos acentuadas até atingir-se a situação, para altas densidades de energia superficial, onde o aumento da superfície do filme causado pela introdução de rugosidade não compensa o decréscimo na energia de tensão coerente do volume. Filmes nessa condição $(\gamma$ 
alto) não possuirão a transição 2D-3D coerente como mecanismo de relaxamento da tensão, devendo relaxar, por exemplo, através da introdução de deslocações. Analogamente, é possível fixar o perfil de rugosidade (parâmetros A e B) e investigar a dependência da razão entre as energias em função do descasamento e da espessura do filme. Com isso, se observaria que, para descasamentos pequenos $(<1 \%)$ o crescimento $2 \mathrm{D}$ é favorável numa faixa extensa de espessuras, enquanto que, para descasamentos elevados, a transição morfológica torna-se favorável a partir de pequenas espessuras. Enfim, esse exemplo ilustra de maneira qualitativa a existência de situações para as quais a tensão pode ser acomodada de uma maneira coerente através de uma transição estrutural no modo de crescimento do filme. É justamente esse o caso para o crescimento da liga binária InAs sobre substratos de GaAs $(\varepsilon=-0.07)$ usado ao longo dessa tese para a produção de pontos quânticos. 


\section{Capítulo 2}

\section{Técnicas experimentais}

Nesse capítulo, discutiremos brevemente os principais aspectos das técnicas experimentais empregadas na tese. O sistema $\mathrm{MBE}$ usado no crescimento das amostras, bem como seu mais importante dispositivo de análise, o RHEED, serão apresentados com maiores detalhes. A técnica de microscopia de força atômica, usada na caracterização topográfica dos pontos quânticos será apresentada sob o ponto de vista de sua aplicação nesse tipo particular de estrutura. A técnica mais usada no trabalho para a investigação das propriedades ópticas das amostras crescidas foi a fotoluminescência, e portanto, será apresentado um resumo de suas peculiaridades.

Ao longo do trabalho, técnicas de caracterização adicionais, tais como microscopia de transmissão de elétrons, fotoluminescência em campo magnético e microfotoluminescência, também foram utilizadas na obtenção de informações relevantes ao contexto do trabalho. No entanto, optamos por apresentar em detalhe apenas as técnicas que de fato serviram de alicerce para a investigação sistemática das amostras. 


\section{1 - O Sistema MBE}

O sistema MBE Varian GEN II do Laboratório de Novos Materiais Semicondutores (LNMS) foi usado no crescimento de todas as amostras discutidas nessa tese. O GEN II é constituído por três câmaras interdependentes conectadas entre si por válvulas do tipo gaveta numa configuração ilustrada pela figura 2.1. A câmara de entrada e saída é usada na introdução de substratos para o crescimento e na retirada das amostras crescidas, tendo portanto, como principal característica, a sua freqüente exposição à pressão atmosférica. Por essa razão a câmara é submetida a um processo de aquecimento $\left(\sim 200^{\circ} \mathrm{C}\right)$ toda vez que novos substratos são introduzidos. Com esse procedimento permite-se a desgaseificação de elementos que em geral adsorvem-se nos elementos recém introduzidos no sistema (substratos novos, porta substratos, suportes móveis, etc.). Em geral, a quebra do vácuo é feita admitindo-se um fluxo de $\mathrm{N}_{2(\mathrm{~g})}$ até que a pressão no interior da câmara se torne positiva, minimizando o fluxo de elementos contaminantes presentes no ar para dentro do sistema durante sua exposição ao ambiente externo. A câmara de entrada e saída é equipada com uma bomba turbomolecular usada na recuperação do vácuo (quando da exposição da câmara ao ar) a partir da pressão atmosférica até um patamar em torno de $1 \times 10^{-5}$ Torr. Desse ponto em diante, uma bomba iônica é acionada para baixar a pressão para $1 \times 10^{-}$ ${ }^{8}$ Torr, aproximando-a da pressão normalmente presente na câmara intermediária. Nessa situação, a válvula gaveta que separa essas duas câmaras pode ser aberta, permitindo a transferência dos substratos para a câmara intermediária. É nesse segundo compartimento que permanecem os substratos que aguardam o crescimento e as amostras que já foram crescidas e esperam para ser retiradas da máquina. Além de uma segunda bomba iônica, responsável pela manutenção do ambiente de vácuo, a câmara intermediária é equipada com um forno capaz de aquecer individualmente cada substrato a ser usado no crescimento. Esse processo de desgaseificação dos substratos é feito por cerca de 30 minutos a uma temperatura de $350^{\circ} \mathrm{C}$. Após a desgaseificação, o substrato é introduzido na câmara de crescimento para o processo de deposição do filme. Na câmara de crescimento, a amostra é posicionada de um modo que sua superfície possa receber frontalmente os feixes incidentes a partir das células de efusão. O sistema possui oito células, duas carregadas com As, duas com Ga e uma célula para cada um dos elementos restantes: In, Al e os dopantes Si e C. As 
células de efusão são responsáveis pela geração dos feixes de átomos (elementos III e dopantes) ou moléculas $\left(\mathrm{As}_{4}\right)$ dirigidos sobre o substrato durante o crescimento. Em uma célula de efusão, o elemento químico a ser usado como fonte do feixe incidente é mantido no interior de um cadinho de PBN (nitreto de boro pirolítico) onde pode ser aquecido através de resistências elétricas que envolvem o cadinho. Um termopar e um sistema de resistências aquecedoras posicionadas em volta do cadinho permitem o monitoramento e controle das temperaturas a serem usadas para a produção dos feixes incidentes no substrato. A temperatura do substrato é também monitorada por um termopar e pode ser independentemente medida através de um pirômetro. O sistema de vácuo para essa câmara inclui uma bomba iônica, uma bomba de sublimação de titânio e um painel criogênico preeenchido com $\mathrm{N}_{2}$ líquido. Medidores de pressão, indicadores de fluxo de partículas e um espectrômetro de massa, utilizado para a detecção das espécies químicas presentes na câmara, são os instrumentos responsáveis pelo monitoramento do ambiente antes, durante e depois do crescimento. O sistema ainda dispõe de um instrumento de monitoramento in situ da superfície da amostra chamado RHEED (reflection high-energy electron diffraction). $\mathrm{O}$ sistema RHEED possui um papel muito importante no crescimento $\mathrm{MBE}$, uma vez que possibilita a calibração das taxas de crescimento a serem usadas e permite um monitoramento em tempo real das condições da superfície do filme em crescimento. Particularmente, em relação ao crescimento de pontos quânticos, o RHEED pode ser usado para acompanhar a sua formação e evolução e, recentemente [25], tem-se demonstrado a possibilidade de usar o RHHED para determinar a forma dos pontos quânticos na superfície da amostra. Diante da sua importância para o controle do crescimento dos pontos quânticos, o sistema RHEED será discutido em maiores detalhes na seção seguinte, enquanto uma apresentação mais minuciosa a respeito da instrumentação de nosso sistema MBE pode ser encontrada nas dissertações de mestrado [26] e doutorado [27] produzidas em nosso grupo de pesquisa. 


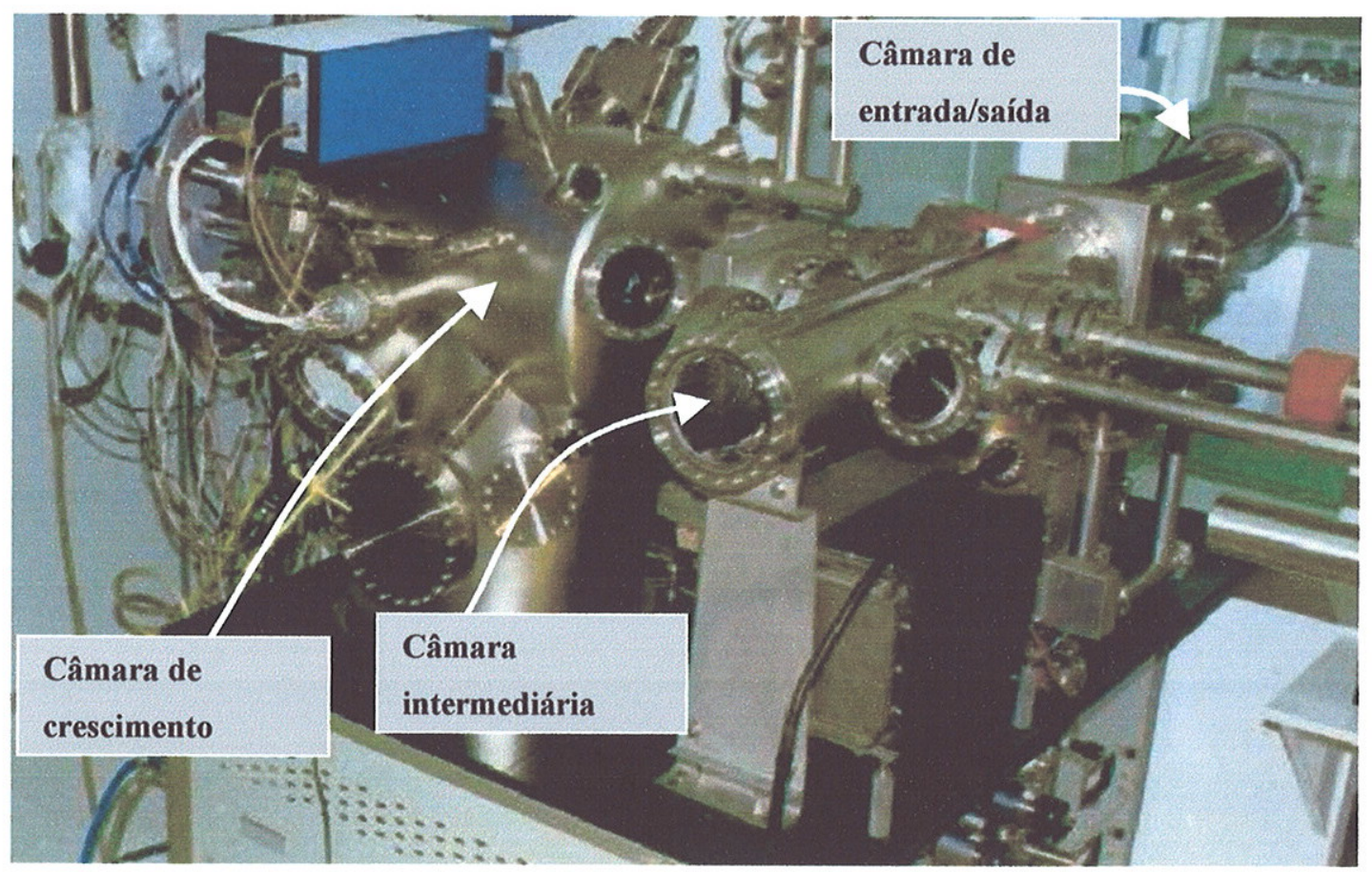

Figura 2.1 - Foto do sistema GEN II do Laboratório de Novos Materiais Semicondutores, com destaque para o posicionamento das três câmaras que compõem o sistema.

\section{2 - Monitoramento in situ do crescimento}

O monitoramento in situ do processo de formação de um filme cristalino no interior da câmara de crescimento MBE é realizado através da detecção do padrão de difração da superfície do filme com uma instrumentação denominada RHEED. Na técnica RHEED, um feixe de elétrons de alta energia $(\sim 10 \mathrm{keV})$ incide com baixo ângulo $\left(\sim 1^{\circ}\right)$ sobre a superfície da amostra e projeta numa tela fósforo o padrão de difração que resulta da interação dos elétrons com o arranjo cristalino do material. Essa geometria é acomodada no interior da câmara de crescimento numa disposição ilustrada pela figura 2.2. O fato do feixe possuir energia da ordem de $\mathrm{keV}$ torna o livre caminho médio para espalhamento elástico da ordem de $1000 \AA$. Porém, como a incidência é rasante, a maior parte dessa distância é percorrida nas primeiras camadas do cristal, fornecendo assim um padrão de difração exclusivamente da superfície da amostra. Na formulação mais geral possível do tratamento do fenômeno da difração em cristais, pode-se considerar um meio cristalino formado por uma disposição 
regular de centros espalhadores, tais como átomos, moléculas, íons, etc, onde cada uma dessas entidades é capaz de espalhar o feixe de elétrons em qualquer direção do espaço. Apesar disso, picos de intensidade do feixe espalhado serão formados em direções particulares a partir da interferência construtiva de partes do feixe espalhadas por diferentes centros, dando origem a um padrão de difração característico do cristal espalhador.

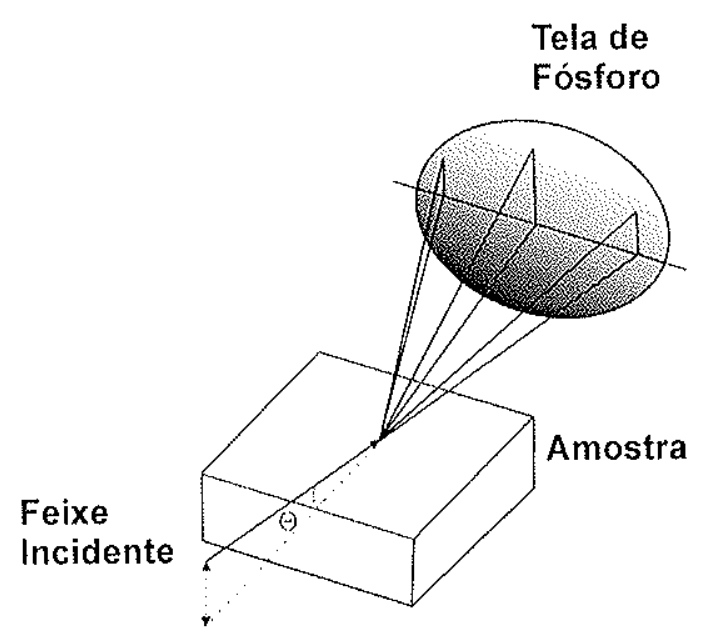

Figura 2.2 --. Ilustração da disposição do sistema RHEED no interior da câmara de crescimento.

A condição de interferência construtiva pode ser melhor explorada com a ajuda da figura 2.3, onde se ilustra dois centros espalhadores (átomos, por exemplo) separados por uma distância d, sobre os quais incide um feixe de elétrons com vetor de onda $\mathbf{k}$. O vetor k' representa a onda espalhada em uma direção particular entre todas as direções possíveis. Os vetores $\mathbf{k}$ e k' são tais que:

$$
\vec{k}=\frac{2 \pi}{\lambda} \hat{n} ; \quad \vec{k}^{\prime}=\frac{2 \pi}{\lambda} \hat{n}^{\prime}
$$

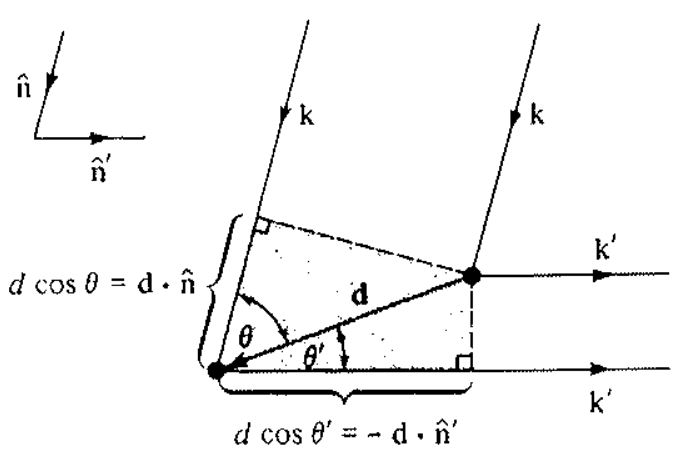

Figura 2.3 - Modelo para a interferência de ondas espalhadas elasticamente por um cristal. 
Essas relações pressupõem o fato de que se está considerando o espalhamento elástico, para o qual:

$$
|\vec{k}|=|\vec{k}|
$$

Pela figura 2.3, pode-se então escrever a condição de interferência construtiva como:

$$
d \cos \theta+d \cos \theta^{\prime}=m \lambda \quad m= \pm 1, \pm 2, \pm 3 \ldots
$$

Ou analogamente:

$$
\begin{aligned}
& \vec{d} \cdot \hat{n}-\ddot{d} \cdot \hat{n}^{\prime}=m \lambda \\
& \vec{d} \cdot\left(\hat{n}-\hat{n}^{\prime}\right)=m \lambda
\end{aligned}
$$

Usando então a equação 2.1 obtém-se:

$$
\vec{d} \cdot(\vec{k}-\vec{k})=2 \pi m
$$

$O$ vetor $\mathbf{d}$ que conecta os centros espalhadores pode, na verdade, ser qualquer vetor da rede cristalina, digamos $\mathbf{R}$. Assim:

$$
\vec{R} \cdot\left(\vec{k}-\ddot{k}^{\prime}\right)=2 \pi m
$$

Como $m$ é um número inteiro:

$$
e^{i(\vec{k} \cdots \ddot{k}) \cdot \ddot{k}}=1
$$

Sabendo que a cada rede de Bravais (rede real do cristal) pode-se associar, por definição, uma rede recíproca, tal que:

$$
e^{i k \cdot R}=1
$$

Comparando as equações 2.7 e 2.8 :

$$
e^{i\left(\vec{k}-\ddot{k}^{\prime}\right) \vec{R}}=e^{i \vec{K} \cdot \vec{k}}
$$


Portanto:

$$
\vec{k}-\vec{k}^{\prime}=\ddot{K}
$$

Desse modo, obtém-se que haverá interferência construtiva sempre que a diferença entre vetores de onda incidente e espalhada for um vetor qualquer da rede recíproca do cristal. Essa formulação é normalmente referida como aproximação de von Laue para a difração de cristais [1].

No caso geral, onde o meio espalhador é um cristal tridimensional, haverá uma distribuíção discreta e finita de vetores que satisfazem a condição 2.10 e, portanto, o padrão de difração criado pelo espalhamento do feixe de elétrons incidente será formado por pontos brilhantes associados com todas essas direções. Segundo a disposição particular do aparato do RHEED, onde lida-se com incidência rasante e feixes de alta energia, a rede que de fato contribui para a formação do padrão de difração provém essencialmente da superfície da amostra, sendo portanto, uma rede bidimensional. Nesse caso, a condição de von Laue, ilustrada pela equação 2.10 , atuará somente nas componentes de $\mathbf{k}$ e k' paralelas à superfície. Se,

$$
\begin{aligned}
& \vec{k}=\ddot{k}_{/ l}+\ddot{k}_{\perp} \\
& \ddot{k}=\vec{k}_{\| l}+\vec{k}_{\perp}
\end{aligned}
$$

então, as condições adequadas para interferência construtiva de ondas elasticamente espalhadas por uma superfície devem ser escritas como:

$$
\vec{k}_{/ l}^{\prime}-\vec{k}_{/ l}=\vec{g}
$$

onde, $\mathrm{g}$ é um vetor da rede recíproca bidimensional (2D) associada à superfície cristalina. $O$ relaxamento da condição de difração na terceira dimensão torna o padrão formado por linhas e não mais por pontos de máximo como no caso de um espalhamento por rede tridimensional (3D). A figura 2.4 mostra um padrão de difração típico da superfície de um filme cristalino obtido através do RHEED. Como na realidade, a rede cristalina de qualquer material, especialmente de um cristal em alta temperatura durante o crescimento $\mathrm{MBE}$, não é uma estrutura estática, nem perfeitamente periódica, e como os feixes incidentes não são 
perfeitamente monocromáticos, as linhas para as quais a condição 2.12 é satisfeita são na verdade barras com uma determinada espessura. Por esse motivo, as linhas de difração são mais comumente chamadas de bastões da rede recíproca.

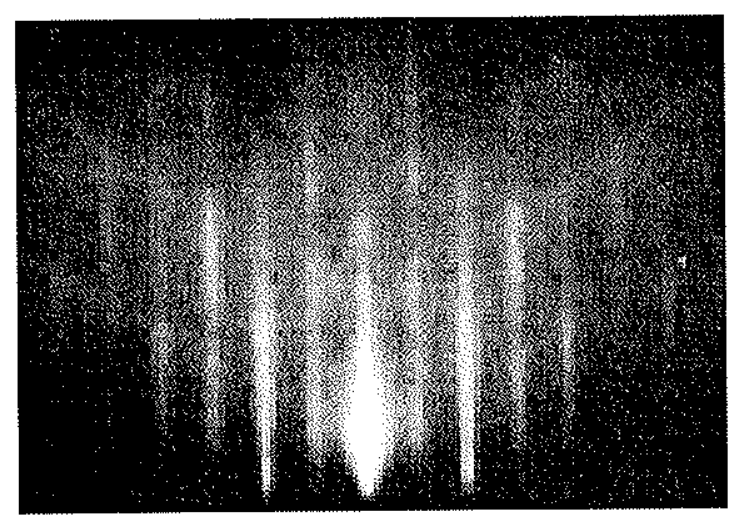

Figura 2. 4 -- Padrão de difração exibido pelo RHEED a partir de uma superfície plana a nivel atômico.

\section{3 - Aplicação do RHEED no crescimento de pontos quânticos}

A geometria particular do RHEED que permite a observação do padrão de difração exclusivamente das primeiras camadas cristalinas e o fato dos padrões de difração de estruturas 2D e 3D serem facilmente distinguíveis, tornam esse instrumento uma ferramenta muito valiosa no estudo da formação e desenvolvimento dos pontos quânticos no processo de crescimento MBE. No sistema InAs/GaAs, os pontos quânticos formados são estruturas tridimensionais com tamanhos de cerca de $5-7 \mathrm{~nm}$ de altura e $20-30 \mathrm{~nm}$ de diâmetro formadas em densidades da ordem de $10^{10} \mathrm{~cm}^{-2}$. Assim, o início da formação dos pontos quânticos a partir de uma superfície inicialmente lisa representa uma transição topográfica suficiente para alterar de modo significativo o padrão de difração exibido pelo RHEED. A figura 2.5 mostra a evolução do padrão de difração quando da formação de pontos quânticos a partir do crescimento inicialmente 2D. Quando $1 \mathrm{MC}$ (figura 2.5a) de InAs é depositada sobre o substrato de GaAs, a superfície apresenta um padrão de difração 
bibimensional, demonstrando que a quantidade de material depositado ainda não foi suficiente para a formação das primeiras ilhas. Após 1,7MC (figura 2.5b), no entanto, o padrão de difração começa a exibir pontos brilhantes característicos de um meio tridimensional, indicando que agora, o feixe de elétrons está sendo espalhado por uma estrutura 3D, de onde se pode concluir que pontos quânticos começam a ser formados. Para uma quantidade de material depositado ainda maior, os pontos tornam-se mais claros refletindo o aumento da densidade de ilhas e, eventualmente, uma evolução no seu tamanho (figura 2.5c).
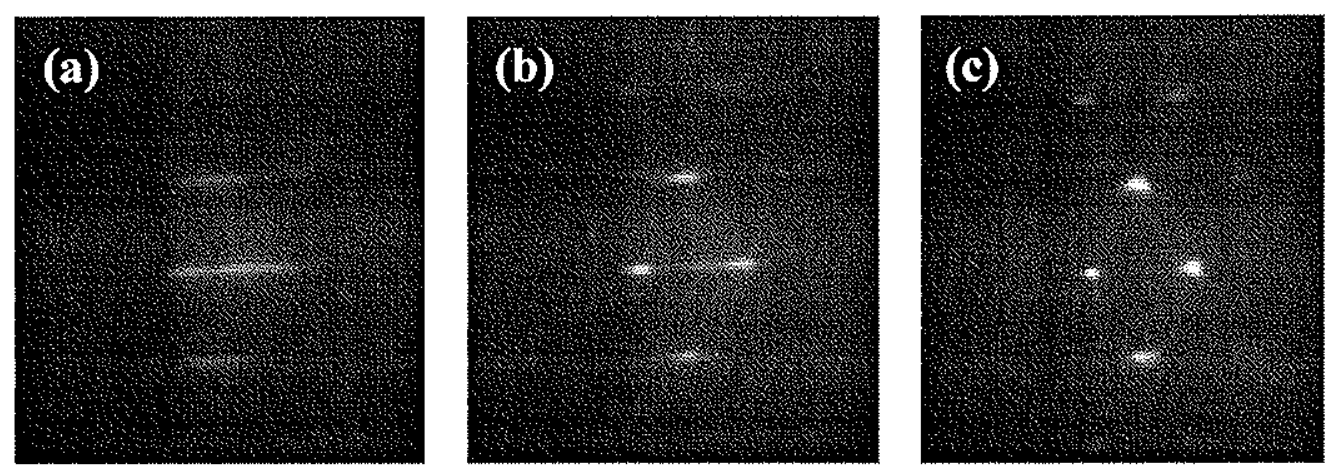

Figura 2.5 - Imagens extraídas da fitmagem digital da evolução do padrão de difração da superfície de uma amostra durante o crescimento de pontos quânticos de InAs a $520^{\circ} \mathrm{C}$ após a deposição de $1 \mathrm{MC}$ (a), 1,7MC (b) e 2,2MC (c). Nessa configuração, o feixe de elétrons incide segundo a direção [110] do cristal.

Se tem tentado obter informações a respeito da forma geométrica dos pontos quânticos através da observação do padrão de difração típico das ilhas em diferentes azimutes. A figura 2.6 mostra um desses padrões de difração quando o feixe de elétrons incide segundo o azimute [1-10]. É possível observar que os pontos de difração são agora acompanhados de linhas que se interceptam formando vértices, os quais passaremos a chamar de chevrons. A formação desse tipo particular de padrão de difração é interpretada [1] como consequiência da existência de uma orientação preferencial das facetas que formam as ilhas ao longo da direção [1-10]. Como o ângulo entre as raias do chevron é da ordem de $50^{\circ}$, o padrão sugere que a forma das ilhas ao longo de [1-10] é a de uma pirâmide de lados paralelos à família de planos (113). O fato de não se poder identificar chevrons ao longo da direção [110] (figura 2.5) mostra que não existe uma familia bem 
definida de planos orientando a forma dos pontos quânticos naquela direção. De fato, ainda não há um consenso a respeito de como se estabelecer a forma exata das estruturas através do padrão de difração do RHEED e muitos trabalhos têm tentado simular formas geométricas e seus respectivos padrões afim de permitir o uso do RHEED como uma ferramenta de investigação topográfica completa para o estudo dessas estruturas. Técnicas de microscopia têm, na verdade, se mostrado muito superiores na investigação das características geométricas dos pontos quânticos, bem como da quantificação de suas densidades e distribuições sobre a superfície. Entre essas técnicas, destaca-se a microscopia de força atômica, usada amplamente nesse trabalho e que será discutida a seguir.

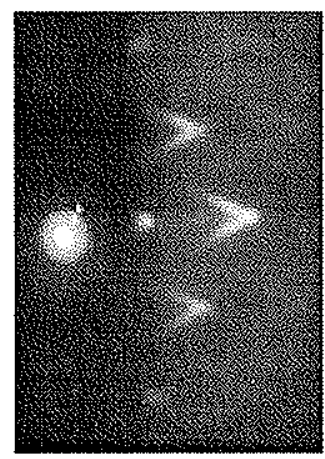

Figura 2.6 - Imagem do padrão de difração após a formação de pontos quânticos de InAs obtidos a partir da incidência do feixe de elétrons ao longo da direção [1-10].

\section{4 - Microscopia de força atômica}

Em 1986, G. Binning, C. F. Quate e C. Gerber construíram o primeiro microscópio de força atômica (AFM), numa colaboração entre a IBM e a Universidade de Stanford Atualmente, o AFM integra uma família de microscópios denominados microscópios de varredura por ponta de prova. Em um microscópio desse tipo, uma sonda percorre a amostra monitorando algum tipo de interação com a superfície. No caso específico do AFM em modo de contato, a interação a ser monitorada é a força de compressão entre a sonda e a 
superfície sobre a qual ela se move. O modo de contato é apenas um dos três tipos básicos de operação de varredura, onde a sonda é mantida continuamente em contato com a superfície durante todo o processo. As imagens realizadas nesse trabalho, no entanto, foram obtidas no regime de varredura intermitente (tapping mode), onde a ponta oscila continuamente sobre a superfície da amostra durante a varredura mantendo uma amplitude de oscilação constante. Nesse caso as alterações de relevo são detectadas através de mudanças nessa amplitude. Na terceira modalidade, denominada modo de não contato, a ponta oscilante não toca a superfície da amostra e as variações de relevo são detectadas por mudanças de amplitude de oscilação devidas à interação de forças do tipo van der Waals.

Em um AFM convencional, a sonda é composta por uma ponta fixada na extremidade de uma haste flexível, denominada cantilever. Inicialmente, o cantilever é aproximado da amostra até que uma força de compressão da ordem do $n N$ (nano-newton) seja exercida sobre a superfície. A aplicação da força implica na deformação do cantilever, de modo que, se for mantida uma força constante durante a varredura de contato, ou amplitude de oscilação constante no modo intermitente, então as deformações do cantilever não devem se alterar ao longo do processo. Basicamente, o sistema procura manter a deformação (e conseqüentemente a força, ou amplitude de oscilação) sobre o cantilever constante, e associa qualquer mudança com alterações de relevo da superfície. Cada vez que uma mudança de topografia altera a deformação/amplitude, o sistema move o cantilever na direção z (normal à superfície) afim de recuperar a deformação/amplitude original. A movimentação da ponta sobre a superfície durante a varredura é realizada pelo scanner piezelétrico. Através da aplicação de tensões alternadas sobre o scanner, é possível produzir a movimentação de varredura da ponta sobre a superfície (plano $x-y$ ). A movimentação na direção z, que está associada ao relevo da superfície, é obtida através de uma tensão aplicada ao scanner em resposta às mudanças topográficas. Essas mudanças são detectadas por variações na posição de um feixe de laser incidente na superfície do cantilever, e refletido para um fotodetector sensível à posição, conforme ilustrado na figura 2.7. A tensão responsável pela movimentação na direção $z$ contrai ou distende o cilindro piezelétrico para manter a deformação/amplitude do cantilever constante durante a varredura, o que implica em manter a reflexão do laser na região central do fotodetector,

- Nessa mesma época Binning recebeu o prêmio Nobel de física pela invenção do STM (Scanning Tunneling 
conforme sugerido pela figura 2.7. A aplicação segura da técnica de AFM no estudo da formação e evolução dos pontos quânticos passa necessariamente por um processo de otimização dos parâmetros de medida e escolha adequada do modo de varredura, pontas e cantilevers a serem usados, dimensões e condições de ambiente para a condução das medidas, etc. Quando todas essas variáveis são controladas, a qualidade das imagens obtidas permite a resolução de detalhes da topografia que permitem analisar não apenas as densidades e dimensões dos pontos quânticos em estágios adiantados de sua formação, mas também monitorar com grande precisão os momentos iniciais de sua nucleação bem como a condição topográfica da superfície que precede sua formação. A imagem AFM obtida em modo de contato apresentada na figura 2.8 ilustra o relevo de uma superfície de $\operatorname{In}(\mathrm{Ga}) \mathrm{As}$ nos momentos iniciais de formação dos pontos quânticos, quando a quantidade de material depositada excede em cerca de um décimo de monocamada a quantidade necessária para a transição 2D-3D. É possível observar nitidamente a presença de degraus de apenas $1 \mathrm{MC}$ de altura limitando terraços bidimensionais. Os pequenos pontos claros que decoram o relevo são aglomerados de átomos que formam ilhas de cerca de 2-3MC de altura e distribuem-se predominantemente ao longo das bordas dos terraços. No próximo capítulo, onde se discutirá o ciclo completo de formação e evolução dos pontos quânticos, tais ilhas serão demonstradas como sendo estados precursores da formação de pontos quânticos bem maiores, no regime de crescimento em baixíssimas taxas de deposição.

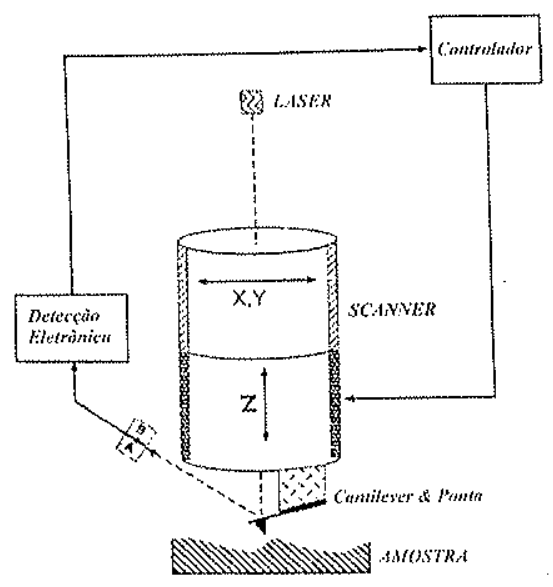

(a)
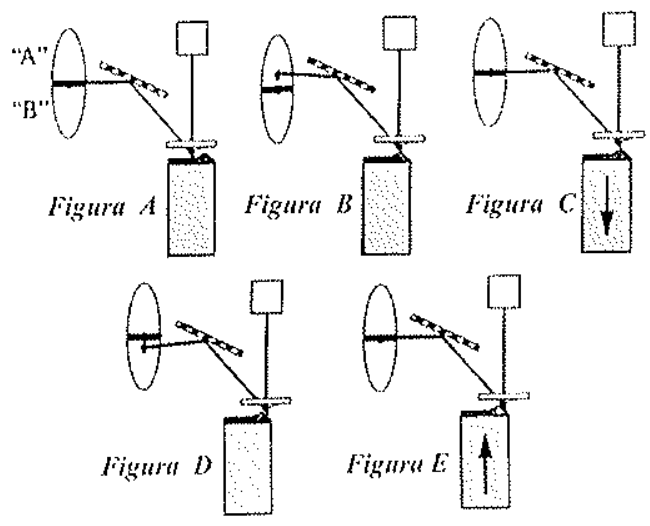

(b)

Figura 2.7 - Ilustração do sistema de deteç̧ão (a) e de movimentação (b) do scanner no Nanoscope IIla da Digital. A movimentação do scanner, registrada ponto a ponto durante a varredura, é usada para a obtenção da imagem topográfica da superficie.

Microscope), em 1982. 


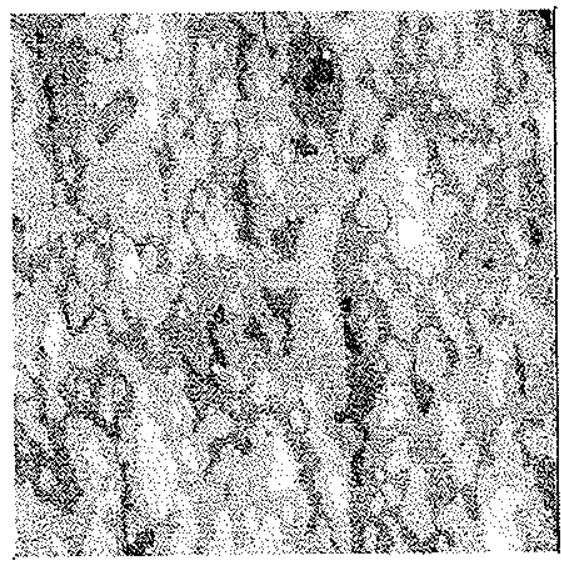

Figura 2.8 -.. Imagem AFM $\left(2 \times 2 \mathrm{~m}^{2}\right)$ obtida em modo de contato de uma amostra onde a quantidade de InAs depositado sobre o substrato de GaAs foi apenas cerca de um décimo de MC maior que o justamente necessário para a transição 2D-3D.

A análise quantitativa das dimensões e densidades dos pontos quânticos detectados é feita através de medidas estatísticas de todas as estruturas presentes em diversas imagens de uma mesma amostra e será ao longo desse trabalho apresentada na forma de histogramas de altura e diâmetro. As medidas e ordenação da informação são realizadas através de um programa de computador elaborado especificamente para o estudo de amostras de pontos quânticos. É no entanto, importante destacar as limitações da técnica quanto a determinação da forma exata dos objetos detectados. O fato das dimensões da ponta serem próximas das dimensões dos pontos quânticos torna o efeito de convolução muito presente, sobretudo nas direções laterais. Em consequiência disso, os valores de diâmetro dos pontos quânticos obtidos por AFM devem ser entendidos como limites superiores. Medidas de TEM em seção transversal sugerem que o tamanho lateral real é quase metade daquele obtido pelo AFM.

\section{5 - Fotoluminescência}

A técnica de fotoluminescência, aplicada ao estudo de amostras semicondutoras, consiste na criação de pares elétron-buraco através da incidência de luz (com energia superior ao gap do material estudado), seguida da detecção da radiação emitida no processo de recombinação do par fotogerado. Um material semicondutor puro (não dopado), na temperatura (idealizada) do zero absoluto, é um meio isolante. Nessa condição, todos os estados da banda de valência estão ocupados por elétrons e a banda de condução possui 
todos os seus estados disponíveis. A existência de uma região de estados proibidos, denominada gap, impede que os elétrons da banda de valência possam, por exemplo, ser acelerados por um campo elétrico externo. Se, no entanto, incidir-se luz sobre a amostra, com fótons de energia $h v$ maior que o gap, então um elétron pode acessar os estados de energia da banda de condução, vencendo a região proibida. A presença de um elétron ocupando um estado que anteriormente estava disponível na banda de condução implica na criação de um estado disponível (para elétrons) na banda de valência, que antes estava totalmente preenchida. Na prática, o estado disponível para elétrons na banda de valência é tratado como um estado ocupado por um buraco, e se diz que a absorção do fóton criou um par elétron-buraco. Com essa configuração, o material semicondutor encontra-se excitado, já que tanto o elétron na banda de condução quanto o buraco na banda de valência possuem excesso de energia em relação ao estado fundamental do sistema. O comportamento inicial dos portadores recém criados envolve um processo denominado termalização, que é a relaxação do elétron para o fundo da banda de condução (e do buraco para o topo da banda de valência) através da emissão de fônons (transições não radiativas). Em seguida, a recombinação radiativa do par elétron-buraco tende a ocorrer a partir dos mínimos de energia das duas bandas, e então um fóton de energia correspondente ao valor do gap é emitido. Na realidade, a interação coulombiana entre o elétron e o buraco (que possuem cargas opostas) cria um estado ligado, denominado éxciton, no qual a energia de recombinação é um pouco menor que a energia do gap do material. Portanto, em condições de baixa temperatura e potência de excitação moderada, o sinal luminoso (luminescência) detectado em um experimento de fotoluminescência é exatamente a emissão de fótons provenientes da recombinação excitônica do par elétron-buraco.

A figura 2.9 apresenta o aparato experimental usado em todas as medidas de fotoluminescência dessa tese. A amostra é posicionada no interior de um criostato óptico capaz de mantê-la em qualquer temperatura entre 1,6K e 300K. As temperaturas abaixo de $4 \mathrm{~K}$ são obtidas através do bombeamento do banho de hélio líquido no qual a amostra está mergulhada. Medidas em temperaturas mais elevadas podem ser realizadas removendo-se o He líquido que envolve a amostra e fornecendo um fluxo de hélio gasoso. O gás é obtido a partir do reservatório de hélio líquido do criostato. O sistema de controle de temperatura possui um conjunto de resistências elétricas que podem ser usadas simultaneamente com o 
fluxo de He gasoso para a obtenção de qualquer temperatura entre $4 \mathrm{~K}$ e $300 \mathrm{~K}$. A fonte de excitação usada é um laser de argônio (Ar), refrigerado com água, que emite luz com comprimento de onda de $5145 \AA$. O feixe de laser é desviado por espelhos $\left(\mathrm{S}_{1}, \mathrm{~S}_{2}\right)$ e focalizado perpendicularmente sobre a amostra por uma lente $\left(\mathrm{L}_{2}\right)$. A luminescência é coletada pela mesma lente $L_{2}$ e focalizada por $L_{1}$ sobre a fenda de entrada de um espectrômetro da marca SPEX com distância focal de $0,75 \mathrm{~m}$ e uma grade de difração de 1200 linhas $/ \mathrm{mm}$. A captação do sinal na fenda de saída do espectrômetro é realizada por um detector de germânio da marca North Coast refrigerado com nitrogênio líquido. O resultado é então filtrado e amplificado por um sistema de detecção síncrona, composto por um lockin e um chopper. O registro do espectro de intensidade luminosa em função da energia, bem como o controle da movimentação da grade de difração do espectrômetro durante a medida, são realizados por um microcomputador.

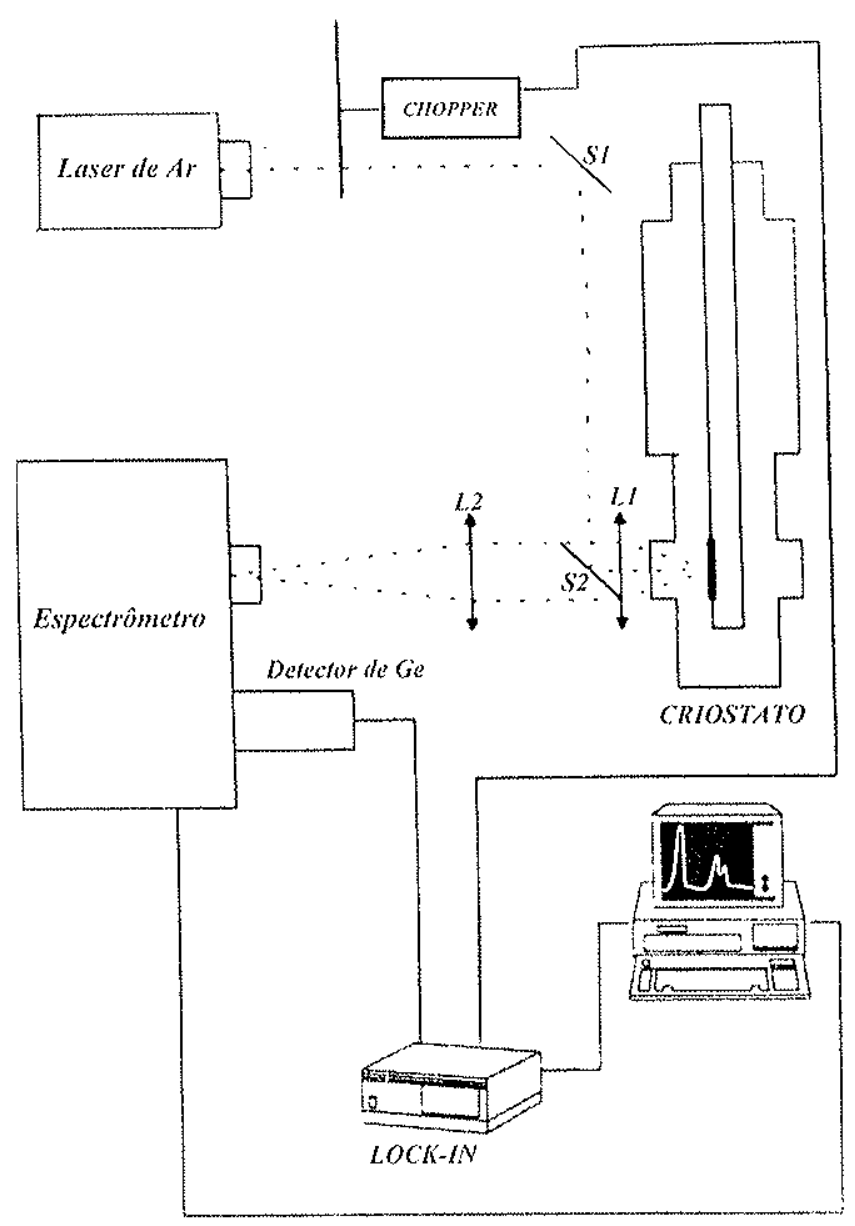

Figura 2.9 - Ilustração do aparato experimental usado nas medidas de fotoluminescência. 
Quando as dimensões de um sólido cristalino são reduzidas para a escala nanométrica em pelo menos uma das direções e a estrutura é envolvida por um segundo cristal que atua como barreira de potencial, então a liberdade de movimento dos portadores naquela direção é restringida. A altura da barreira é estabelecida pelo band offset entre os dois materiais nas bandas de condução e valência. Esses tipos de confinamento resultam na quantização da energia e na discretização da densidade de estados para elétrons e buracos, o que na verdade são as características de maior interesse para a tecnologia de semicondutores atualmente. Nesse contexto, os pontos quânticos representam a redução definitiva da dimensionalidade do meio cristalino uma vez que o movimento de portadores é restringido nas três direções, o que implica na quantização total dos estados de energia. Em geral a determinação desses estados de energia se vale da chamada aproximação da massa efetiva, onde os estados eletrônicos na aproximação da função envelope em um semicondutor podem ser obtidos a partir da solução da equação de Schröedinger na seguinte forma:

$$
\left(-\frac{\hbar^{2}}{2 m^{*}} \nabla^{2}+V(r)\right) \Psi_{n \vec{k}}=E_{n \rightarrow k} \Psi_{n \vec{k}}
$$

Efetuando uma grande simplicação ao assumir-se um potencial de altura infinita em todas as direções, a função potencial para o confinamento de um ponto quântico cúbico será da forma: $V(r)=V(x)+V(y)+V(z)$. Nesse caso os autovalores de energia serão:

$$
E(k)=E_{n x}+E_{n y}+E_{n z}=\frac{h^{2}}{2 m^{*}}\left[\left(\frac{n_{x} \pi}{L_{x}}\right)^{2}+\left(\frac{n_{y} \pi}{L_{y}}\right)^{2}+\left(\frac{n_{z} \pi}{L_{z}}\right)^{2}\right]
$$

onde, $n_{x}, n_{y}$ e $n_{z}=1,2,3 \ldots$ e $k_{x}=n_{x} \pi / L_{x} ; k_{y}=n_{y} \pi / L_{y}$ e $k_{z}=n_{z} \pi / L_{z}$. Os estados de energia são completamente discretos e a densidade de estados é uma série de funções do tipo delta.

A densidade de estados discreta, inerente ao confinamento nas três direções, é uma das características mais importantes das estruturas de pontos quânticos, e suas implicações 
nos processos de recombinação de pares elétron-buraco criam propriedades ópticas de grande interesse para a aplicação em dispositivos. 


\section{Capítulo 3}

\section{Pontos quânticos ativos em $1,3 \mu \mathrm{m}$}

Nesse capítulo, serão apresentados os resultados obtidos com o estudo do crescimento e da caracterização (óptica e morfológica) dos pontos quânticos opticamente ativos na banda $\mathrm{O}$. Apresentaremos uma descrição das motivações para o estudo bem como nossa receita para o crescimento de tais estruturas no regime de baixa taxa de deposição. 


\section{1 - Motivação}

Desde o trabalho teórico pioneiro de Arakawa et al. [28] no início da década de 80 , demonstrando que amostras semicondutoras exibindo potencial de confinamento 3D (chamadas atualmente de pontos quânticos) poderiam ser usadas para aperfeiçoar o desempenho de laseres, tem havido grande interesse na realização prática desse tipo de estrutura. Dentre as diversas possibilidades inicialmente propostas de se fabricar pontos quânticos, a formação espontânea de ilhas durante o crescimento sob tensão no regime conhecido como Stranski-Krastanov (S-K), particularmente presente na deposição epitaxial de InAs sobre GaAs e Ge sobre Si, tem sido apontada como o modo mais promissor para tal intento. Apesar de ilhas coerentes de Ge crescidas sobre uma superfície de SiGe terem sido reportadas em 1990 [29], estruturas de pontos quânticos totalmente imersos numa matriz cristalina perfeita emitindo intenso sinal de fotoluminescência só foram observadas pela primeira vez em 1993 por Leonard et al. [30] e logo a seguir por Madhukar et al. [31]. Em ambos os trabalhos, a liga binária InAs foi usada como meio constituinte das ilhas e o GaAs foi o material escolhido como matriz cristalina. Desde então, o sistema InAs/GaAs vem sendo exaustivamente estudado por dezenas de grupos de pesquisa em todo o mundo. Esse esforço sistemático conduziu em meados da década de 90 à fabricação dos primeiros laseres baseados em pontos quânticos produzidos em laboratório, e recentemente uma empresa americana (Zia Laser) e um consórcio europeu anunciaram ter dominado o knowhow necessário para a produção de laseres de pontos quânticos usando o sistema $\ln (\mathrm{Ga}) \mathrm{As} / \mathrm{GaAs}$.

No contexto da manufatura de dispositivos optoeletrônicos, particularmente laseres e detectores dedicados à telecomunicação por fibras ópticas, o maior desafio atualmente consiste em sintonizar a resposta óptica (emissão ou absorção de luz) nas chamadas janelas de telecom. As janelas de transmissão de sinais dedicadas à comunicação em longa distância foram estabelecidas recentemente pela International Telecomunication Union

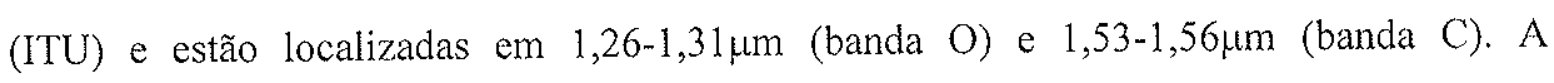
importância dessas duas faixas de comprimento de onda está no fato de representarem regiões espectrais de mínimo de atenuação de sinal em fibras ópticas de sílica, conforme pode ser observado a partir da curva mostrada na figura 3.1. Além disso, essas duas regiões 
do espectro óptico se beneficiam da tecnologia dos melhores amplificadores de sinal disponíveis, conhecidos como EDFAs (Erbium-doped Fiber Amplifier). No aspecto dispersão do sinal a emissão em $1,3 \mu \mathrm{m}$ é ainda superior a qualquer outra região do espectro. Uma noção mais clara do quanto representam as diferenças nos coeficientes de atenuação entre as regiões pode ser obtida a partir do exame da tabela 3.1 .

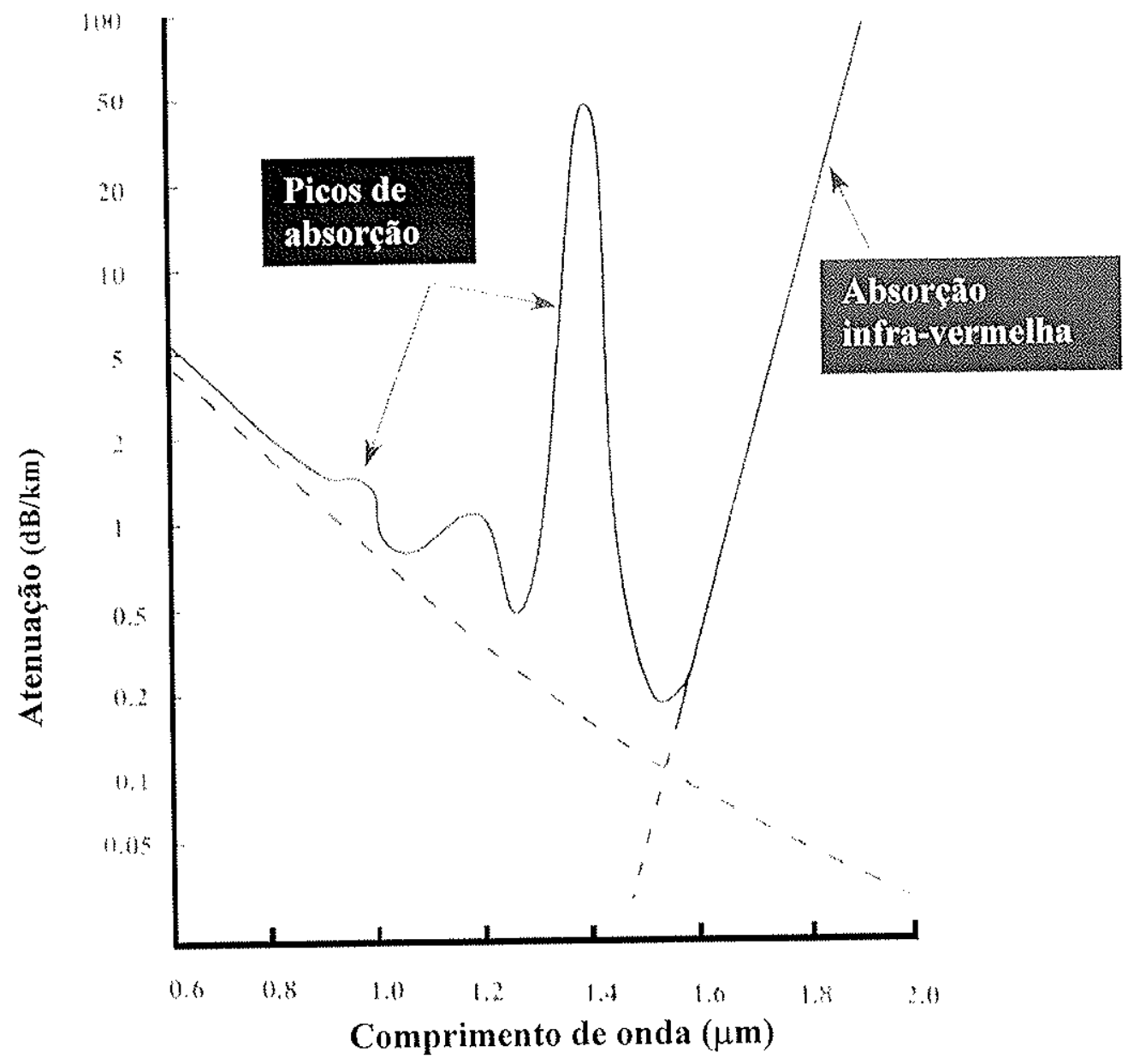

Figura 3.l - Curva de atenuação em fibras ópticas em função do comprimento de onda usado na transmissão do sinal.

\begin{tabular}{|c|c|c|c|c|}
\hline $\begin{array}{c}\text { Comprimento } \\
\text { de } \\
\text { Onda }(\mu \mathbf{m})\end{array}$ & $\begin{array}{c}\text { Coeficiente de } \\
\text { atenuação } \\
(\mathbf{d B} / \mathbf{k m})\end{array}$ & $\begin{array}{c}\mathbf{I}_{\mathrm{f}} / \mathbf{I} \mathbf{l} \mathbf{~ e m} \\
\mathbf{1} \mathbf{~ k m}\end{array}$ & $\begin{array}{c}\mathbf{I}_{\mathrm{f}} / \mathbf{I o} \mathbf{~ e m} \\
\mathbf{5} \mathbf{~ k m}\end{array}$ & $\begin{array}{c}\mathbf{I}_{\mathrm{f}} / \mathbf{I o} \mathbf{~ e m} \\
\mathbf{5 0} \mathbf{~ k m}\end{array}$ \\
\hline 0,98 & 1,0 & $79 \%$ & $31 \%$ & $0,001 \%$ \\
\hline 1,31 & 0,5 & $89 \%$ & $56 \%$ & $0,3 \%$ \\
\hline 1,55 & 0,2 & $95 \%$ & $79 \%$ & $10 \%$ \\
\hline
\end{tabular}

Tabela 3.1 - Atenuação esperada ao longo da transmissão do sinal óptico. $I_{f}$ e $I_{0}$ referem-se, respectivamente, às intensidades final e inicial da transmissão. 
Tipicamente, as condições de crescimento usadas para a confecção de pontos quânticos de InAs/GaAs produzem ilhas coerentes de tamanhos que variam entre 5-7nm de altura e 20-30nm de diâmetro quando as estruturas ainda não se encontram encapsuladas por GaAs, ou seja, ainda são ilhas de superfície. Em geral, a dimensão vertical sofre severa diminuição pelo processo de recobrimento por GaAs, sendo reduzida para aproximadamente metade de seu valor inicial. Na direção horizontal, as alterações de tamanho são muito menos agressivas, praticamente preservando o diâmetro durante a cobertura das ilhas com GaAs. Além das alterações morfológicas, uma significativa mudança na composição química das ilhas ocorre durante a deposição do GaAs. Tem-se demonstrado [32] através de medidas analíticas de TEM (transmission electron microscopy) que uma ilha de superfície (InAs) tem sua concentração média de In reduzida para cerca de 30\% após a deposição do cap layer de GaAs, tornando-se uma ilha de $\operatorname{In}_{0,3} \mathrm{Ga}_{0,7} \mathrm{As}$. Até meados da década de 90 , a possibilidade de manipulação das dimensões e composição química dos pontos quânticos no sistema $\operatorname{lnAs} / \mathrm{GaAs}$ através das condições de crescimento foi seriamente abordada e o resultado foi a capacidade de se obter pontos

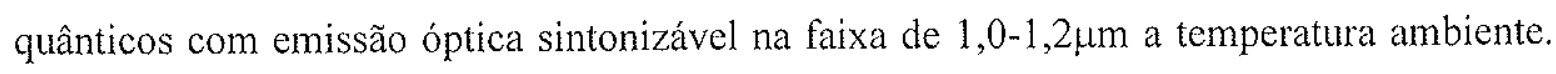
Apesar da produção de pontos quânticos representar um avanço significativo em direção às janelas ópticas das bandas $\mathrm{O}$ e $\mathrm{C}$, em comparação com o que é possível obter com poços quânticos bidimensionais de InGaAs/GaAs $(\sim 0,9 \mu \mathrm{m})$, um grau ainda maior de manipulação é exigido para o intento final de se produzir estruturas opticamente ativas nas regiões de real interesse tecnológico. É exatamente nesse contexto que essa tese se insere, tendo como objetivos principais investigar a possibilidade de manipulação extrema das condições de crescimento a fim de deslocar as emissões ópticas para dentro da banda $O$, em torno de $1,3 \mu \mathrm{m}$, e analisar as propriedades morfológicas e ópticas das ilhas resultantes dessa manipulação, bem como os processos presentes no surgimento e evolução dos pontos quânticos crescidos.

Evidentemente, essa tese não foi o único estudo sistemático desse importante tópico da física e engenharia de materiais. Ao longo dos últimos quatro anos, vários grupos de pesquisa atacaram esse mesmo problema obtendo a cada etapa progressos significativos. 
Basicamente três métodos diferentes de se deslocar as emissões para o vermelho* foram propostos. O primeiro deles [33] baseia-se no acoplamento vertical de múltiplas camadas de pontos quânticos proximamente espaçadas (closely-stacked quantum dots) por finas camadas de GaAs que vale-se da tendência natural de alinhamento vertical das ilhas em camadas sucessivas para promover um potencial de confinamento efetivo onde os níveis de energia sofrem um significativo redshift em relação àqueles de uma única camada de ilhas. A figura 3.2 mostra imagens TEM em seção transversal de amostras onde crescemos pares de camadas de pontos quânticos de InAs separadas por $20 \mathrm{~nm}$ (3.2a) e 10nm (3.2b) de GaAs, respectivamente. As imagens obtidas na condição two-beam dark-field (004) mostra, através do contraste predominantemente devido aos campos de tensão, que de fato as ilhas tendem a alinhar-se na direção vertical, permitindo a possibilidade de acoplamento entre níveis eletrônicos. O mesmo efeito de interação entre campos de tensão de camadas sucessivas que promove o alinhamento dos pontos quânticos exerce, no entanto, um efeito limitante quanto às perspectivas de se maximizar o redshift das emissões. Basicamente, a presença de um campo de tensão criado por uma camada inferior de ilhas no sítio de formação de uma nova camada aumenta a troca entre átomos de In dos pontos quânticos por átomos de Ga da vizinhança, reduzindo sensivelmente a concentração média de In, aumentando assim o gap de energia quando comparado com uma camada única de pontos quânticos. Como resultado, o máximo redshift obtido com esse método não é capaz de sintonizar as emissões ópticas para muito além de $1,2 \mu \mathrm{m}$ em temperatura ambiente $[34,35]$.
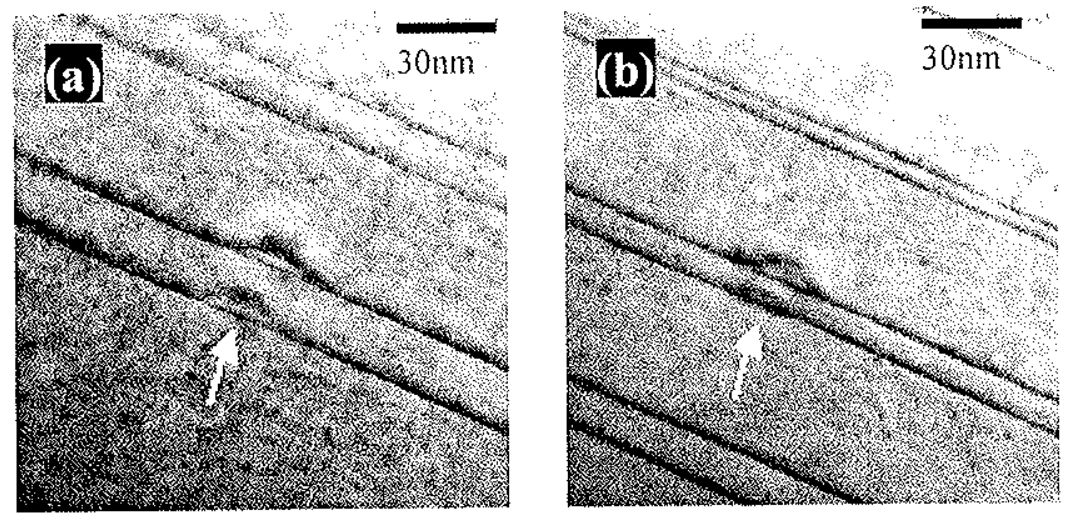

Figura 3.2 - Imagens TEM mostrando o alinhamento (indicado pela seta) de pares de camadas de pontos quânticos quando o espaçamento de GaAs é de $20 \mathrm{~nm}$ (a) e $10 \mathrm{~nm}$ (b).

\footnotetext{
* Usaremos os termos em inglês redshift e blueshift para nos referirmos aos deslocamentos para os comprimentos de onda do vermelho e azul, seguindo o jargão fortemente enraizado nessa área da fissica.
} 
$\mathrm{O}$ segundo método proposto para se tentar alcançar a banda $\mathrm{O}$ baseia-se no crescimento de uma única camada de pontos quânticos de InAs coberta por um cap layer híbrido de InGaAs e GaAs. A figura 3.3 mostra o quanto obtivemos de redshift quando uma liga de $\mathrm{In}_{0,1} \mathrm{Ga}_{0,9}$ As é depositada logo após a formação dos pontos quânticos e seguida de um filme de GaAs. A manipulação necessária para atingir $1,3 \mu \mathrm{m}$ exige, no entanto, que se eleve a concentração de In na camada de InGaAs, o que causa dois efeitos negativos: aumento excessivo do stress e densidade de defeitos interfaciais e redução significativa do offset entre as bandas do poço e da barreira de potencial. Atualmente, como mencionado na introdução da tese, uma variação desse método conhecida como DWELL parece promissora para o objetivo final.

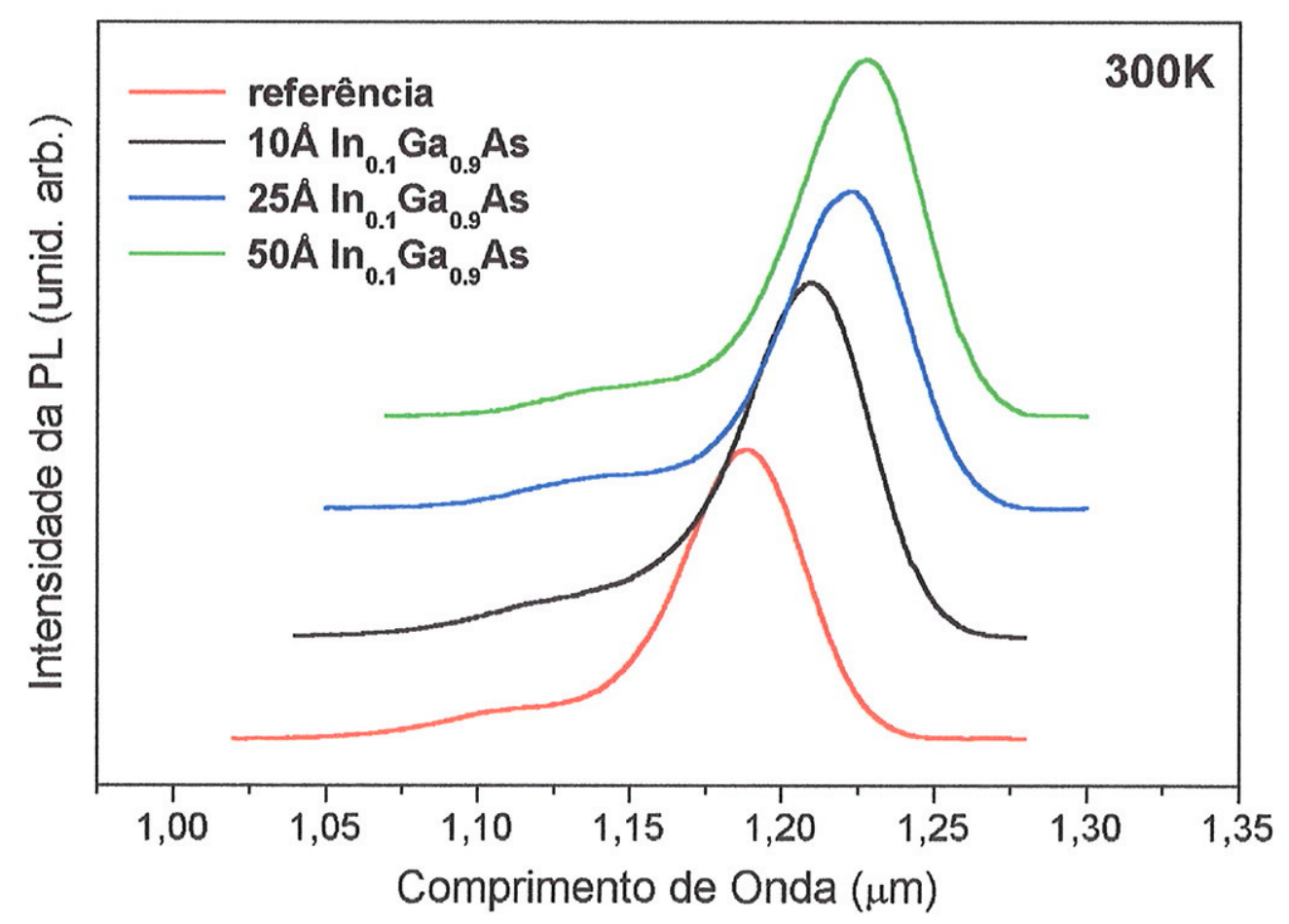

Figura 3.3 - Espectros de PL (300K) de uma única camada de pontos quânticos com deposição de 2,4MC de InAs coberta por $0 \AA, 10 \AA, 25 \AA$ e $50 \AA$ (conforme indicado na figura) de $\operatorname{In}_{0,1} \mathrm{Ga}_{0,9} A s$. Após a deposição do filme de $\mathrm{In}_{0,1} \mathrm{Ga}_{0,9} \mathrm{As}$, o cap layer foi completado com GaAs com uma espessura tal que a soma dos filmes $(\mathrm{GaAs}+\mathrm{InGaAs})$ atingisse $30 \mathrm{~nm}$. 
O terceiro modo possivel para a obtenção de redshifi nas emissões ópticas de pontos quânticos é o mais direto deles e baseia-se simplesmente no crescimento de pontos quânticos maiores. Apesar dos trabalhos iniciais de pontos quânticos com o sistema InAs/GaAs terem sugerido que a manipulação das condições de crescimento para se obter estruturas com tamanho suficiente para emitir luz em torno de $1,3 \mu \mathrm{m}$ seria uma tarefa difícil, Nakata et al. [36] obtiveram pontos quânticos de superfície com 10nm de altura e $30 \mathrm{~nm}$ de diâmetro com emissão a temperatura ambiente exatamente em $1,3 \mu \mathrm{m}$. O método usado foi o de reduzir drasticamente a taxa de deposição do InAs para cerca de $0,002 \mathrm{MC} / \mathrm{s}$, cerca de 50 vezes menor que as taxas normalmente usadas para esse sistema. Posteriormente Joyce et al. [37] reportaram a obtenção de luminescência intensa nessa mesma faixa de comprimento de onda com o crescimento de pontos quânticos de InAs a $0,0065 \mathrm{MC} / \mathrm{s}$. Imediatamente o efeito da redução extrema da taxa de crescimento sobre as características ópticas e morfológicas dos pontos quânticos passou a ser o objeto de estudo de vários grupos e é exatamente esse o foco dessa tese.

\section{2 - Aspectos gerais do crescimento de pontos quânticos ativos em $1,3 \mu \mathrm{m}$}

\subsection{1 - Controle das condições de crescimento}

O estudo sistemático do efeito da redução da taxa de crescimento de pontos quânticos, ao qual se destina essa tese, envolve o crescimento de centenas de amostras, de modo que o controle da reprodutibilidade das condições de crescimento para a formação de cada camada de pontos quânticos tem uma importância essencial. Além disso, a produção de um conjunto de amostras onde apenas um dos parâmetros de deposição é variado é uma prática comum no estudo do crescimento. Para que não existam interpretações errôneas dos resultados, é preciso garantir que as condições de crescimento, supostamente mantidas fixas, de fato não variaram entre as amostras de um mesmo conjunto. Para testar a 
reprodutibilidade do sistema $\mathrm{MBE}$, especificamente para amostras de pontos quânticos de InAs, realizamos o crescimento de amostras-teste cuja estrutura é ilustrada na figura 3.4. A primeira camada de pontos quânticos (imersa totalmente na matriz de GaAs) foi usada para a caracterização óptica por fotoluminescência, e a camada de pontos quânticos na superfície do substrato (que é uma réplica da primeira) foi incluída para permitir uma caracterização morfológica das ilhas formadas (tamanho, densidade, disposição espacial, etc.) por microscopia de força atômica.

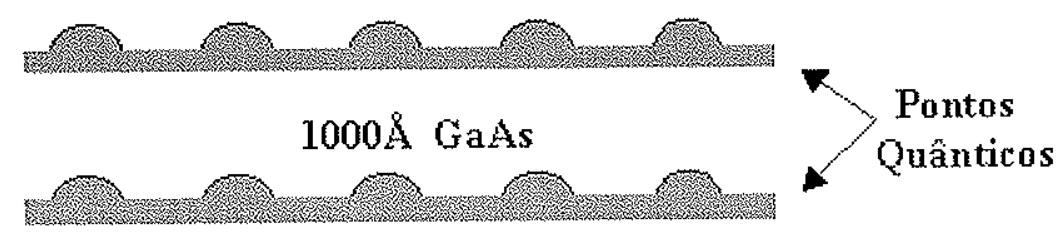

$2000 \mathrm{~A}$ GaAs

\section{Substrato GaAs(100)}

Figura 3.4 - Estrutura da amostra teste, onde duas camadas idênticas de pontos quânticos são incluidas, uma para caracterização óptica por fotoluminescência e outra para medidas de microscopia de força atômica.

Duas amostras com a estrutura da figura 3.4 foram crescidas uma após a outra no mesmo dia e outras duas amostras foram crescidas uma semana depois, também no mesmo dia. Os resultados, mostrados na figura 3.5 , indicam que a reprodutibilidade das condições de crescimento em nosso sistema MBE é suficiente para não detectarmos diferenças na emissão óptica das camadas de pontos quânticos. Os espectros A e B representam amostras crescidas sob as mesmas condições no mesmo dia de crescimento e os espectros C e D são de amostras crescidas sob as mesmas condições uma semana depois. Imagens AFM da superfície, como a da figura $3.5\left(2 \times 2 \mu \mathrm{m}^{2}\right)$, demonstraram que as camadas são também idênticas morfologicamente. 


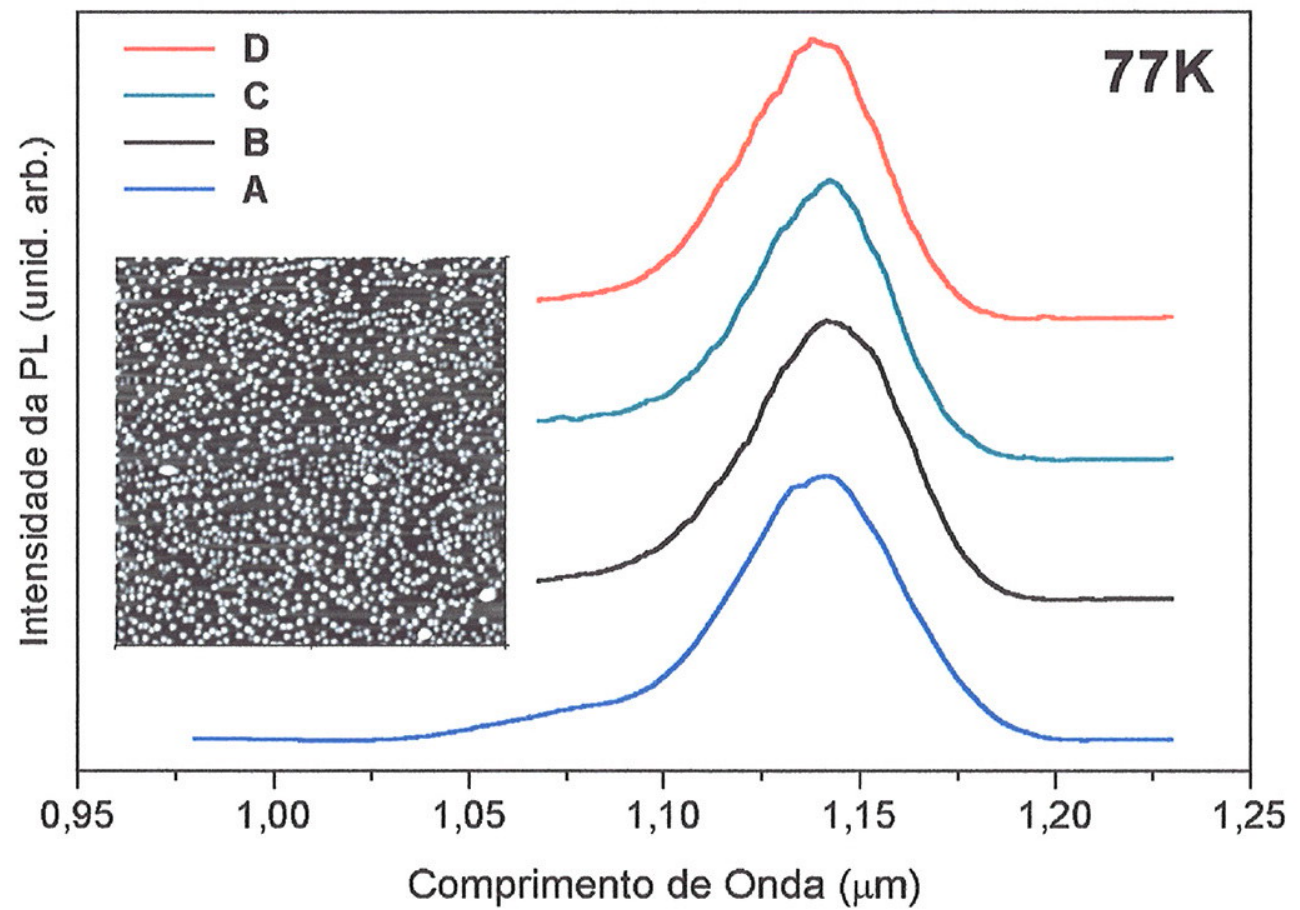

Figura 3.5 - Medidas de fotoluminescência (77K) mostrando a reprodutibilidade das camadas de pontos quânticos de InAs crescidas com uma espessura nominal de 2,4MC. A imagem AFM $\left(2 \times 2 \mu m^{2}\right)$ da superfície da amostra A apresenta pontos quânticos com dimensões médias de 7,5nm de altura e 40nm de diâmetro, com uma densidade de $3,5 \times 10^{10} \mathrm{~cm}^{-2}$.

Além da possibilidade de se reproduzir os resultados em diferentes amostras de pontos quânticos, temos ainda que garantir que uma mesma amostra seja idêntica ao longo de sua área, que em nosso caso é geralmente algo em torno de $1 \mathrm{~cm}^{2}$. Para esse teste, foram crescidas quatro amostras com uma estrutura semelhante à da figura 3.4. As amostras foram crescidas simultaneamente em diferentes posições em relação ao ponto central dos feixes incidentes. A deposição ocorreu sem qualquer movimento de rotação do substrato. A possibilidade de se girar as amostras durante o crescimento do filme poderia ser usada para compensar uma eventual inomogeneidade ao longo da área da amostra crescida. Os resultados, apresentados nas figuras 3.6 e 3.7, mostram que não há variações significativas tanto nas características ópticas quanto topográficas para as amostras crescidas sem rotação dentro da área testada. No canto superior direito da figura 3.6 estão mostradas as regiões em relação à célula de efusão do In de onde foram obtidos os espectros de PL e as imagens 
AFM da figura 3.7. As imagens AFM mostram que as densidades e tamanhos médios dos pontos quânticos obtidos não apresentaram variações significativas ao longo da área.

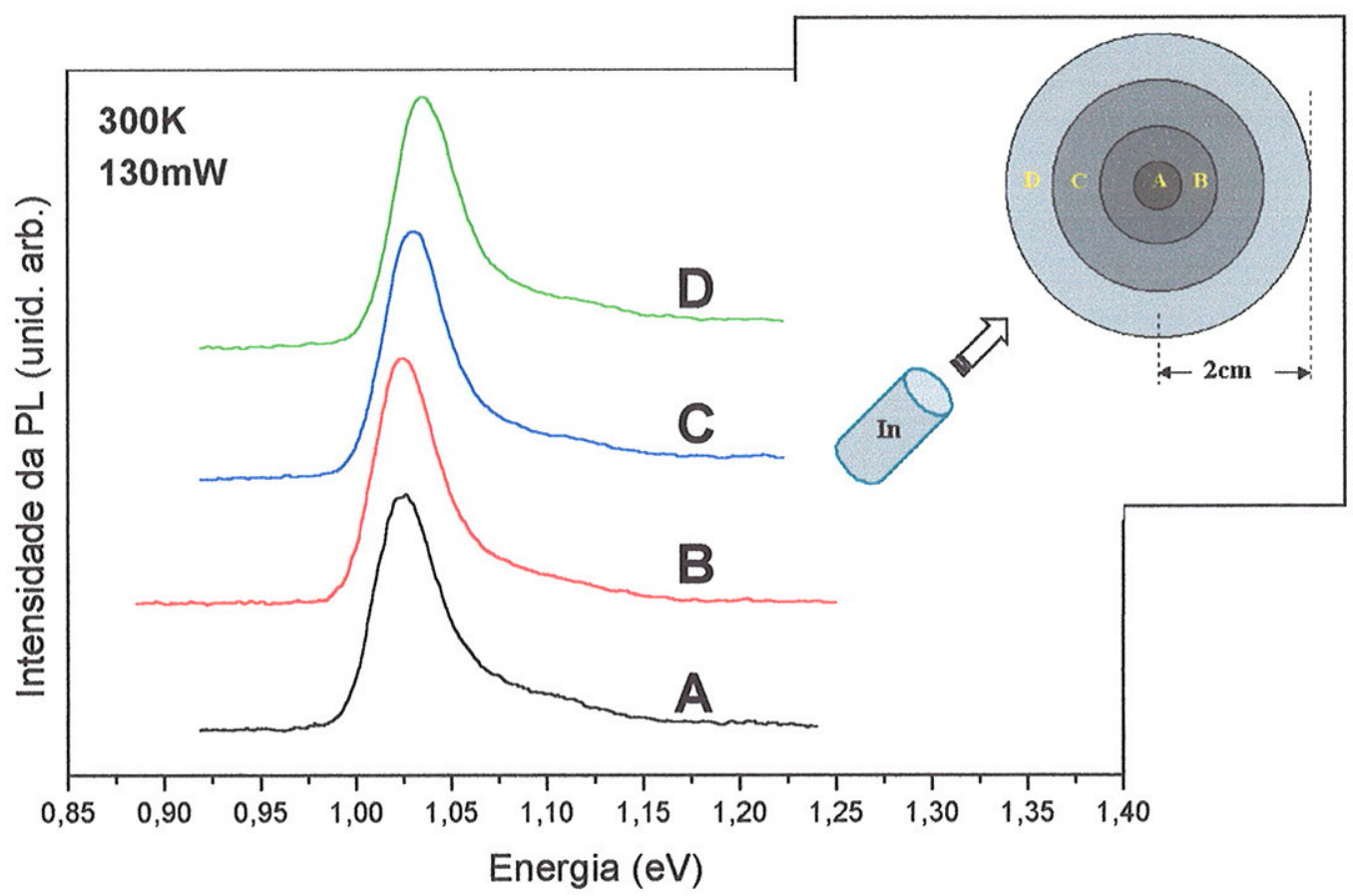

Figura 3.6 - Espectros de PL (300K) de diferentes regiões da amostra-teste crescida sem rotação. A espessura nominal de InAs para a formação dos pontos quânticos foi de 2,4MC. A ilustração da direita mostra a posição da amostra em relação à célula de In, destacando as regiões $\mathrm{A}, \mathrm{B}, \mathrm{C}$ e $\mathrm{D}$, de onde foram realizados os respectivos espectros.

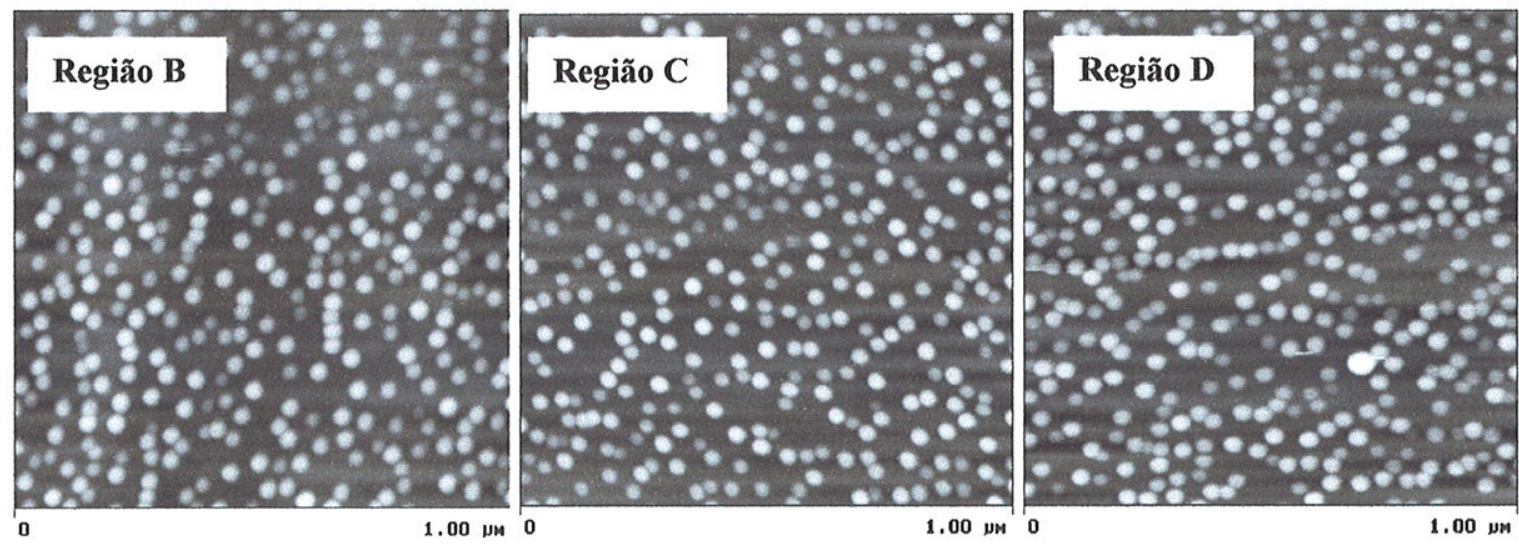

Figura 3.7 - Imagens AFM $\left(1 \times 1 \mu \mathrm{m}^{2}\right)$ das amostras analisadas na figura 3.4 nas regiões $\mathrm{B}, \mathrm{C}$ e D. As dimensões médias dos pontos quânticos são $7,5 \mathrm{~nm}$ de altura e $35 \mathrm{~nm}$ de diâmetro e a densidade é $3,5 \times 10^{10} \mathrm{~cm}^{-}$ 2 
Esses resultados indicam com segurança que não são esperados problemas com a reprodutibilidade das condições de crescimento para as amostras crescidas ao longo do trabalho.

\subsection{2 - Calibração de taxas de crescimento baixas}

O registro das oscilações de intensidade do ponto especular do padrão de difração produzido pelo sistema RHEED é o método padrão de determinação das taxas de crescimento na técnica MBE. As oscilações são causadas pelas alterações topográficas na superfície durante a formação, camada por camada do filme em crescimento, de tal modo que o período de cada oscilação é exatamente o tempo de crescimento de uma monocamada atômica completa. Para que as oscilações de fato ocorram e possam ser usadas para as calibrações de taxas de crescimento, é preciso que não exista um desacordo significativo entre os parâmetros de rede do substrato e do filme em crescimento. Assim, não há problemas no uso desse método para as calibrações de GaAs, AlAs e AlGaAs sobre substratos de GaAs. Porém, a existência de desacordo entre parâmetros de rede da ordem de $7 \%$ entre o InAs e GaAs impede que esse material possa ser calibrado sobre substratos de GaAs através de medidas do período das oscilações RHEED, pois o crescimento é bidimensional (camada por camada) apenas nas primeiras 1,7MC (espessura crítica para a formação de pontos quânticos). Como alternativa, é possível utilizar um substrato de InAs para o qual o crescimento homoepitaxial de um filme de InAs produz oscilações de boa qualidade permitindo assim a calibração. O uso de substratos de InAs é uma importante ferramenta para a calibração desse material em taxas de crescimento padrão $(\sim 0,1$ $0,2 \mathrm{MC} / \mathrm{s})$. Quando usamos taxas de crescimento muito baixas $(<0,01 \mathrm{MC} / \mathrm{s})$, que são as que de fato nos interessam nesse trabalho, o crescimento ocorre na vizinhança do equilíbrio, não havendo grandes variações topográficas na superfície durante a deposição do filme, o que implica na ausência de oscilações de intensidade do ponto especular do padrão de difração. Portanto, apesar dos substratos de InAs nos permitirem a calibração desse material em taxas altas, necessitamos de um método diferente para calibrar o crescimento no regime de baixíssimas taxas. $O$ método proposto para esse caso consiste em determinar a taxa de deposição através da identificação, pelo padrão de difração do RHEED, do momento em 
que ocorre a formação de pontos quânticos durante o crescimento de InAs sobre GaAs. Sabendo-se que tal transição ocorre após 1,7MC de InAs, pode-se determinar a taxa de crescimento simplesmente calculando a razão entre $1,7 \mathrm{MC}$ e o tempo de crescimento para a transição. O fato da transição representar uma clara e abrupta mudança no padrão de difração nos permite usar esse método com grande facilidade e reprodutibilidade.

\subsection{3 - Nossa receita para o crescimento e caracterização de pontos quânticos ativos em $1,3 \mu \mathrm{m}$}

As amostras crescidas ao longo do trabalho possuem uma estrutura simples que consiste em uma camada buffer de GaAs de 300nm, depositada com temperatura do substrato igual a $580^{\circ} \mathrm{C}$, pressão de $\mathrm{As}_{4}$ de $1,0 \times 10^{-5}$ Torr e taxa de crescimento de $0,7 \mathrm{MC} / \mathrm{s}$ sobre substratos de GaAs (001), seguida do filme de InAs responsável pela formação dos pontos quânticos. As condições de crescimento do InAs, tais como a taxa de deposição, a quantidade de material depositado e a temperatura de crescimento, foram variadas de acordo com o objetivo específico de cada conjunto de amostras crescido. Em geral, usamos temperaturas entre $460^{\circ} \mathrm{C}$ e $515^{\circ} \mathrm{C}$ e taxas de deposição inferiores a $0,01 \mathrm{MC} / \mathrm{s}$. Para amostras destinadas à caracterização por AFM, o crescimento foi encerrado logo após a deposição do filme de InAs, mantendo as ilhas descobertas na superfície. Nas amostras crescidas para o estudo de propriedades ópticas, o filme de InAs, após a formação dos pontos quânticos, foi coberto por uma camada de $30 \mathrm{~nm}$ de GaAs, deixando as estruturas de InAs totalmente imersas na matriz de GaAs que desempenha o papel de barreira de potencial para os pontos quânticos.

A figura 3.8 apresenta algumas das características topográficas (3.8a) e ópticas (3.8b) típicas de pontos quânticos de InAs formados nas condições mencionadas acima após a deposição de $2,4 \mathrm{MC}$ de InAs no regime de baixa taxa de crescimento $(0,01 \mathrm{MC} / \mathrm{s})$. Do ponto de vista topográfico, a imagem AFM revela uma densidade predominante $\left(1 \times 10^{10} \mathrm{~cm}^{-2}\right)$ de pontos quânticos uniformes com altura média de $10 \mathrm{~nm}$. Ihas muito maiores e irregulares são também observadas. 

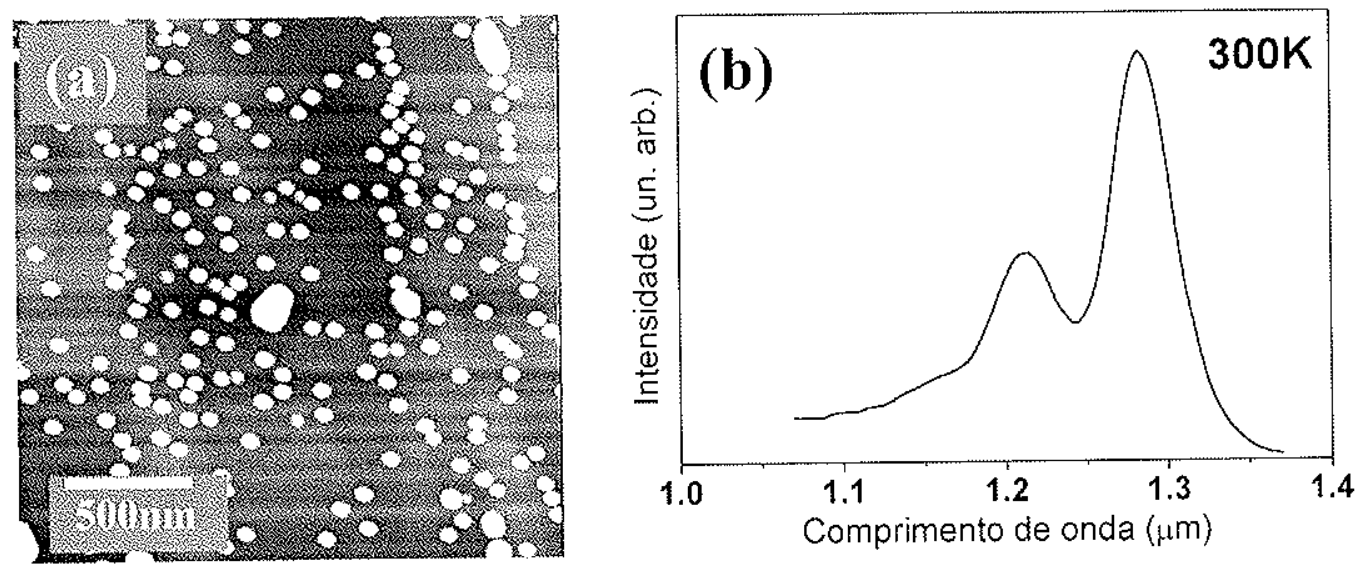

Figura 3.8 - A topografia revelada pela imagem AFM (a) mostra predominantemente pontos quânticos com alturas médias em torno de $10 \mathrm{~nm}$ e uma densidade da ordem de $1 \times 10^{10} \mathrm{~cm}^{-2}$. As emissóes ópticas desses pontos quânticos, quando cobertos por um filme de GaAs (b), atingem a vizinhança de $1,3 \mu \mathrm{m}$ a $300 \mathrm{~K}$.

O espectro de fotoluminescência (figura 3.8b) mostra que tais estruturas, quando

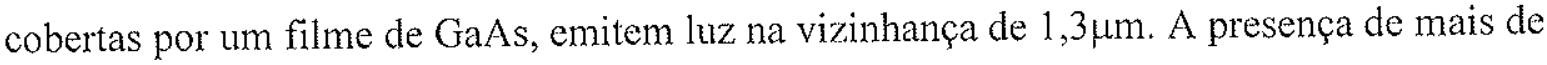
um estado de energia no espectro óptico é uma característica desse tipo de estrutura e está relacionada com o tamanho e densidade das ilhas. A figura 3.8 mostra apenas aspectos gerais do tipo de pontos quânticos produzidos no regime de baixa taxa. Detalhes da morfologia apresentada nas imagens de AFM, bem como o estudo sistemático do caminho percorrido pelo sistema em crescimento até a formação dessas estruturas e como evoluem as suas propriedades ópticas serão abordados sistematicamente nas seções seguintes desse capítulo.

Medidas de AFM como a ilustrada na figura 3.8a serão usadas ao longo de todo o trabalho como fonte de informação a respeito das densidades, distribuições espaciais, tamanhos e forma dos pontos quânticos estudados. Deve-se ter em mente, portanto, as vantagens e limitações da técnica AFM para esse tipo de análise. Primeiramente, o AFM é uma técnica extremamente conveniente para um estudo que envolve a observação de um grande número de amostras em regiões amplas ao longo da superfície. Nenhum tipo de preparação prévia de amostras é necessário e os tempos de varredura para a obtenção de cada imagem são da ordem de apenas alguns minutos. Uma vez estabelecidas condições otimizadas de medidas, a isenção de artefatos é possível e as medidas de densidades e distribuição superficial de ilhas podem ser feitas com segurança. A maior limitação da 
técnica quanto ao estudo de amostras de pontos quânticos de superfície está, no entanto, relacionada com efeitos de convolução da ponta de varredura. Esse efeito está sempre presente em conseqüência do objeto usado como ponta possuir dimensões comparáveis àquelas das estruturas que se deseja observar. Mais precisamente, a varredura AFM tende a super estimar as dimensões laterais dos pontos quânticos e tem pouca influência sobre as dimensões verticais. Assim, os valores apresentados de diâmetro devem ser entendidos não como medidas exatas do tamanho lateral das ilhas mas sim como medidas da interação ponta-objeto. Como o efeito é aproximadamente o mesmo para todas as amostras, espera-se que nenhum erro de interpretação possa decorrer disso. Uma idéia do quanto o efeito de convolução tende a aumentar o diâmetro das ilhas e seu pequeno efeito sobre a altura pode ser obtida comparando-se resultados entre as técnicas AFM e TEM de resolução atômica em seção transversal. A figura 3.9 mostra uma imagem TEM de alta resolução de um ponto quântico de superfície isolado. O contraste entre as interfaces InAs/GaAs e InAs/epoxi permite estimar as dimensões como sendo $7 \mathrm{~nm}$ de altura e $20 \mathrm{~nm}$ de diâmetro. Imagens AFM da mesma amostra mostram que a altura média dos pontos quânticos detectados está de fato, em torno de $7 \mathrm{~nm}$, porém o diâmetro médio medido pelo AFM foi de $35 \mathrm{~nm}$.

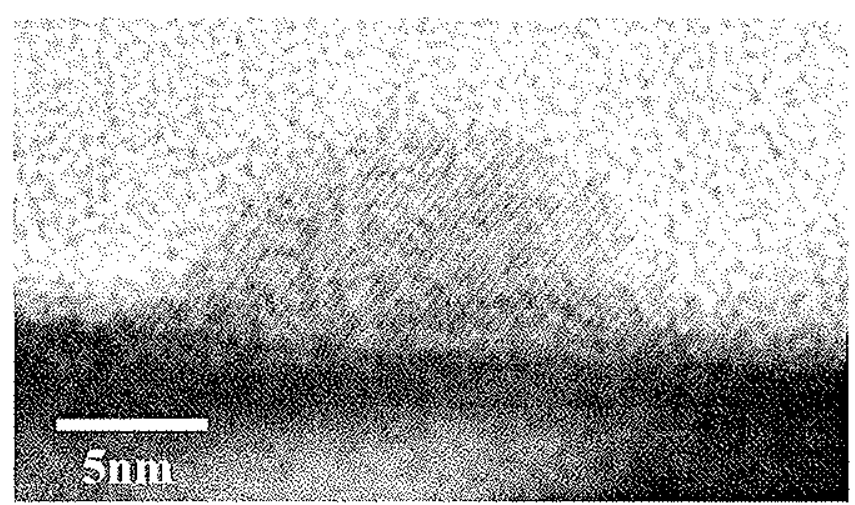

Figura 3.9 - Imagem TEM de alta resolução em seção transversal mostrando um ponto quântico típico com altura de $7 \mathrm{~nm}$ e diâmetro de cerca de $20 \mathrm{~nm}$. 


\section{3 - Estudo do efeito da redução da taxa de crescimento}

\subsection{1 - Efeito sobre a morfologia}

O estudo do efeito da redução sistemática da taxa de crescimento sobre as propriedades morfológicas dos pontos quânticos tem dois objetivos principais:

i) Identificar a maneira com a qual o tamanho, a densidade e a uniformidade das estruturas respondem à diminuição da taxa;

ii) Demonstrar até que ponto a redução da taxa de deposição do InAs pode ser usada como meio de se incrementar o tamanho médio dos pontos quânticos.

O aumento da difusão de material sobre a superfície causado pela redução sucessiva da taxa de crescimento tem como efeito esperado um decréscimo concomitante da densidade de ilhas, uma vez que a probabilidade de incorporação de material em uma ilha pré-existente aumenta em detrimento à nucleação de novas estruturas. Assim, para uma quantidade fixa de material depositado em cada amostra, a disponibilidade de InAs em cada ilha deve ser necessariamente maior à medida que a taxa de crescimento se reduz. A maior dúvida em relação ao comportamento do sistema nesse experimento é saber em que medida a maior quantidade de material disponibilizada pode, de fato, ser incorporada nos pontos quânticos afím de produzir ilhas maiores sem a perda da coerência.

A figura 3.10 mostra através de imagens AFM com $1 \times 1 \mu \mathrm{m}^{2}$ os resultados da caracterização morfológica dos pontos quânticos crescidos a $0,1 \mathrm{MC} / \mathrm{s}(\mathrm{a}) ; 0,04 \mathrm{MC} / \mathrm{s}$ (b); $0,01 \mathrm{MC} / \mathrm{s}$ (c); $0,005 \mathrm{MC} / \mathrm{s}$ (d) e $0,003 \mathrm{MC} / \mathrm{s}$ (e), e a tabela (f) resume as condições de crescimento usadas. Com a taxa de crescimento mais alta usada $(0,1 \mathrm{MC} / \mathrm{s})$, detecta-se uma elevada densidade de ilhas na superfície $\left(\sim 1 \times 10^{11} \mathrm{~cm}^{-2}\right)$ onde duas famílias de estruturas podem ser identificadas. As estruturas predominantes representam pontos quânticos uniformes com 4,0nm de altura média e 13,0nm de diâmetro. 

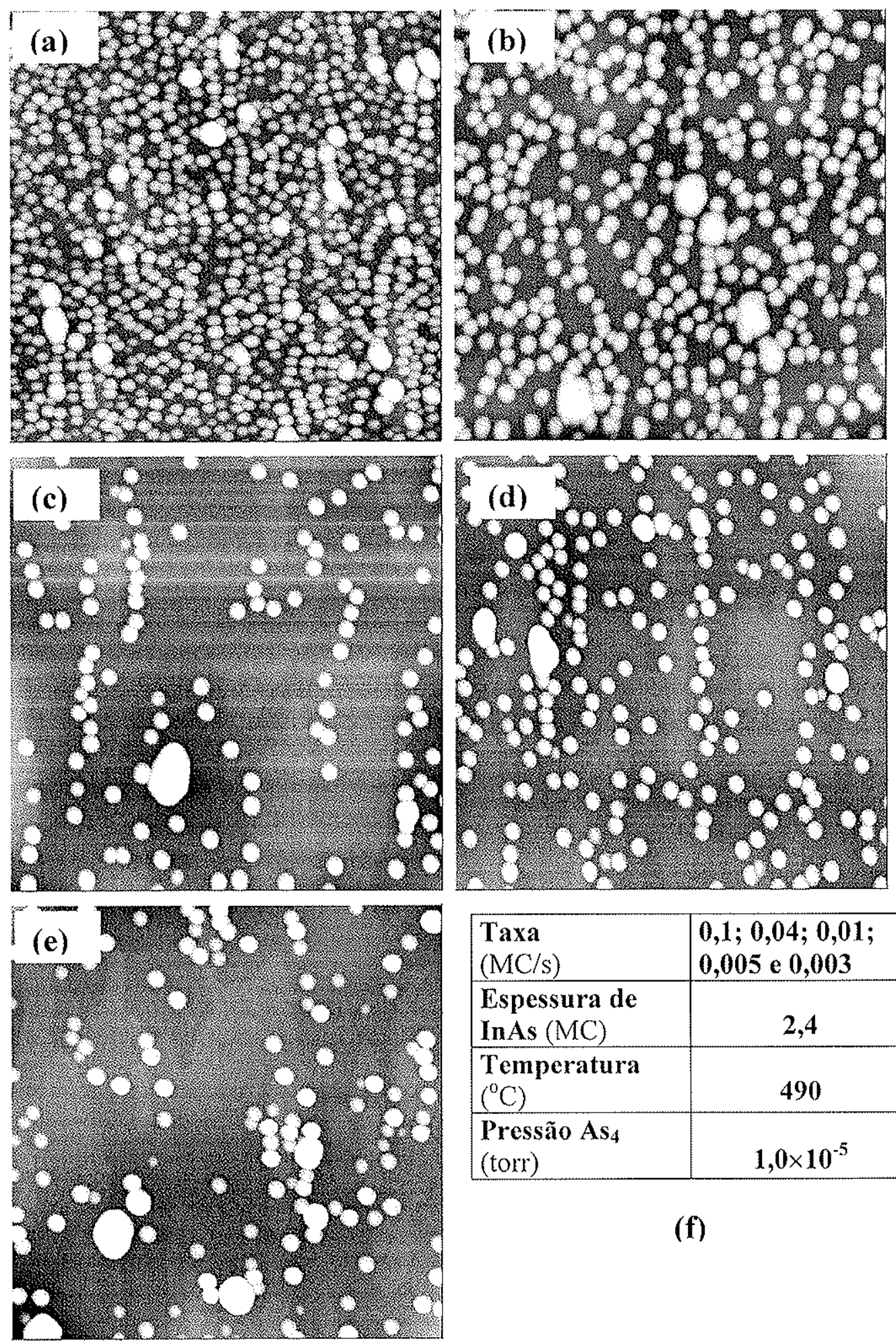

\begin{tabular}{|l|c|}
\hline $\begin{array}{l}\text { Taxa } \\
(\mathrm{MC} / \mathrm{s})\end{array}$ & $\begin{array}{c}0,1 ; 0,04 ; 0,01 ; \\
0,005 \mathrm{e} 0,003\end{array}$ \\
\hline $\begin{array}{l}\text { Espessura de } \\
\text { InAs }(\mathrm{MC})\end{array}$ & $\mathbf{2 , 4}$ \\
\hline $\begin{array}{l}\text { Temperatura } \\
\left({ }^{\circ} \mathrm{C}\right)\end{array}$ & 490 \\
\hline $\begin{array}{l}\text { Pressão } \mathrm{As}_{4} \\
\text { (torr) }\end{array}$ & $1,0 \times 10^{-5}$ \\
\hline
\end{tabular}

(f)

Figura 3.10 - Imagens AFM $\left(1 \times 1 \mu \mathrm{m}^{2}\right)$ de uma sucessão de amostras onde a taxa de crescimento fö sistematicamente reduzida: $0,1 \mathrm{MC} / \mathrm{s}$ (a); $0,04 \mathrm{MC} / \mathrm{s}$ (b); $0,01 \mathrm{MC} / \mathrm{s}$ (c); $0,005 \mathrm{MC} / \mathrm{s}$ (d) e $0,003 \mathrm{MC} / \mathrm{s}$ (e). A tabela (f) mostra um resumo das condições de crescimento usadas. 


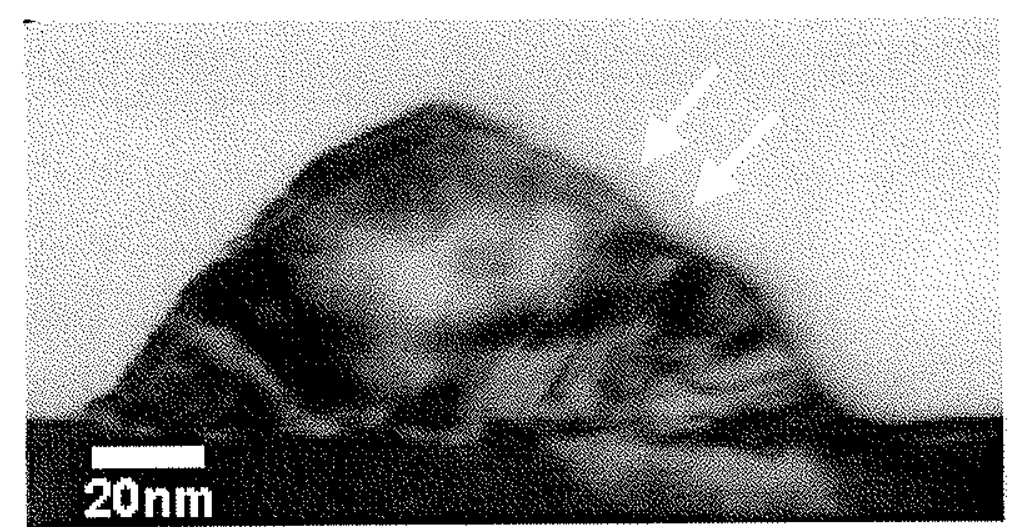

Figura 3.11 -.. Imagem TEM (dark field (002)) em seção transversal de uma ilha relaxada típica, facilmente identificada também em imagens AFM em razão de sua não uniformidade quando comparada a pontos quânticos. A descontinuidade no contraste indica a presença de defeitos estruturais.

Ilhas bem maiores e irregulares com alturas de 20-40nm e diâmetros superiores a $60 \mathrm{~nm}$ podem ser claramente observadas. As condições de crescimento usadas nessa amostra podem ser chamadas de condições de crescimento padrão para pontos quânticos em razão da grande maioria dos trabalhos apresentados nessa área utilizar taxas deposição em torno de $0,1 \mathrm{MC} / \mathrm{s}$ e deposição de $2-3 \mathrm{MC}$ de InAs. É atualmente muito bem determinado que além das diferenças morfológicas óbvias entre as duas famílias de estruturas detectadas, os pontos quânticos distinguem-se das ilhas maiores por serem essas últimas estruturas incoerentes, parcialmente relaxadas através da introdução de defeitos estruturais, tais como deslocações. A figura 3.11 apresenta uma imagem TEM em seção transversal onde se destaca a presença de defeitos estruturais (indicados por setas) numa das ilhas irregulares da mesma amostra apresentada na figura 3.10a. Mesmo sem ser uma técnica estrutural, e sim topográfica, a técnica AFM nos permite distinguir entre famílias de ilhas coerentes (pontos quânticos) e relaxadas através da observação das distribuições estatísticas de tamanho e forma do grande número de entidades detectadas. Pontos quânticos são estruturas uniformes e formam-se nos estágios iniciais da deposição de InAs, enquanto as ilhas relaxadas, são muito maiores, possuem forma irregular, e em princípio devem surgir após a formação dos primeiros pontos quânticos.

Uma posterior redução da taxa de crescimento para $0,04 \mathrm{MC} / \mathrm{s}$ reduz a densidade de ilhas para aproximadamente a metade $\left(\sim 4 \times 10^{10} \mathrm{~cm}^{-2}\right)$. A altura média atinge $5,7 \mathrm{~nm}$ e o diâmetro $20 \mathrm{~nm}$. Conforme indicado na fïgura 3.12, onde se apresentam os histogramas de 
altura obtidos a partir das imagens da figura 3.10*, a redução gradual da taxa de crescimento até $0,005 \mathrm{MC} / \mathrm{s}$ possui um comportamento monotônico, reduzindo a densidade e elevando o tamanho médio dos pontos quânticos, que atingem $1 \times 10^{10} \mathrm{~cm}^{-2} ; 10,7 \mathrm{~nm}$ (altura) e $49 \mathrm{~nm}$ (diâmetro) quando a taxa de crescimento usada foi $0,005 \mathrm{MC} / \mathrm{s}$. Uma posterior redução da taxa para $0,003 \mathrm{MC} / \mathrm{s}$ tem no entanto, um caráter diferenciado. Observa-se a presença de uma terceira família de ilhas, com densidade de cerca de $5 \times 10^{9} \mathrm{~cm}^{-2}$ e altura média de $5,5 \mathrm{~nm}$. A imagem mostra que, ao contrário das etapas anteriores, não há aumento de tamanho nos pontos quânticos e parte dos pontos quânticos com altura média de $10 \mathrm{~nm}$ persiste porém com um decréscimo de sua densidade para cerca de $5 \times 10^{9} \mathrm{~cm}^{-2}$. O fato da densidade total de ilhas entre as imagens $3.10 \mathrm{~d}$ e $3.10 \mathrm{e}$ permanecer estável e não haver aumento de tamanho na família de pontos quânticos maiores demonstra que uma quantidade significativa de material esta "faltando" nos pontos quânticos. A xazão para esse comportamento está na elevação do tamanho e densidade de defeitos nas ilhas relaxadas. Tais defeitos são centros de incorporação privilegiados em relação aos pontos quânticos e atuam no sentido de drenar o material presente na superfície. Além disso a taxa de desadsorção de material a partir da superfície do substrato, praticamente desprezível quando o crescimento se processa em altas taxas, passa agora a ter um papel importante, sendo assim responsável por parte da diminuição do volume total de InAs nos pontos quânticos.

\footnotetext{
* Nos histogramas da figura 3.12, optou-se por não incluir os dados estatísticos de todas as ilhas relaxadas para uma melhor visualização.
} 


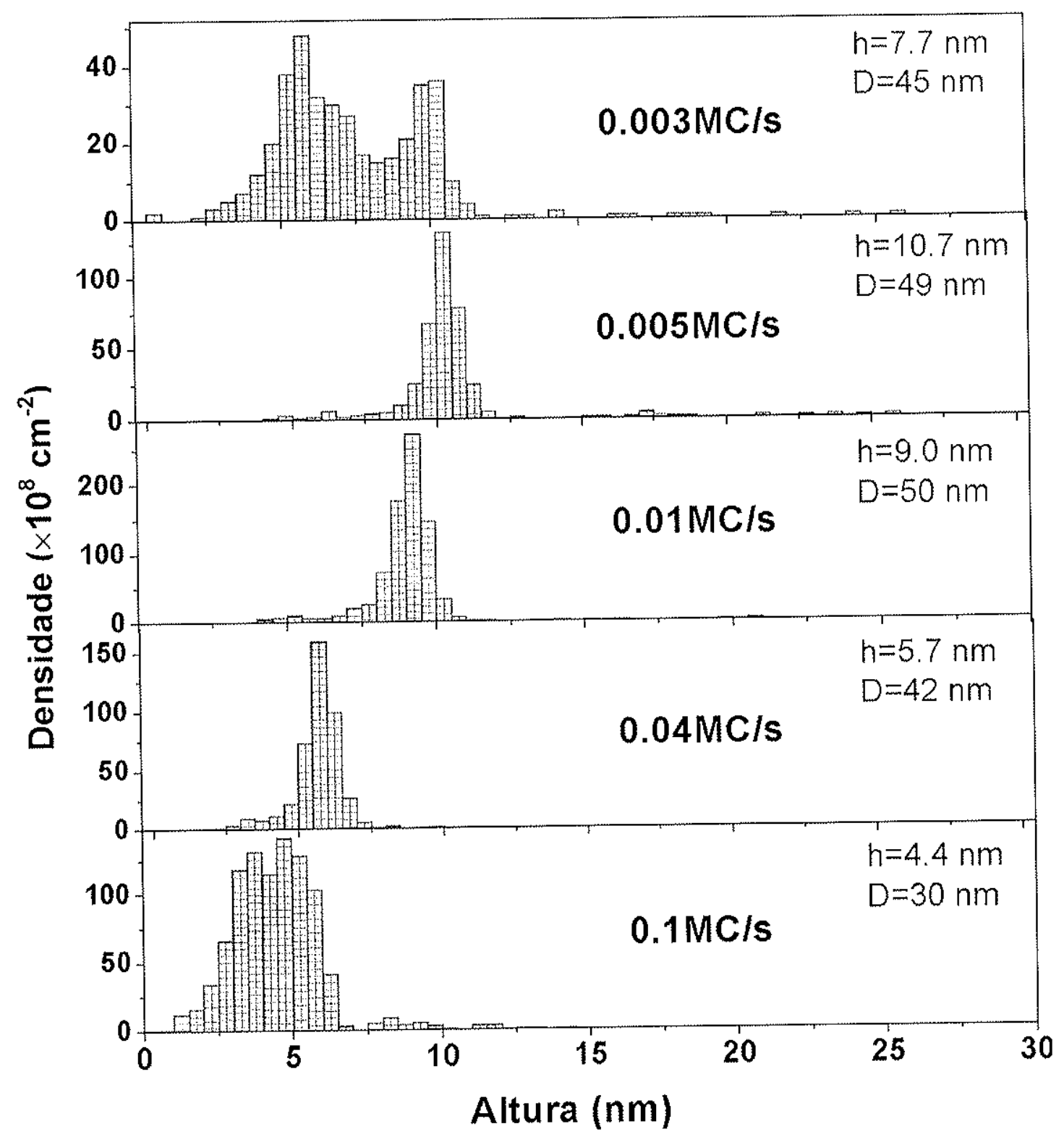

Figura 3.12 - Histogramas de altura obtidos a partir da análise das imagens AFM da figura 3.10. h e D representam os valores médios de altura e diâmetro, respectivamente.

O monitoramento da resposta do sistema frente às reduções sucessivas da taxa de crescimento aponta para a existência de uma altura máxima de $10 \mathrm{~nm}$ para os pontos quânticos. Como a altura é a menor dimensão de confinamento nos pontos quânticos, é ela que possui o maior impacto na manipulação das regiões de emissão óptica, e portanto a existência desse limite de altura sugere um limite para a sintonia das emissões através do aumento do tamanho dos pontos quânticos. 


\subsection{2 - Efeito sobre as propriedades ópticas - sintonia da emissão em $1,3 \mu \mathrm{m}$}

Após a determinação do comportamento morfológico da distribuição de pontos quânticos em função da diminuição sistemática da taxa de crescimento, resta verificar em que extensão o aumento gradual de tamanho, sobretudo da altura, pode ser usado para a sintonia da emissão na faixa de comprimento de onda de interesse. Para isso, foram crescidas amostras nas mesmas condições que as discutidas na figura 3.10. Porém, após a formação dos pontos quânticos uma camada (cap layer) de GaAs de 30nm de espessura foi crescida para envolver completamente as ilhas na matriz cristalina permitindo medidas de fotoluminescência. A figura 3.13 apresenta os espectros medidos em temperatura ambiente com densidade de potência de excitação de $0,2 \mathrm{kWcm}^{-2}$. É possível observar que, conforme esperado diante dos resultados prévios da caracterização topográfica, a redução da taxa de deposição do InAs atua no sentido de deslocar o pico das emissões para a região de longo comprimento de onda. Quando a taxa de crescimento é reduzida de $0,1 \mathrm{MC} / \mathrm{s}$ para $0,01 \mathrm{MC} / \mathrm{s}$, un deslocamento de $64 \mathrm{meV}$ posiciona a emissão em $1,28 \mu \mathrm{m}$, em consistência com o aumento substancial de tamanho detectado pelas imagens AFM para essa mesma faixa de variação de taxa de deposição. A partir desse ponto, posteriores reduções de taxa não afetam muito o posicionamento das emissões, como também esperado a partir da caracterização topográfica. Para as menores taxas de crescimento testadas $(0,005 \mathrm{MC} / \mathrm{s}$ e $0,003 \mathrm{MC} / \mathrm{s}$ ), o pico de emissão atinge exatamente $1,3 \mu \mathrm{m}$. Juntamente com o deslocamento para longo comprimento de onda, a diminuição gradual da taxa é acompanhada por uma redução significativa da largura à meia altura das emissões (FWHM, full-width at half maximum), que passa de cerca de $36 \mathrm{meV}$ para a taxa de $0,1 \mathrm{MC} / \mathrm{s}$ a apenas $22 \mathrm{meV}$ quando a taxa de crescimento é reduzida para $0,005 \mathrm{MC} / \mathrm{s}$. A FWHM de $22 \mathrm{mev}$ em temperatura ambiente representa uma das mais estreitas luminescências observadas na literatura para esse sistema [38]. Novamente em analogia com os resultados da caracterização morfológica, a diminuição acentuada da largura das emissões pode ser entendida em termos do substancial ganho de uniformidade nas distribuições de tamanho dos pontos quânticos crescidos em baixa taxa conforme mostrado nos histogramas da figura 3.12. 


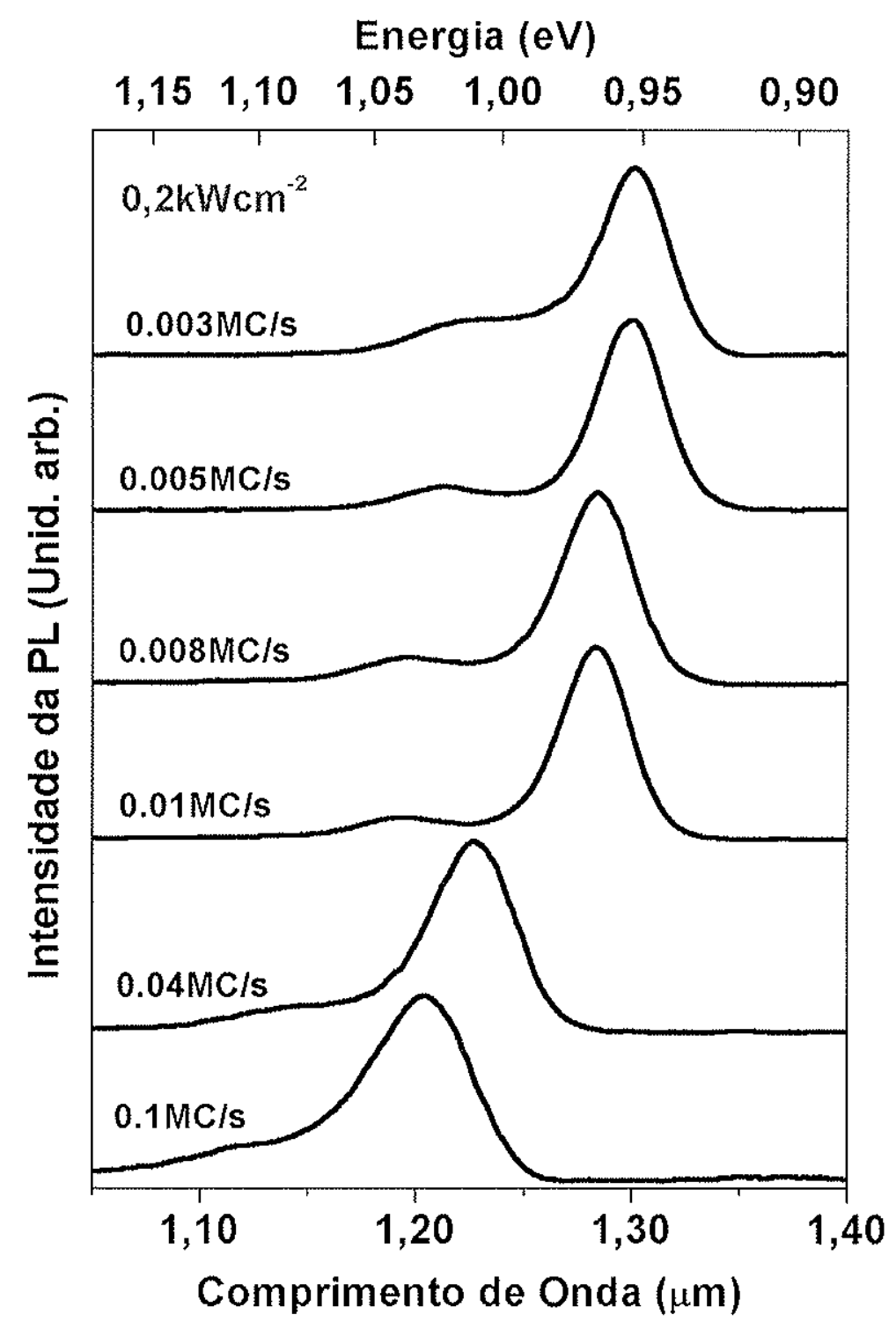

Figura 3.13 - Espectros de PL normalizada $(300 \mathrm{~K})$ de amostras crescidas com taxas gradualmente reduzidas (conforme indicado). É possível observar a sintonia das emissões na vizinhança de 1,3um para taxas de deposição menores que $0,01 \mathrm{MC} / \mathrm{s}$.

\subsection{3 - Natureza das emissões ópticas em $1,3 \mu \mathrm{m}$}

A obtenção de emissões tão estreitas abre uma via para a investigação mais detalhada da natureza do sinal de fotoluminescência nas amostras de pontos quânticos crescidos em baixa taxa, uma vez que características mais finas dos espectros (presença de estados excitados, forma de linha, etc.) podem ser acessadas. A figura 3.14 mostra os 
espectros de PL medidos em baixa temperatura $(2 \mathrm{~K})$ e alta densidade de potência de excitação $\left(1,4 \mathrm{kWcm}^{-2}\right)$ de onde se pode observar que cada espectro, sobretudo aqueles de amostras crescidas em baixas taxas, exibem múltiplas emissões. Analogamente ao observado em temperatura ambiente, o deslocamento entre os picos de mais baixa energia para as taxas de crescimento de $0,1 \mathrm{MC} / \mathrm{s}$ e $0,003 \mathrm{MC} / \mathrm{s}$ está em torno de $70 \mathrm{meV}$, e as emissões tornam-se muito mais estreitas, permitindo uma excelente definição entre múltiplos picos nas taxas de crescimento menores que $0,04 \mathrm{MC} / \mathrm{s}$.

A ocorrência de múltiplos picos em emissões de amostras de pontos quânticos num experimento de fotoluminescência possui três possíveis razões. Diante da disponibilidade de um grande número de éxcitons fotogerados no experimento, o espectro de energia de natureza discreta de cada ponto quântico tende a conduzir ao preenchimento de estados de mais baixa energia aumentando a probabilidade de recombinações de estados de mais alta energia, produzindo um efeito conhecido na literatura como state-filling effect [39]. Esperase que tal efeito seja particularmente presente em amostras crescidas em baixas taxas, uma vez que pontos quânticos maiores podem acomodar um maior número de estados ligados. A segunda possível razão para a presença de múltiplas emissões também está relacionada com a densidade de estados discreta dos pontos quânticos. As severas dificuldades de relaxação impostas pelo potencial de confinamento 3D tendem a diminuir as taxas de transição entre subníveis caso as diferenças de energia entre eles não concordar com as energias disponíveis para os fônons da rede. Nesse caso, a falta de processos de recombinação por fônons ou mesmo de processos que envolvem múltiplos fônons torna os tempos de relaxação e recombinação radiativa muito próximos, o que conduz à observação de estados excitados mesmo quando os estados inferiores ainda estão disponíveis. Esse efeito é conhecido na literatura como phonon bottleneck [40]. Uma outra possivel origem para a presença de múltiplos picos no espectro de PL vem da possibilidade de haver mais de uma família de pontos quânticos da amostra, com diferenças de forma, tamanho ou composição química. Nessa situação, as diferentes emissões viriam das diferentes distribuições de pontos quânticos presentes. 


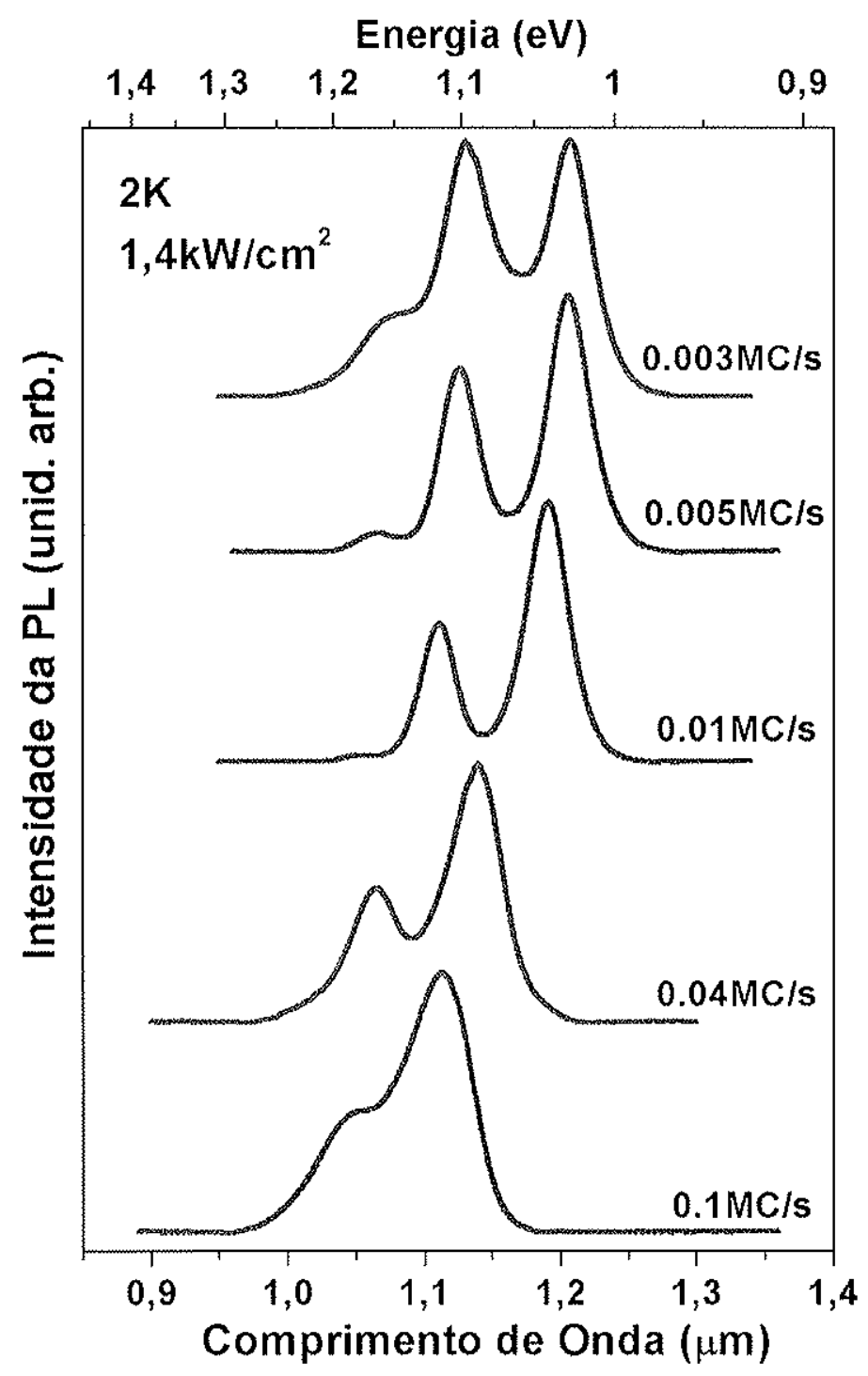

Figura 3.14 - Espectros de PL em baixa temperatura $(2 \mathrm{~K})$ e alta densidade de potência de excitação $\left(1,4 \mathrm{~kW} / \mathrm{cm}^{2}\right)$ das amostras crescidas em função da redução da taxa de crescimento. Nessas condições, é possível observar com clareza a presença de múltiplas emissões em cada espectro, sobretudo naqueles de amostras crescidas em baixas taxas.

Apesar de cada um dos três efeitos mencionados acima poder conduzir a um mesmo resultado quanto à presença de emissões no espectro de PL das amostras de pontos quânticos, eles podem ser diferenciados através de experimentos simples de PL em razão de cada um deles possuir uma natureza distinta. Se o efeito de state filling está presente, um aumento gradual da densidade de potência de excitação da PL, partindo de potências muito baixas, tende a saturar inicialmente o estado fundamental, para posteriormente se observar 
as emissões do primeiro estado excitado, e assim sucessivamente até a observação de vários estados do potencial. $\mathrm{E}$ de modo inverso, a redução da densidade de potência de excitação, partindo de altos valores, pode depopular gradualmente os estados excitados até a condição onde somente o estado fundamental (um único pico de emissão) possa ser observado. Se, por outro lado, o efeito de phonon bottleneck é dominante, a detecção de estados excitados não depende da população de éxcitons, e não se extingue quando a potência de excitação da amostra é reduzida por mais que uma ordem de grandeza. Finalmente, a presença de mais que uma família de pontos quânticos na amostra pode ser identificada como fonte de múltiplas emissões se o aumento do número de éxcitons produzidos por um aumento de potência de excitação por várias ordens de grandeza não alterar a amplitude relativa dos picos de emissão observados, uma vez que, nesse caso, essas amplitudes refletem a abundância relativa de pontos quânticos em cada família.

Afim de identificar a natureza das emissões nas amostras da figura 3.14, medidas de PL em baixa temperatura em função da densidade de potência de excitação numa faixa de variação de quatro ordens de grandeza foram realizadas, e os resultados são apresentados na figura 3.15. A figura 3.15a diz respeito à amostra crescida a $0,01 \mathrm{MC} / \mathrm{s}$, de onde se pode observar que, em baixíssima potência $\left(140 \mathrm{mWcm}^{-2}\right)$, apenas o estado fundamental é observado, centrado em $1,19 \mu \mathrm{m}$ e com FWHM de $23 \mathrm{meV}$. A posição, largura e forma de linha permanecem inalteradas ao longo de toda a faixa de potência de excitação investigada, e apenas a partir de uma densidade de potência 100 vezes maior que a inicial é que se inicia a detecção de uma segunda emissão, que a partir daí passa a evoluir gradualmente até que com a potência máxima usada $\left(1,4 \mathrm{kWcm}^{-2}\right)$ se detecta a terceira emissão. De acordo com a discussão apresentada no parágrafo anterior, é evidente que o efeito de múltiplas famílias ou phonon bottleneck não estão presentes na amostra. Os picos observados são então devidos ao preenchimento sucessivo dos estados ligados, sendo o estado fundamental identificado em $1,19 \mu \mathrm{m}(1,043 \mathrm{eV})$, o primeiro estado excitado em $1,11 \mu \mathrm{m}(1,117 \mathrm{eV})$ e o segundo estado excitado em $1,04 \mathrm{~mm}(1,192 \mathrm{eV})$. O fato dos níveis serem perfeitamente eqüidistantes $(75 \mathrm{meV})$ sugere que, apesar da complexidade do potencial real ao qual se submete um portador no interior da estrutura dos pontos quânticos, o potencial efetivo é semelhante àquele de um oscilador harmônico simples. A figura $3.15 \mathrm{~b}$ mostra os resultados do mesmo experimento realizado na amostra crescida a $0,1 \mathrm{MC} / \mathrm{s}$. $\mathrm{O}$ 
resultado é análogo ao observado anteriormente, exceto pelo fato de que a maior FWHM das emissões $(\sim 36 \mathrm{meV})$ não permite uma completa resolução de múltiplos picos em densidades de potência de excitação abaixo de $1,4 \mathrm{kWcm}^{-2}$. Observando a forma de linha dos espectros, sobretudo daqueles de mais baixa excitação, é possível detectar uma acentuada assimetria na emissão para o lado de alta energia. Uma possível explicação pode decorrer da larga distribuição de tamanhos de pontos quânticos crescidos a $0,1 \mathrm{MC} / \mathrm{s}$ evidenciada na caracterização topográfica. Uma análise mais detalhada da forma de linha mostra, no entanto, que a assimetria de cada curva se altera continuamente com o aumento da potência de excitação. Isso sugere que o efeito não está relacionado com a distribuição de tamanhos ou concentrações dos pontos quânticos. Além disso, o ajuste matemático (fit) de cada emissão com duas curvas gaussianas mostra que a posição da curva que descreve a assimetria muda em comprimento de onda com o aumento da densidade de potencia de excitação, indicando que o efeito também não está relacionado com a presença de estados excitados, ao menos até as primeiras três ordens de grandeza de potência usadas. Apenas acima de uma potência de excitação da ordem de $14 \mathrm{Wcm}^{-2}$ o primeiro estado excitado torna-se detectável.

Um maior entendimento a respeito das possíveis razões para a assimetria dos espectros da figura $3.15 b$ pode ser obtido através da comparação das formas de linha das medidas em baixa potencia $\left(<1,4 \mathrm{Wcm}^{-2}\right)$ das amostras crescidas a $0,1 \mathrm{MC} / \mathrm{s} ; 0,04 \mathrm{MC} / \mathrm{s}$ e $0,01 \mathrm{MC} / \mathrm{s}$, conforme mostrado na figura 3.16. Sobrepondo os espectros através do alinhamento da região de baixa energia (onde as curvas são idênticas), é possível analisar a maneira com a qual a assimetria se extingue a medida que a taxa de crescimento é reduzida. 

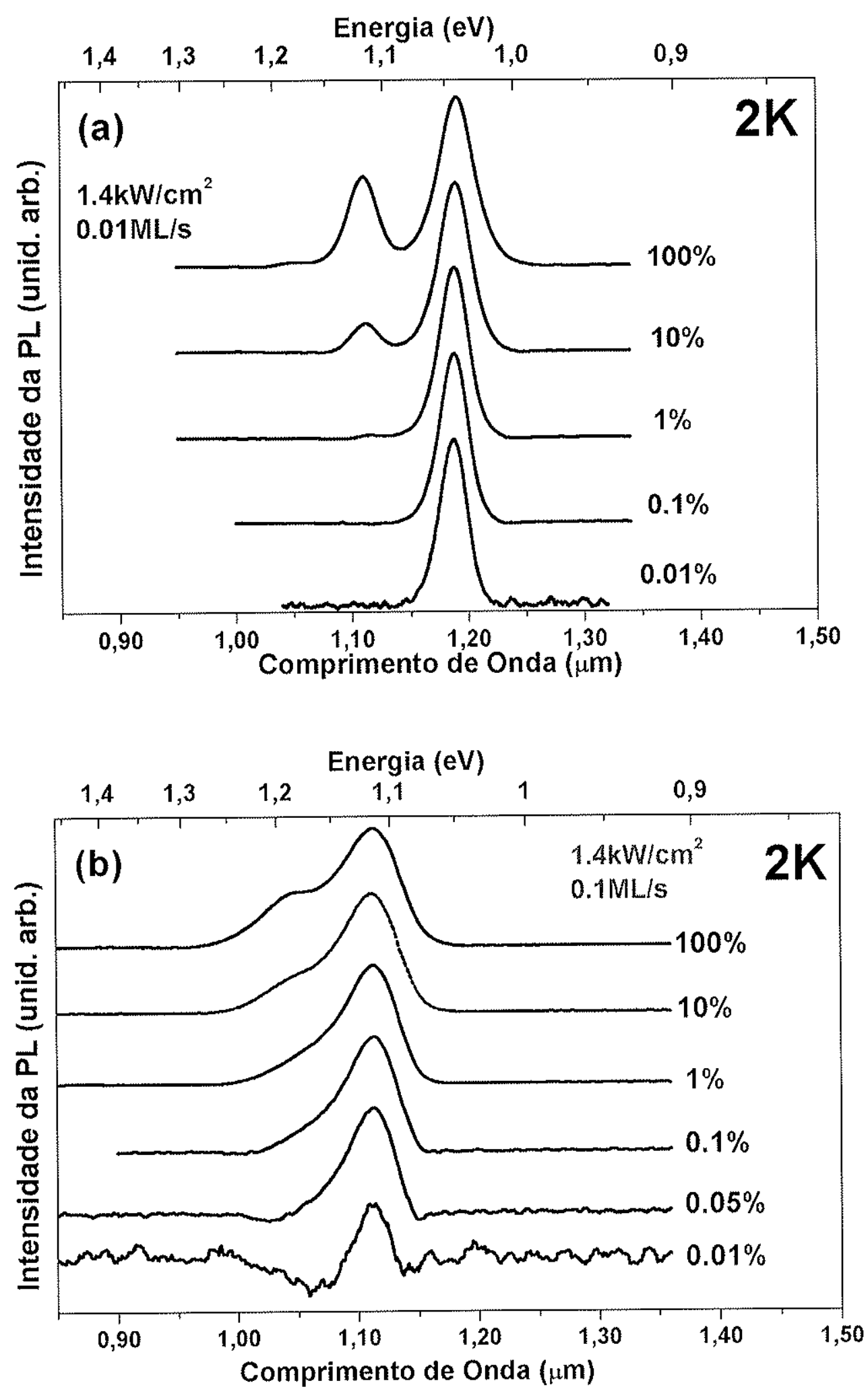

Figura 3.15 - Espectros de PL em baixa temperatura em função da densidade de potência de excitação para as amostras crescidas em $0,01 \mathrm{MC} / \mathrm{s}$ (a) e $0,1 \mathrm{MC} / \mathrm{s}$ (b). 
O gráfico no canto superior direito da figura 3.16 mostra que o aumento de FWHM com o aumento da taxa de crescimento de $0,005 \mathrm{MC} / \mathrm{s}$ até $0,1 \mathrm{MC} / \mathrm{s}$ é tal que apenas $6 \mathrm{meV}$ concentram-se na região de baixa energia, enquanto cerca de $20 \mathrm{meV}$ estão associados à região do espectro do lado de alta energia. Esse comportamento confirma que a ocorrência de assimetria não está ligada à não uniformidade na distribuição de tamanho dos pontos quânticos, uma vez que, entre $0,04 \mathrm{MC} / \mathrm{s}$ e $0,005 \mathrm{MC} / \mathrm{s}$, essas distribuições possuem uniformidades semelhantes, conforme mostra a figura 3.10. Aparentemente o efeito está associado ao aumento sucessivo de tamanho dos pontos quânticos obtido com a diminuição da taxa de deposição do InAs. A medida que os pontos quânticos tornam-se maiores, os níveis de energia são deslocados para o fundo do poço de potencial e portanto, afastam-se da borda do continutum de estados da camada bidimensional de InAs formada antes da criação dos pontos quânticos (WL, wetting layer). A maneira pela qual a assimetria evolui com a potência de excitação mostrada na figura 3.15b e o fato dessa assimetria diminuir com o aumento de tamanho dos pontos quânticos sugere então que o efeito possa ser causado pelo fato da emissão envolver processos de recombinação entre níveis eletrônicos dos pontos quânticos com níveis de buraco da WL. Os experimentos realizados aqui não permitem, na verdade, apresentar uma explicação definitiva para o efeito, e um estudo mais dedicado a esse problema se faz necessário. Assim, se grande parte da motivação em se estudar as estruturas de pontos quânticos deriva do fato das transições ópticas envolverem potenciais de confinamento $3 \mathrm{D}$, pode-se dizer que pontos quânticos crescidos em baixa taxa de crescimento são preferíveis, uma vez que a influência do continuum é minimizada pelo distanciamento dos estados dos pontos quânticos daqueles da WL. 


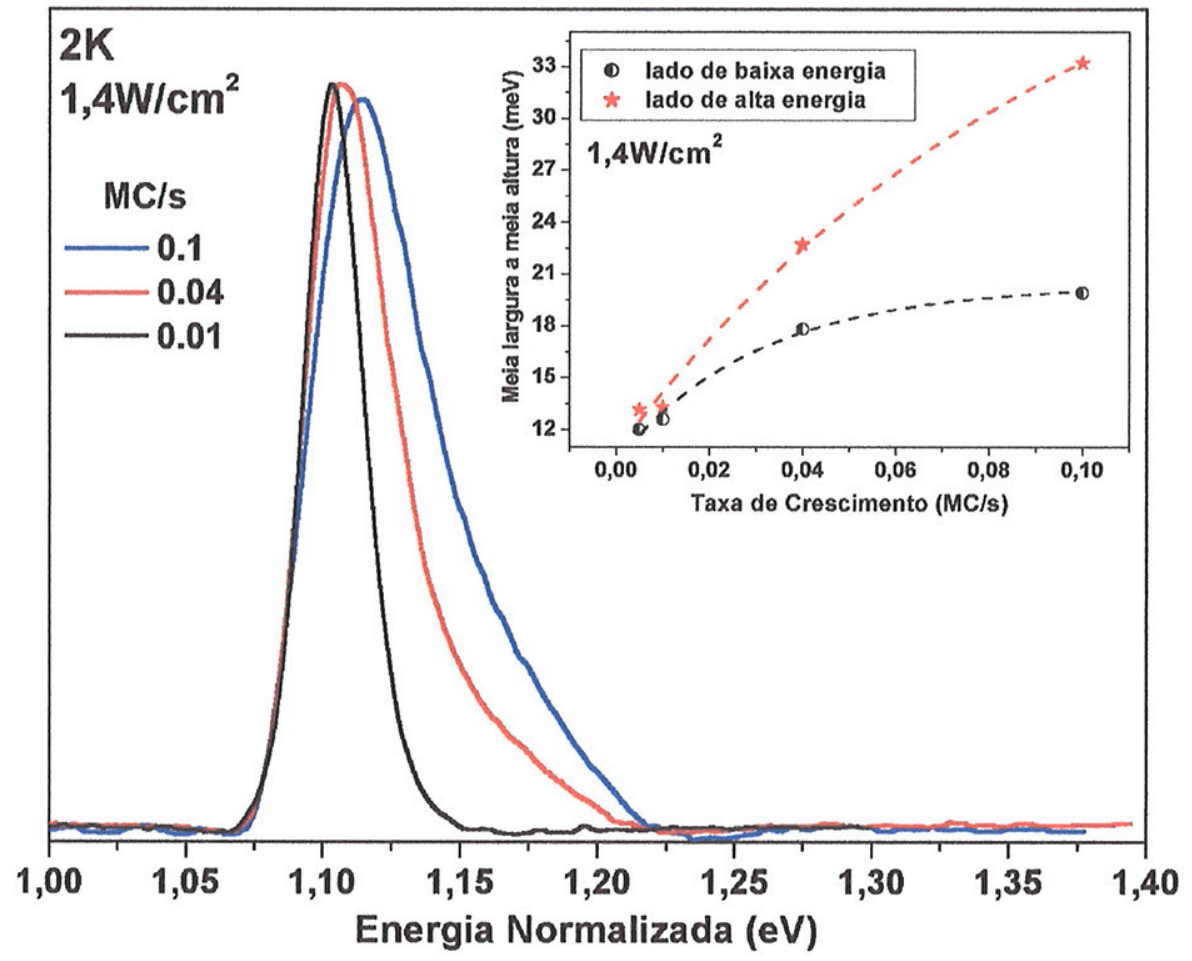

Figura 3.16 - Sobreposição em energia dos espectros das amostras crescidas a 0,1MC/s; 0,04MC/s e 0,01MC/s para comparação das variações na forma de linha. O gráfico do canto superior direito mostra a meia largura em função da taxa de crescimento para os lados de baixa e alta energia, de onde se pode ver que a assimetria cresce rapidamente com o aumento da taxa de deposição do InAs e, consequentemente, com o aumento de tamanho das estruturas.

Um experimento adicional capaz de evidenciar a natureza 3D do potencial de confinamento de pontos quânticos consiste na realização de medidas de PL em campo magnético. $\mathrm{O}$ fato do crescimento em baixa taxa elevar as dimensões laterais das estruturas até cerca de $45 \mathrm{~nm}$ poderia causar uma diminuição do confinamento no plano da amostra, aproximando o potencial efetivo daquele de um poço quântico, onde o confinamento é apenas na direção vertical. A aplicação de um campo magnético em um experimento de PL numa estrutura onde éxcitons são livres em todas as direções, como num bulk por exemplo, tende a confiná-los na direção perpendicular ao campo aumentando sensivelmente sua energia, e produzindo o chamado deslocamento diamagnético. Se, por outro lado, o éxciton já se encontra confinado lateralmente, o efeito adicional de confinamento do campo será menos evidente, e o deslocamento diamagnético será menor. Pode-se então identificar a existência de um potencial de confinamento lateral (paralelo à superfície da amostra) 
através da verificação da ausência de deslocamento diamagnético quando o campo magnético é orientado perpendicularmente à superfície da amostra. Esse comportamento é uma assinatura do potencial de confinamento lateral dos pontos quânticos, e sua medição é usada comumente quando se pairam dúvidas a respeito da natureza das emissões observadas [41]. A figura 3.17 mostra uma comparação entre o comportamento do deslocamento diamagnético em um poço quântico de $\operatorname{In}_{0,15} \mathrm{Ga}_{0,85} \mathrm{As} / \mathrm{GaAs}$ e uma amostra de pontos quânticos crescida a baixa taxa $(0,01 \mathrm{MC} / \mathrm{s})$ numa configuração onde o campo magnético é orientado perpendicularmente à superfície da amostra. A ausência de deslocamento significativo para a estrutura de pontos quânticos não deixa dúvidas sobre o caráter 3D do potencial sentido pelos éxcitons nesse tipo de amostra.

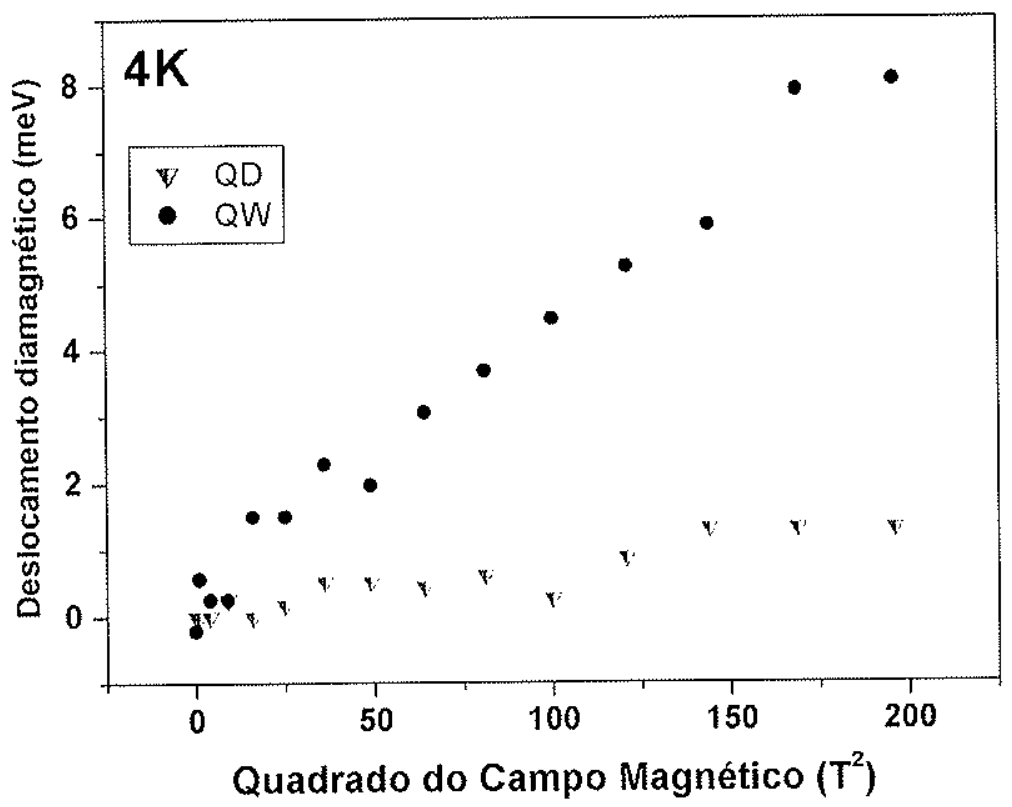

Figura 3.17 - Medida do deslocamento diamagnético das emissões de PL em função do campo magnético aplicado perpendicularmente à superfície da amostra. Na faixa de campo investigada (1T a 14T), a emissão do estado fundamental dos pontos quânticos deslocou-se apenas $1 \mathrm{meV}$, enquanto o deslocamento para a amostra de poço quântico foi de $8 \mathrm{meV}$.

O comportamento das emissões de PL em função da temperatura representa um aspecto crucial das propriedades ópticas de amostras de pontos quânticos. A natureza discreta dos estados de energia e as inomogeneidades de forma, tamanho e composição química faz com que uma família de pontos quânticos não possa ser adequadamente 
descrita pela suposição de um nível de Fermi comum. Tem-se demonstrado [42] que o aumento gradual da temperatura num experimento de PL leva a uma redistribuição de éxcitons em favor dos maiores pontos quânticos presentes num ensemble de pontos quânticos com altura média da ordem de $5 \mathrm{~nm}$ e densidade de $1 \times 10^{11} \mathrm{~cm}^{-2}$. O efeito ocorre pela possibilidade de migração através dos estados da WL, e tem como principal consequiência causar um estreitamento significativo na largura à meia altura das emissões associadas com a família de pontos quânticos. Poder-se-ia esperar, então, que o fato de pontos quânticos crescidos em baixas taxas possuírem estados de energia bem mais profundos que aqueles normalmente obtidos com taxas de crescimento padrão tenderá a limitar a transferência de éxcitons via WL, ou até mesmo suprimi-la completamente. A figura 3.18 mostra a dependência dos espectros de $\mathrm{PL}$ da amostra crescida a $0,01 \mathrm{MC} / \mathrm{s}$ (a mesma que na figura $3.15 \mathrm{a}$ ) com a temperatura na faixa de $2 \mathrm{~K}$ a $300 \mathrm{~K}$. Para maior clareza, apenas alguns dos espectros medidos no estudo são mostrados na figura 3.18 e o eixo vertical é ajustado em escala logarítmica para realçar as múltiplas emissões. Os espectros em mais baixa temperatura $(2-100 \mathrm{~K})$ exibem quatro emissões distintas. Com o aumento da temperatura, as emissões deslocam-se para baixa energia (alto comprimento de onda) em conseqüência da diminuição dos gaps de energia do GaAs e InAs, porém mantêm aproximadamente a mesma forma até $100 \mathrm{~K}$. Somente acima dessa temperatura, o terceiro estado excitado (quarta emissão) extingue-se em consequuência da perda de portadores para a WL. Os estados mais profundos (estado fundamental e primeiro excitado) permanecem com aproximadamente a mesma forma de linha por toda a faixa de temperatura investigada. 


\section{Comprimento de onda ( $\mu \mathrm{m})$}

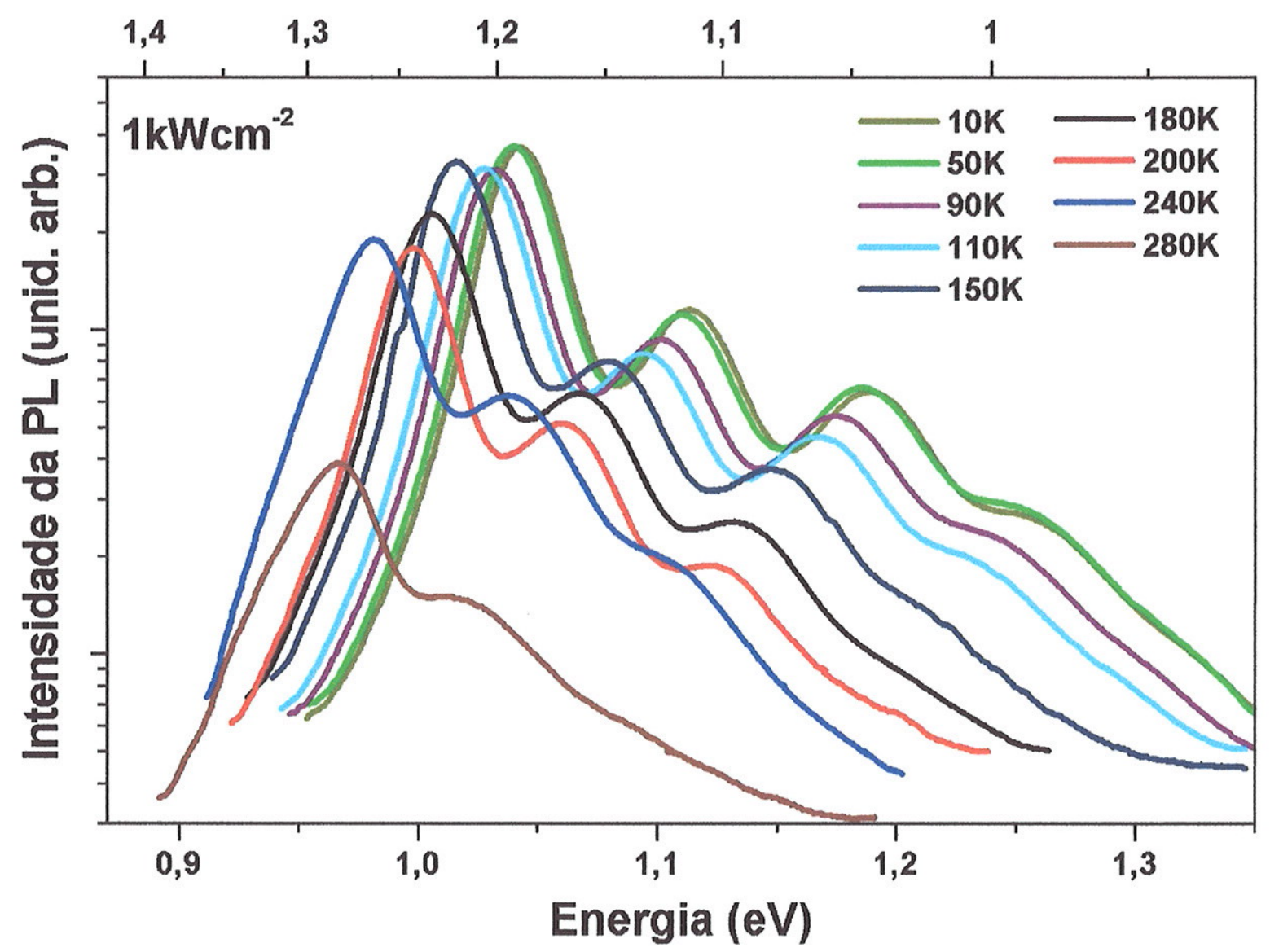

Figura 3.18 - Espectros de PL da amostra crescida a 0,01MC/s em função da temperatura em escala logarítmica.

Uma melhor análise da forma de linha, largura e posição dos diversos picos presentes em cada espectro foi possível após a realização de ajustes matemáticos (fits) das emissões através de curvas gaussianas. A figura 3.19 mostra o comportamento da largura à meia altura obtida através dos fits para o estado fundamental dos pontos quânticos. $\mathrm{O}$ resultado mostra que não há uma diminuição significativa da largura com a temperatura, como no caso de distribuições de pontos quânticos menores. De fato, a largura permanece quase inalterada ao longo de toda a faixa de temperatura investigada, o que representa uma conseqüência da insensibilidade da distribuição de portadores com a temperatura, o que é uma característica particular do potencial de confinamento de pontos quânticos crescidos no regime de baixa taxa de crescimento. Para comparação, a figura 3.19 também mostra o efeito da temperatura sobre a forma da emissão associada ao GaAs. 


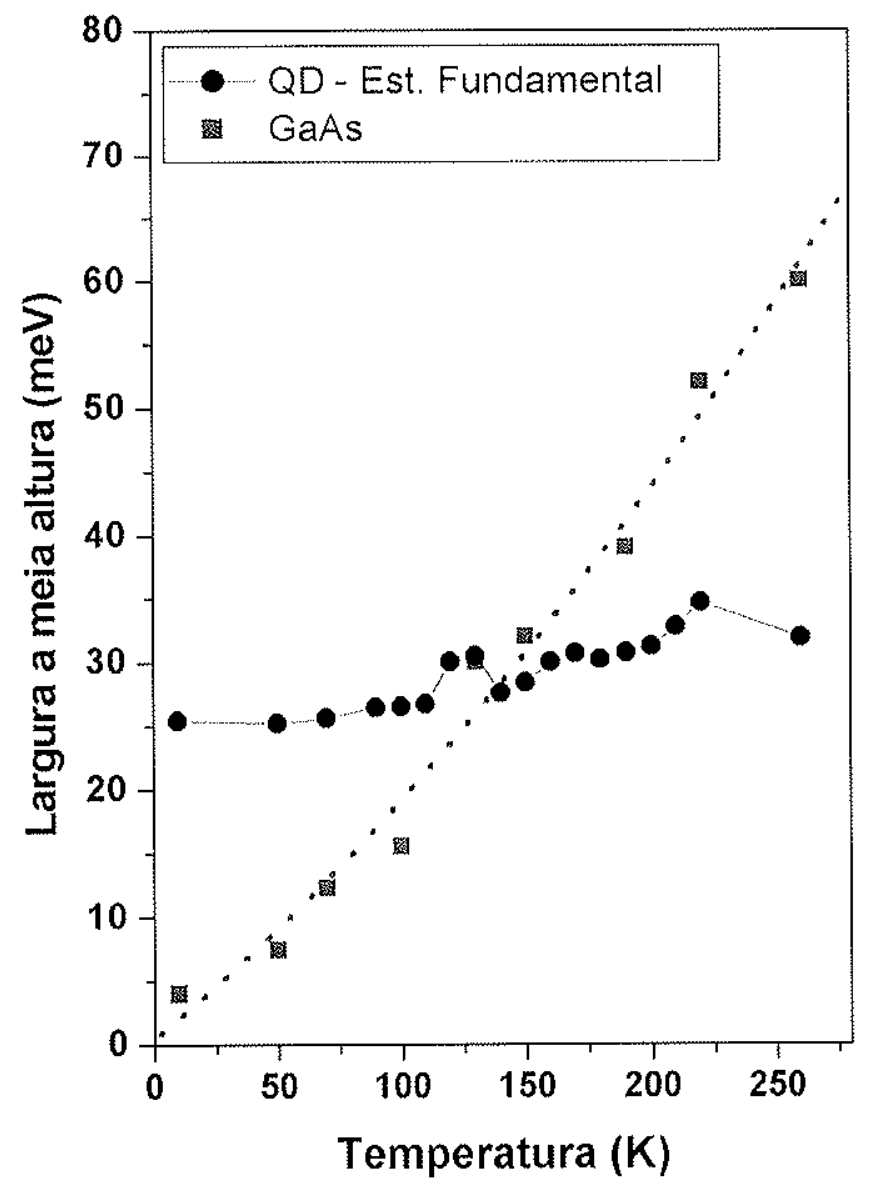

Figura 3.19 - Comportamento da largura à meia altura da emissão do estado fundamental dos pontos quânticos crescidos a $0,01 \mathrm{MC} / \mathrm{s}$ após sua deconvolução usando fits gaussianos. Na faixa de temperatura investigada uma variação de apenas $10 \mathrm{meV}$ é detectada. Para comparação, a curva da largura à meia altura da emissão associada ao bulk de GaAs é também apresentada.

A figura 3.20 mostra a dependência da energia de recombinação no experimento de PL em função da temperatura. A descrição exata dessa dependência para uma amostra de pontos quânticos exige a execução de cálculos teóricos realizados com modelos precisos a respeito da distribuição de pontos quânticos presentes na amostra. Apesar de, até o momento, tais cálculos não terem sido obtidos, pode-se, como uma aproximação, esperar que a dependência da posição das emissões com a temperatura seja muito parecida com aquela presente nos bulks de GaAs ou InAs. A linha contínua na figura 3.20 mostra exatamente o comportamento da variação da energia do gap do GaAs com a temperatura, porém deslocada verticalmente para melhor comparação. É possível observar que até $150 \mathrm{~K}$, o sistema segue exatamente o comportamento do GaAs, tornando-se porém menos sensível 
à temperatura acima desse ponto e assemelhando-se ao InAs. O canto superior direito da figura 3.20 mostra o comportamento da posição em energia das emissões associadas com os dois primeiros estados excitados. Os resultados mostram que o deslocamento das emissões para mais baixa energia com o aumento da temperatura é levemente mais íngreme que o observado para o estado fundamental. Para esses estados, o comportamento aproxima-se daquele esperado para o GaAs, sugerindo a existência de uma maior sensibilidade dos níveis mais altos com a temperatura, o que é consistente com a maior delocalização desses estados de confinamento.

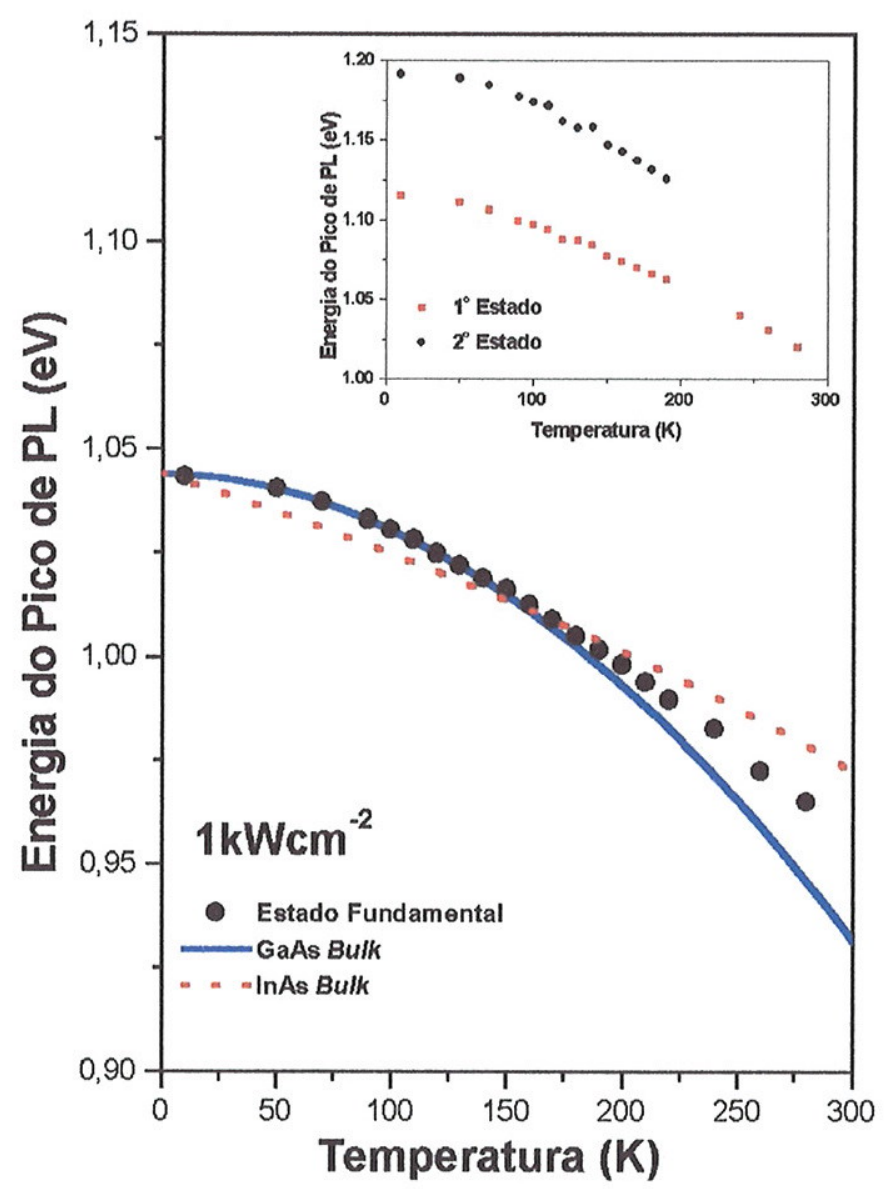

Figura 3.20 - Dependência da energia da emissão do estado fundamental e dos dois primeiros estados excitados (canto superior direito) da amostra de pontos quânticos crescida a $0,01 \mathrm{MC} / \mathrm{s}$ em função da temperatura. A linha contínua (tracejada) representa o deslocamento esperado caso as emissões acompanhassem a curva conhecida para o GaAs (InAs). 


\section{4 - Evolução dos pontos quânticos em função da quantidade de InAs depositado}

Como mostrado nas seções anteriores, o efeito de se reduzir drasticamente a taxa de crescimento sobre o resultado final da topográfica da superfície para uma quantidade de InAs suficiente para a produção de pontos quânticos em estágios avançados de seu desenvolvimento foi o de produzir estruturas com cerca de $10 \mathrm{~nm}$ de altura que, quando cobertas por GaAs, emitem radiação na vizinhança de $1,3 \mu \mathrm{m}$ a temperatura ambiente. A pergunta imediata após essa verificação é: qual o caminho realizado pelo filme em crescimento até a produção de tais estruturas? Ou em outras palavras: de que modo os pontos quânticos evoluem em função da quantidade de material depositado até atingirem seu estado final? Afim de abordar esses aspectos, realizou-se um estudo sistemático da evolução da superfície da amostra em função da espessura de InAs depositado desde a quantidade justamente necessária para a formação das primeiras estruturas $3 \mathrm{D}(1,5-1,7 \mathrm{MC})$, até momentos avançados do desenvolvimento das ilhas $(\sim 3,2 \mathrm{MC})$. Para que a possibilidade de identificar características sutis da superfície, tais como degraus monoatômicos e estruturas precursoras quase-3D, dependa apenas dos limites da técnica AFM, é preciso que as condições e parâmetros de medida sejam otimizados. A figura 3.21 mostra o nível de detalhes que podem ser detectados em medidas sob tais condições, tomando como exemplo uma superfície onde a quantidade de material depositado é em torno da mínima necessária para a transição 2D-3D. Os terraços monoatômicos $(\sim 0,3 \mathrm{~nm}$ de altura) alongados na direção [1-10] (figura 3.21a) e a presença de pequenos clusters de InAs (0,6-1,0nm de altura) (figura 3.21 b) preferencialmente formados nas bordas dos terraços são claramente visíveis.

A taxa de crescimento de $0,01 \mathrm{MC} / \mathrm{s}$ foi usada para o estudo da dependencia da quantidade de InAs depositado por ser a taxa que produz pontos quânticos opticamente ativos na vizinhança de $1,3 \mu \mathrm{m} \quad(300 \mathrm{~K})$ em maior densidade. O ciclo de formação e evolução de pontos quânticos em função da quantidade de material depositado possui dois momentos diferenciados pelo ritmo com o qual a superfície muda com a quantidade de InAs depositado. 

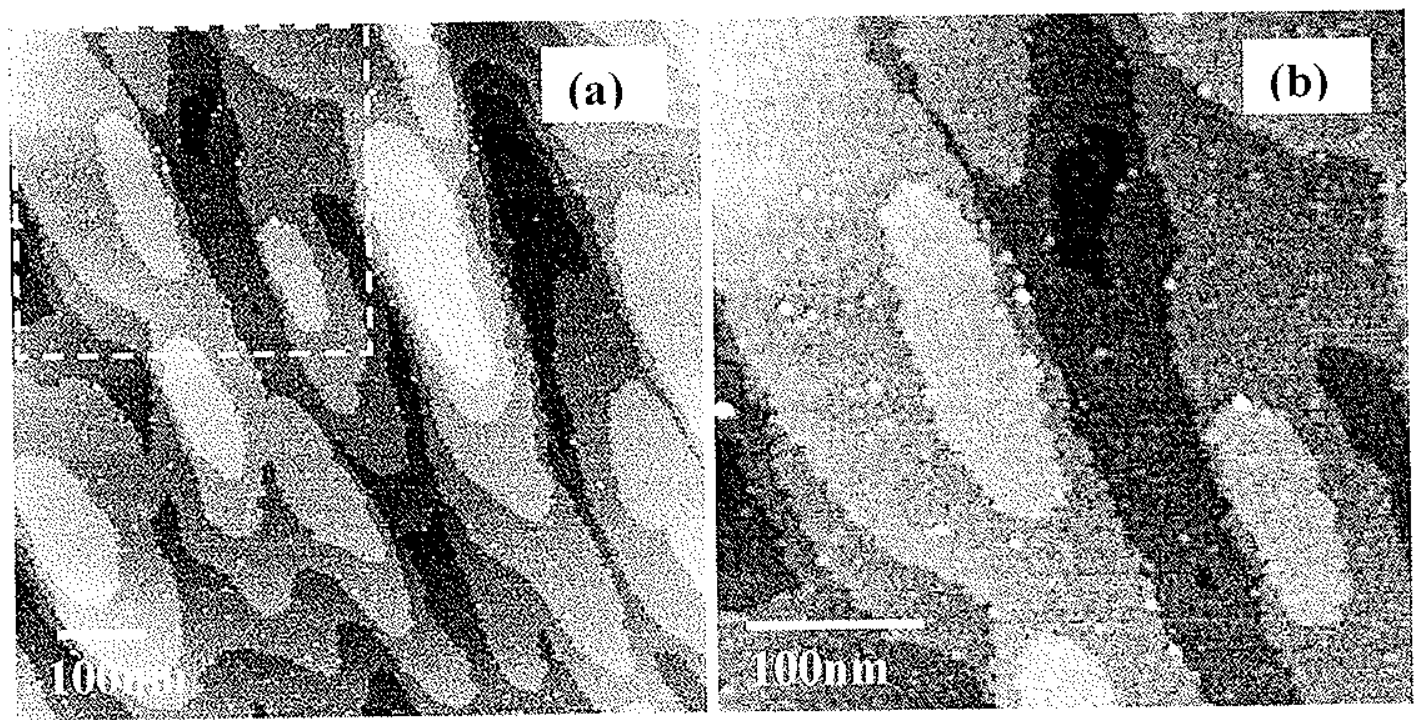

Figura 3.21 - Imagens ilustrativas da possibilidade de deteç̧ão de detalhes finos da topografia de amostras de pontos quânticos de InAs com a técnica AFM. A imagem (b) representa uma magnificação da região destacada na imagem (a).

No primeiro momento, na vizinhança da transição 2D-3D $(\sim 1,7 \mathrm{MC})$ quando os primeiros pontos quânticos são nucleados, a evolução de tamanho e densidade das estruturas é muito abrupta, e variações de quantidade de material menores que $0,01 \mathrm{MC}$ são suficientes para produzir importantes alterações topográficas. A partir de cerca de $2,0 \mathrm{MC}, 0$ cilco de evolução entra em um segundo momento, onde as variações topográficas são mais suaves, a densidade não muda tão rapidamente, e as dimensões finais das estruturas estão próximas de serem atingidas. A estratégia usada para se permitir a investigação completa do ciclo de evolução foi a de usar o efeito de inomogeneidade do sistema MBE para obter um gradiente suave de variação da quantidade de InAs depositado afim de se investigar em detalhe o primeiro momento de desenvolvimento do sistema. Como mostrado na seção 3.2 , nosso sistema MBE possui grande uniformidade dentro de uma área de aproximadamente $10 \mathrm{~cm}^{2}$, de modo que o uso de variações de fluxo exigem que as amostras sejam posicionadas a mais que $3 \mathrm{~cm}$ do centro do feixe. De fato, utilizamos uma área maior que $50 \mathrm{~cm}^{2}$ para a exploração dos efeitos de não uniformidade. As primeiras três imagens da figura $3.22(a, b$, e c) são justamente os resultados do crescimento simultâneo de três amostras separadas por distâncias maiores que $2 \mathrm{~cm}$ do centro. $O$ segundo momento da evolução, por ser menos abrupto foi investigado através do crescimento tradicional, onde cada amostra é crescida de uma vez com a quantidade de material a ser depositado controlada pelo tempo de exposição aos fluxos de material. As imagens (d), (e) e (l) da 
figura 3.22 mostram a superfície de amostras onde a quantidade de InAs depositado foi de $1,9 \mathrm{MC}, 2,2 \mathrm{MC}$ e $2,6 \mathrm{MC}$, respectivamente.
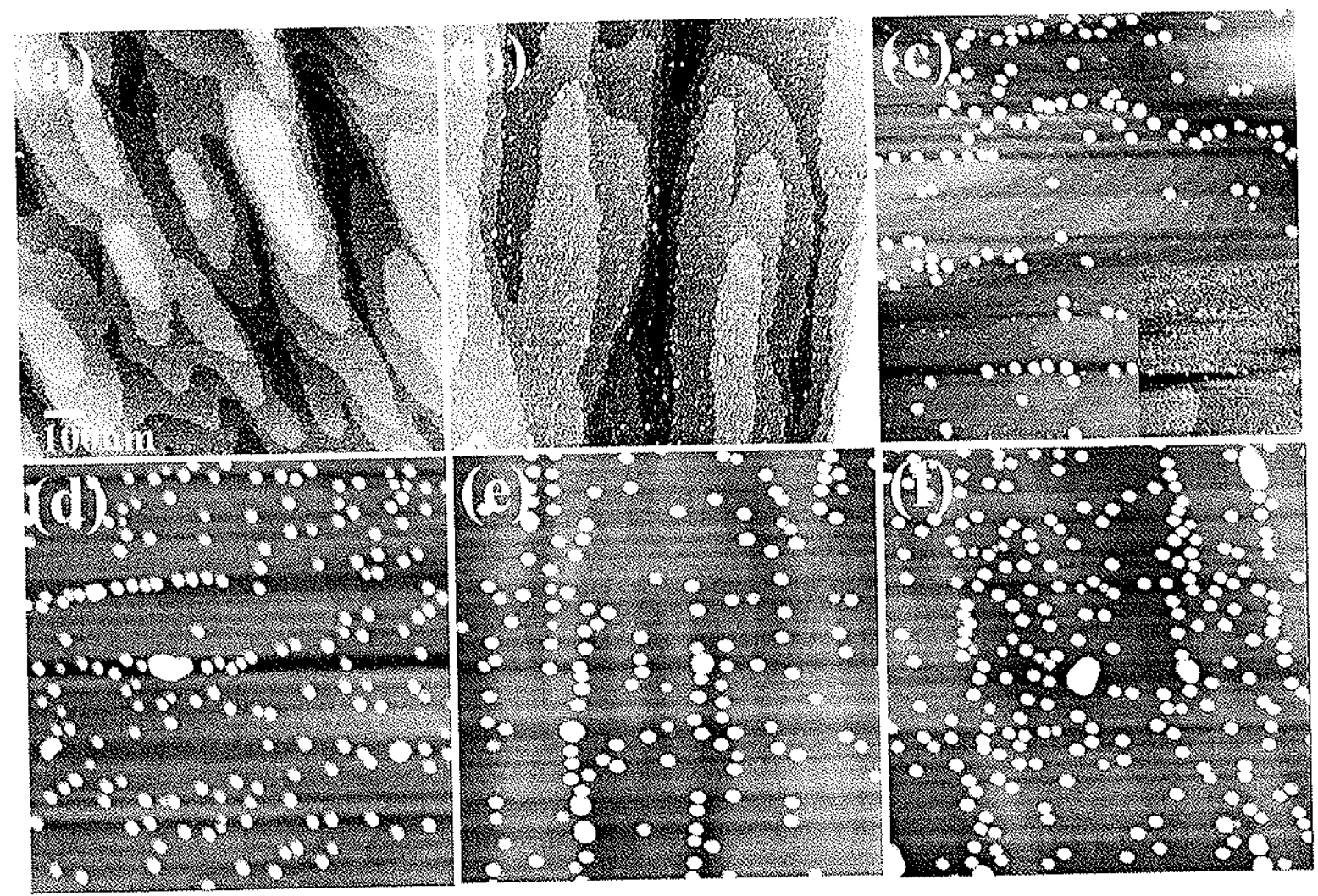

Figura 3.22 - Imagens AFM $\left(1 \times 1 \mu \mathrm{m}^{2}\right)$ do monitoramento da evolução morfológica dos pontos quânticos em função da quantidade de material depositado. As amostras das imagens (a), (b) e (c) foram crescidas simultaneamente explorando o gradiente de fluxo incidente durante o crescimento para investigar o comportamento do sistema em tomo da espessura nominal de InAs de 1,7MC. As amostras das imagens (d), (e) e (f) foram crescidas independentemente, com deposição nominal de $1,9 \mathrm{MC}, 2,2 \mathrm{MC}$ e $2,6 \mathrm{MC}$, respectivamente.

Inicialmente (imagem 3.22a), quando a quantidade de material é aproximadamente a mínima necessária para a transição 2D-3D, a superfície exibe terraços bidimensionais $(\sim 0,3 \mathrm{~nm}$ de altura) com dimensões variáveis e alongados preferencialmente na direção [110]. Thas com densidade de cerca de $8,0 \times 10^{10} \mathrm{~cm}^{-2}$ e dimensões médias de apenas $0,7 \mathrm{~nm}$ de altura e $12,2 \mathrm{~nm}$ de diâmetro decoram a superfície, distribuindo-se ora ao longo dos degraus formados pelos terraços e ora sobre suas superfícies. Em uma etapa posterior (3.22b), apesar da densidade de estruturas sofrer um incremento muito pequeno, atingindo $8,5 \times 10^{10} \mathrm{~cm}^{-2}$, a distribuição de tamanhos torna-se mais larga, levando os valores médios 
para $0,9 \mathrm{~nm}$ de altura e $14,2 \mathrm{~nm}$ de diâmetro. Uma alteração significativa da topografia da superfície é detectada na etapa seguinte (3.22c), quando as pequenas ilhas de 0,6-1,0nm de altura têm sua densidade severamente reduzida para $4,2 \times 10^{10} \mathrm{~cm}^{-2}$ e forma-se uma segunda família de pontos quânticos com altura média de $6,2 \mathrm{~nm}$, diâmetro de $33,6 \mathrm{~nm}$ e densidade de $1,2 \times 10^{10} \mathrm{~cm}^{-2}$. O fato da densidade total diminuir em cerca de $36 \%$ mostra que o surgimento de cada ilha maior foi acompanhado da extinção de cerca de 3 ou 4 ilhas menores, como se as ilhas formadas no estágio inicial fossem usadas como um estado precursor para a formação de pontos quânticos maiores durante a evolução do sistema. A coexistência das duas famílias de pontos quânticos é realçada no canto inferior direito da imagem $3.22 \mathrm{c}$ através de um aumento no contraste da imagem. Os histogramas de altura e diâmetro associados com as imagens $3.22 \mathrm{a}$, b e c são apresentados na figura 3.23 , onde para maior clareza, são indicados os valores médios de altura, diâmetro e densidade parciais de cada família de pontos quânticos detectada.

A figura 3.24 mostra os histogramas de altura e diâmetro do segundo momento da evolução dos pontos quânticos obtidos a partir das imagens $3.22 \mathrm{c}$, d, e e f. O histograma referente à imagem 3.22c é repetido para facilitar a comparação. Quando 1,9MC de InAs são depositadas, é possível detectar o surgimento de uma terceira família de pontos quânticos com densidade de cerca de $8,3 \times 10^{\circ} \mathrm{cm}^{-2}$, altura média de $9,9 \mathrm{~nm}$ e diâmetro de 40nm. Uma diminuição significativa é observada na densidade das estruturas com 0,6 $1,0 \mathrm{~nm}$ de altura que assume o valor de $7,0 \times 10^{8} \mathrm{~cm}^{-2}$. Os pontos quânticos com altura média de $6,2 \mathrm{~nm}$ também sofrem uma sensível redução em densidade, atingindo $8,3 \times 10^{9} \mathrm{~cm}^{-2}$. Analogamente ao que acontece no primeiro momento da evolução quando as ilhas menores (0,6-1,0nm de altura) atuam como precursoras na formação de pontos quânticos maiores $(6,2 \mathrm{~nm})$, agora essas ilhas são consumidas na formação de pontos quânticos ainda maiores, com $11,7 \mathrm{~nm}$ de altura média e densidade igual a $1,17 \times 10^{10} \mathrm{~cm}^{-2}$, conforme indicado na figura $3.24 \mathrm{c}$, correspondente a uma deposição de $2,2 \mathrm{MC}$ de InAs. Finalmente, após a deposição de $2,6 \mathrm{MC}$, as duas primeiras distribuições de pontos quânticos praticamente se extinguem, e a altura média das estruturas sofre uma redução, atingindo cerca de $10 \mathrm{~nm}$, com uma densidade próxima de $2,0 \times 10^{10} \mathrm{~cm}^{-2}$. Apesar da existência de estados precursores para a formação de pontos quânticos nos estágios iniciais de sua formação ser bem conhecida e usada nos principais modelos desse sistema [1], a existência de um segundo 
estado intermediário, onde pontos quânticos de tamanhos estáveis no regime de taxa de crescimento elevada [43] são detectados como estados precursores da formação de estruturas ainda maiores, é um resultado muito interessante e particular do regime de baixa taxa de crescimento. 


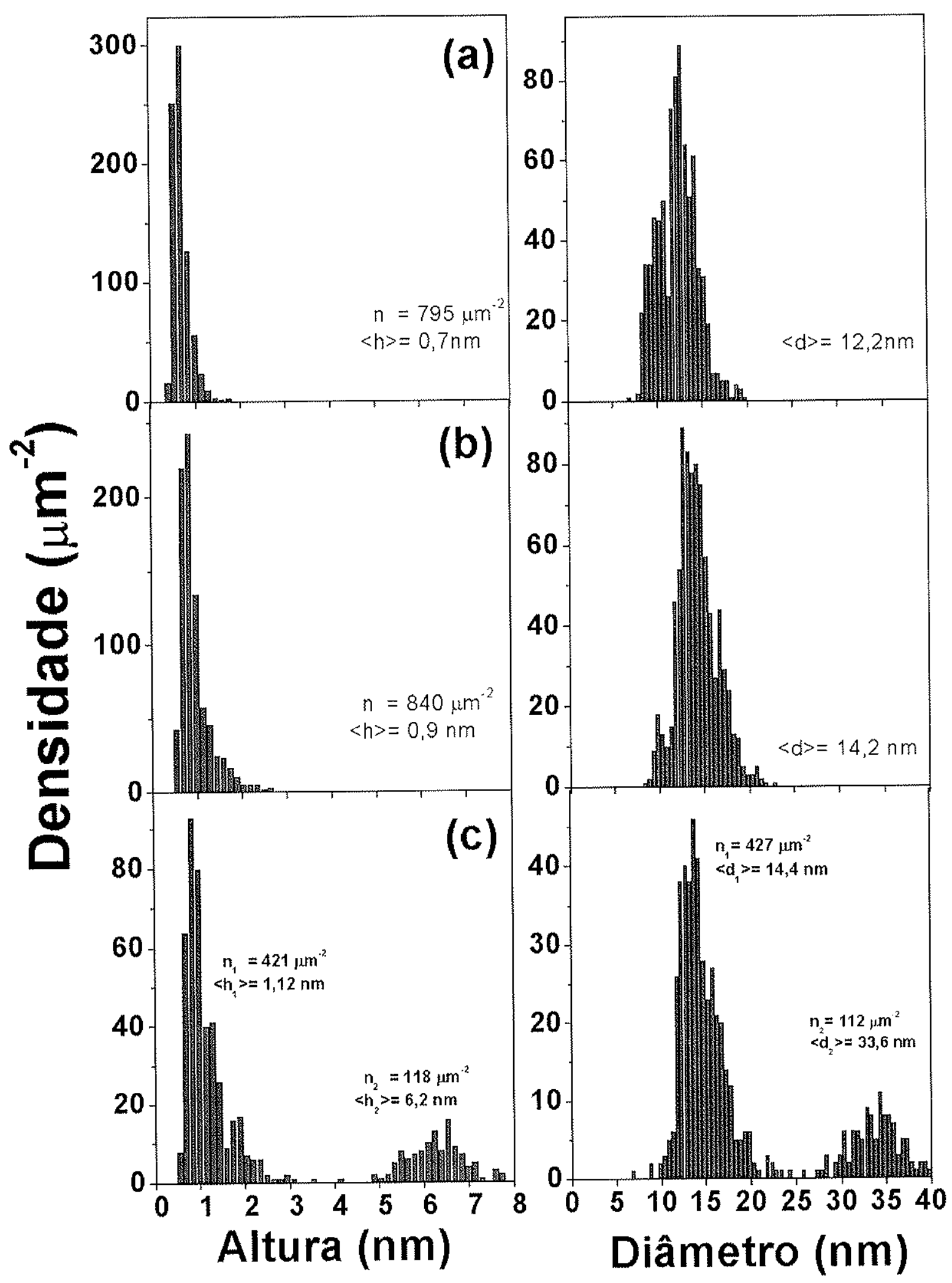

Figura 3.23 - Histogramas de altura e diâmetro extraídos a partir da análise das imagens AFM das figuras $3.22 \mathrm{a}, 3.22 \mathrm{~b}$ e $3.22 \mathrm{c}$. Quando mais que uma família de pontos quânticos está presente, os valores parciais de tamanho e densidade são indicados. 


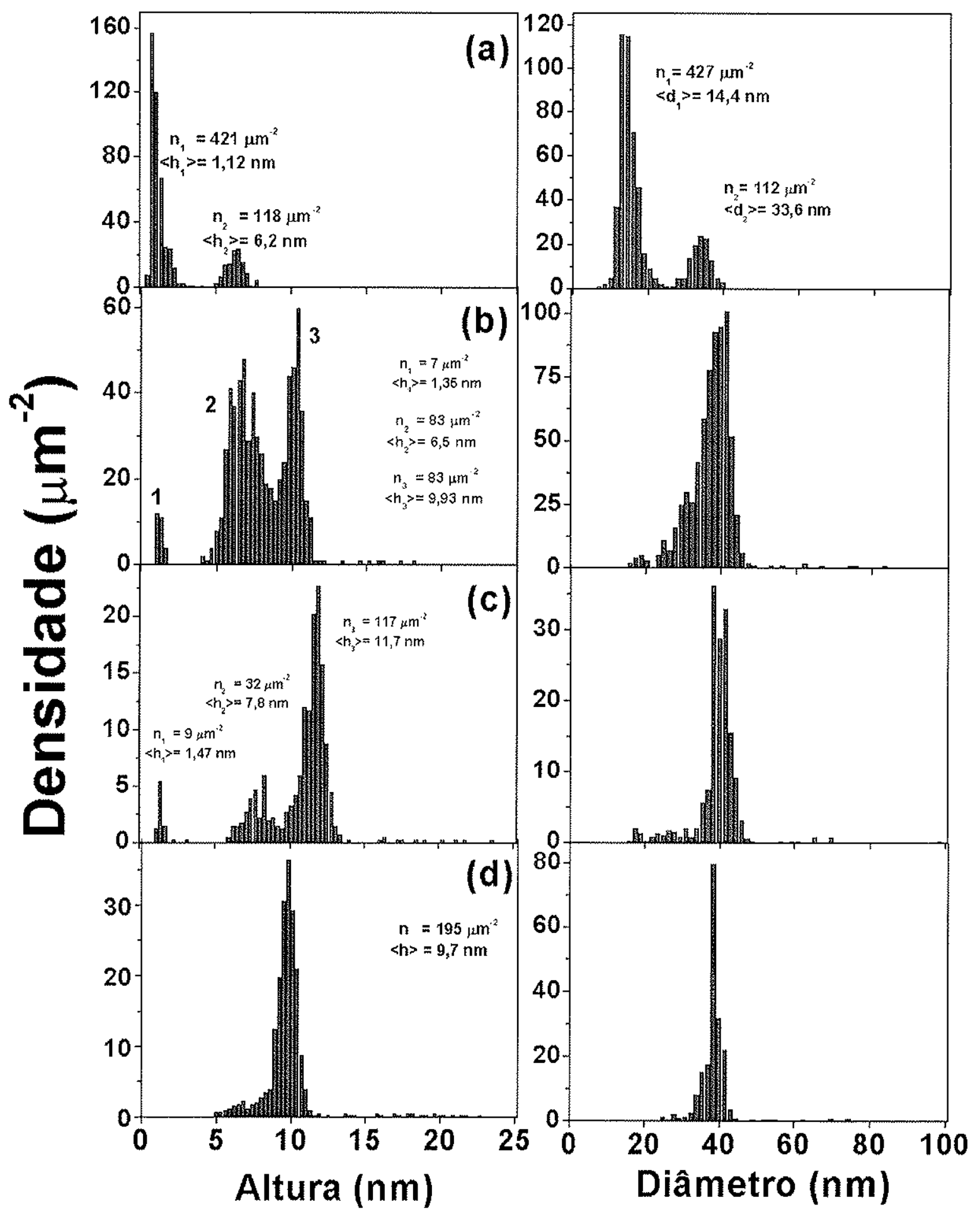

Figura 3.24 -- Histogramas de altura e diâmetro extraídos a partir da análise das imagens AFM das figuras 3.22d, 3.22e e 3.22f. Quando mais que uma familia de pontos quânticos está presente, os valores parciais de tamanho e densidade são indicados. 


\section{5 - Breve sumário do capítulo}

O estudo do comportamento do sistema em função da taxa de crescimento mostrou que o valor de $0,01 \mathrm{MC} / \mathrm{s}$ é aquele capaz de sintonizar a emissão do estado fundamental dos pontos quânticos na vizinhança de $1,3 \mu \mathrm{m}(300 \mathrm{~K})$ com boa uniformidade e densidade superficial. Em taxas mais altas, a sintonia se perde e em deposições ainda mais lentas, além de não haver deslocamento adicional significativo das emissões, há uma severa queda na densidade superficial de pontos quânticos. Com essas considerações, a taxa de crescimento de $0,01 \mathrm{MC} / \mathrm{s}$ parece ser a mais adequada para o crescimento otimizado de estruturas ativas na banda $O$. A investigação da evolução da superfície em função da quantidade de InAs depositado a $0,01 \mathrm{MC} / \mathrm{s}$ mostrou que dois estados precursores precedem a formação definitiva dos pontos quânticos com $10 \mathrm{~nm}$ de altura responsáveis pela sintonia da emissão. Resta saber em que extensão o manuseio dos outros parâmetros de crescimento, tais como temperatura do substrato e pressão de $\mathrm{As}_{4}$, podem permitir um maior grau de manipulação dos pontos quânticos. O próximo capítulo é dedicado a esse tema. 


\section{Capítulo 4}

\section{Manipulação das condições de crescimento para atividade óptica em $1,5 \mu \mathrm{m}$}

Nesse capítulo será abordada a possibilidade de se alcançar a janela óptica da banda C com o uso de pontos quânticos de InAs imersos numa matriz pura de GaAs, em oposição às técnicas propostas atualmente onde cap layers de InGaAs e/ou adição de nitrogênio $(\mathrm{N})$ nas ilhas são empregados. Os resultados mostram que é possível atingir a região do espectro entre $1,4 \mu \mathrm{m}$ e $1,5 \mu \mathrm{m}(300 \mathrm{~K})$ através de uma escolha adequada das condições de crescimento que combinam a deposição em baixas taxas $(0,003-0,01 \mathrm{MC} / \mathrm{s}) \mathrm{com}$ a elevação da temperatura de crescimento para cerca de $510-520^{\circ} \mathrm{C}$. Tais resultados abrem novas perspectivas para aplicações práticas desse tipo de estrutura. 


\section{1 - Extensão do grau de manipulação das propriedades de pontos quânticos de InAs/GaAs}

Nas seções 3.3 e 3.4, mostramos que, com escolhas adequadas da taxa de crescimento e quantidade de InAs depositado, é possivel fabricar pontos quânticos com $10 \mathrm{~nm}$ de altura e cerca de $40 \mathrm{~nm}$ de diâmetro sobre a superfície de um buffer de GaAs. Quando imersas totalmente na matriz de GaAs, tais estruturas apresentam emissões ópticas de seu estado fundamental em $1,3 \mu \mathrm{m}$ a temperatura ambiente. Como discutido na seção 3.1, a investigação da possibilidade de se estender ainda mais a faixa de atividade óptica das

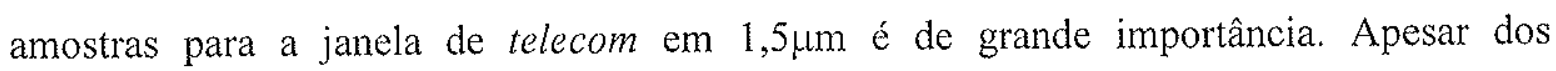
resultados obtidos até aqui terem mostrado que uma redução posterior da taxa de crescimento $(<0,01 \mathrm{MC} / \mathrm{s})$ ou aumento da quantidade de InAs depositado não são meios efetivos para aumentar ainda mais a faixa de comprimentos de onda emitidos, pode-se no entanto incidir sobre outras condições de crescimento tais como a temperatura do substrato e a pressão de $\mathrm{As}_{4}$. A seção seguinte mostra que, de fato, a combinação de baixa taxa de crescimento e elevação da temperatura do substrato permite demonstrar a possibilidade de obtenção de pontos quânticos ainda maiores que os mostrados no capítulo anterior. Tais

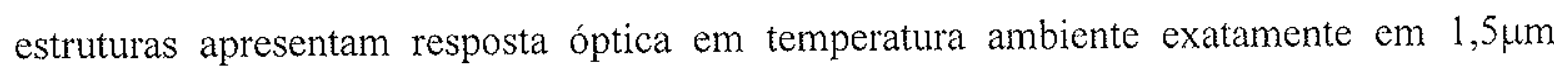
quando totalmente cobertas por GaAs.

\subsection{1 - Combinação de baixa taxa de crescimento com alta temperatura do substrato}

Afim de maximizar a difusão dos átomos de In e moléculas de $\mathrm{As}_{2}$ na superfície durante a formação do filme de InAs, a combinação de baixa taxa de crescimento e uma sensível elevação na temperatura do substrato foi usada para o crescimento das amostras da figura 4.1. A quantidade de InAs depositado foi 2,4MC (figura 4.1 a), 3,2MC (figura 4.1b) e $4,0 \mathrm{MC}$ (figura $4.1 \mathrm{c}$ ), a uma taxa de $0,003 \mathrm{MC} / \mathrm{s}$ e temperatura do substrato igual a $510^{\circ} \mathrm{C}$. Para 2,4MC de material depositado, é possível observar, como esperado diante dos resultados anteriores, a formação de uma família predominante de pontos quânticos com altura de $10 \mathrm{~nm}$, conforme indicado pelos histogramas de altura da figura 4.2. Observa-se, 
no entanto, uma segunda distribuição de ilhas com altura em torno de $15-20 \mathrm{~nm}$, além de uma baixa densidade de ilhas relaxadas. A presença dos pontos quânticos de $10 \mathrm{~nm}$ de altura, com luminescência esperada em torno de $1,3 \mu \mathrm{m}$ (300K) e de algumas ilhas relaxadas, assemelha-se com os resultados obtidos no capítulo 3 para amostras crescidas em $0,003 \mathrm{MC} / \mathrm{s}$. Por outro lado, a formação de estruturas com 15-20nm de altura representa uma possibilidade de se explorar as emissões ópticas além da faixa até aqui obtida. Observa-se que para 3,2MC de InAs (figuras $4.1 \mathrm{~b}$ e $4.2 \mathrm{~b}$ ) há uma sensível diminuição na altura média dos pontos quânticos predominantes (com $10 \mathrm{~nm}$ na figura $4.2 \mathrm{a}$ ) reduzindo-a para cerca de $5 \mathrm{~nm}$. A presença de estruturas com $15 \mathrm{~nm}$ de altura torna-se, no entanto, mais evidente (4.2b) e a distribuição de ilhas relaxadas aumenta. Para 4.0MC de InAs (figuras $4.1 \mathrm{c}$ e $4.2 \mathrm{c}$ ) as três famílias de ilhas são claramente evidenciadas. Os histogramas das figuras $4.2 \mathrm{a}$ e $4.2 \mathrm{~b}$ foram tomados com dados coletados a partir de uma área de $4 \mu \mathrm{m}^{2}$ enquanto aquele da figura $4.2 \mathrm{c}$ foi obtido a partir de uma área de $100 \mu \mathrm{m}^{2}$ afim de se obter suficiente estatística numa condição onde a densidade de estruturas é muito baixa.
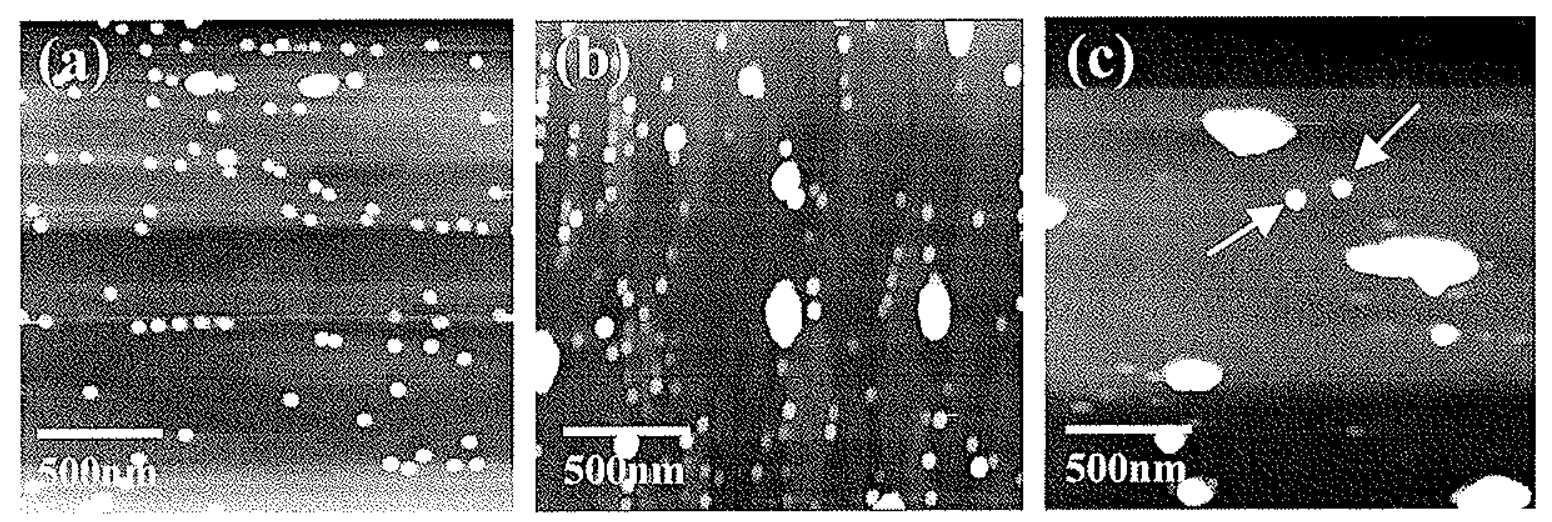

Figura 4.1 - Imagens AFM $\left(2 \times 2 \mu \mathrm{m}^{2}\right)$ de pontos quânticos de superfície crescidos a partir da deposição de 2,4MC (a), 3,2MC (b) e 4,0MC (c) de InAs. A taxa de crescimento usada foi de $0,003 \mathrm{MC} / \mathrm{s}$ e a temperatura do substrato de $510^{\circ} \mathrm{C}$. As setas na figura (c) indicam pontos quânticos uniformes detectados em todas as áreas investigadas da amostra com altura de $\sim 15 \mathrm{~nm}$. 


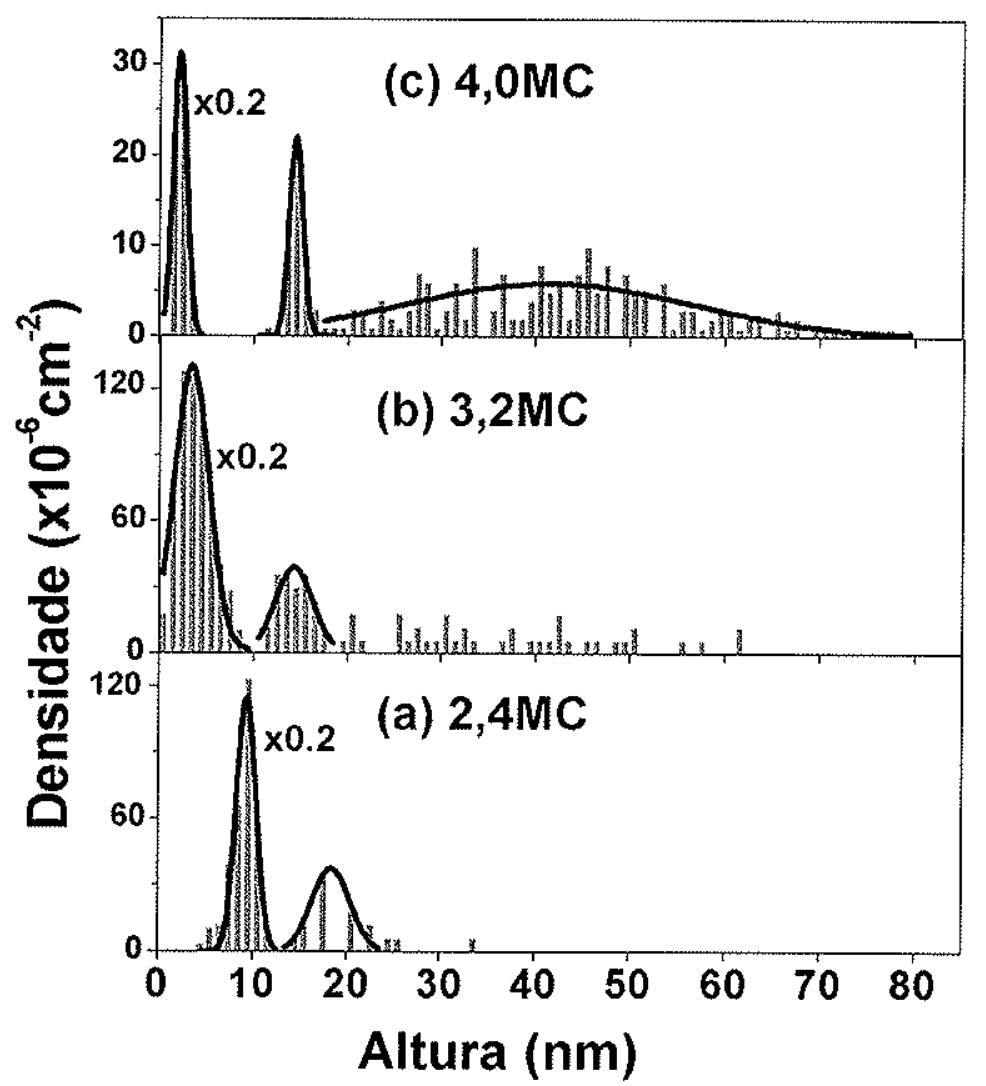

Figura 4.2 - Histogramas de altura tomados a partir das imagens AFM da figura 4.1. As curvas gaussianas (linhas contínuas) são usadas para destacar a existência das múltiplas famílias de pontos quânticos detectados.

As imagens AFM da figura 4.1 e os histogramas de altura, sobretudo o da figura $4.2 \mathrm{c}$, mostram que a família de estruturas com $15 \mathrm{~nm}$ de altura assemelha-se quanto à forma e homogeneidade aos pontos quânticos com $10 \mathrm{~nm}$ de altura ou menores. Apesar da técnica AFM representar essencialmente uma caracterização morfológica, é possível determinar se uma distribuição particular de ilhas é formada por estruturas coerentes ou relaxadas através da análise da homogeneidade de tamanho e forma das estruturas que compõem a distribuição. O crescimento de ilhas coerentes é controlado por barreiras de potencial (para incorporação de átomos) dependentes da tensão das ilhas em crescimento. Tais barreiras impedem que ilhas coerentes (pontos quânticos) possam crescer livremente, mantendo a flutuação de tamanho estreita $(<10 \%$ tipicamente). Essa tendência espontânea de ordem no sistema é na verdade uma das características mais atraentes em amostras de pontos quânticos. De modo oposto, a ausência de barreiras de potencial dependentes da tensão em regiões de ilhas relaxadas (em torno de defeitos, por exemplo) permite que tais estruturas 
absorvam material livremente, alargando sua distribuição de tamanhos numa faixa muito maior de valores. Além disso, a incorporação anisotrópica de material torna as ilhas relaxadas extremamente irregulares, predominantemente alongadas segundo a direção [110]. Isso sugere que as estruturas com $15 \mathrm{~nm}$ de altura observadas nas figura 4.1 e 4.2 não são relaxadas por defeitos estruturais, sendo portanto pontos quânticos de InAs. A discriminação entre ilhas relaxadas e coerentes no sistema InAs/GaAs através de medidas estatísticas em imagens AFM vem sendo usada com freqüência na literatura [44] e representa uma ferramenta importante num estudo sistemático que envolve a caracterização de um número muito grande de amostras.

É possível estimar a quantidade de InAs presente na superficie da amostra através da integração dos perfis topográficos das ilhas obtidos por AFM. Quando isso é feito nas imagens da figura 4.1, observa-se que, quando a deposição nominal é de $2,4 \mathrm{MC}$, cerca de 1,2MC estão presentes nas ilhas (pontos quânticos e ilhas relaxadas). Se considerarmos que a camada bidimensional de InAs absorve cerca de $1 \mathrm{MC}$ do material depositado, então é possível constatar o acordo entre a quantidade de material depositado e aquele que se encontra na superfície. Para as amostras com 3,2MC e 4,0MC, a quantidade de material obtida pela integração do volume de todas as ilhas é cerca de $1,0 \mathrm{MC}$ e 1,8MC menor que o valor nominal. Esse fato reflete a relevância do efeito reevaporação de material a partir da superfície no regime de crescimento em baixa taxa e alta temperatura. Se considerarmos que o tempo de crescimento de 4,0MC numa taxa de $0,003 \mathrm{MC} / \mathrm{s}$ é de cerca de 22 minutos, enquanto que o mesmo crescimento em uma taxa convencional, digamos $0,1 \mathrm{MC} / \mathrm{s}$, é de apenas 40 segundos, então é sensato esperar que o fenômeno de reevaporação passe a ser relevante no primeiro regime. Isso explica parcialmente porque as estruturas inicialmente formadas tendem a reduzir-se de tamanho mesmo quando a quantidade de material depositado é aumentada. Além disso, como destacado no capítulo 3, a presença de ilhas relaxadas tende a desestabilizar os pontos quânticos e drenar parte de seu material. Assim, qualquer tentativa de se obter amostras com pontos quânticos com dimensões superiores àquelas já encontradas no capítulo 3 deve promover uma redução do tempo de crescimento para minimizar o efeito de reevaporação e ao mesmo tempo procurar diminuir a formação de estruturas relaxadas através de uma maximização da difusão de material. A formação e propagação de um defeito podem ser amenizadas em certa extensão aumentando a 
eficiência dos elementos adsorvidos na procura por sítios adequados de incorporação. Para favorecer a migração de material através do aumento da temperatura, sem no entanto tornar o efeito de reevaporação crucial, é necessário encontrar o correto compromisso entre a temperatura e o tempo de crescimento (ou taxa de crescimento) a serem usados.

A figura 4.3 mostra a imagem AFM de uma amostra crescida a $0,01 \mathrm{MC} / \mathrm{s}$ com uma temperatura de $520^{\circ} \mathrm{C}$ e espessura de InAs de $2,4 \mathrm{MC}$. O aumento da taxa de crescimento em relação às amostras da figura 4.1 torna o crescimento mais rápido e o aumento de temperatura (mais $10^{\circ} \mathrm{C}$ em relação ao usado na figura 4.1) mantém uma boa difusão de elementos adsorvidos. Com esse regime, apesar da reevaporação ser favorecida, o menor tempo de crescimento torna o objetivo de se crescer ilhas maiores sem a presença de estruturas relaxadas algo possível. De fato, o histograma de altura na figura $4.3 \mathrm{~b}$ mostra que a superfície exibe pontos quânticos com grande uniformidade e com altura média de $14 \mathrm{~nm}$. Uma segunda família de ilhas muito menores, com cerca de 2-3nm de altura também pode ser observada. A formação de ilhas relaxadas, no entanto, é severamente reduzida, não sendo detectada numa área de cerca de $100 \mu \mathrm{m}^{2}$. Como havia sido observado nas seções anteriores, a presença de ilhas relaxadas atua fortemente no sentido de absorver o material da superfície reduzindo o volume dos pontos quânticos existentes e drenando o material depositado durante o crescimento. A severa redução de tais estruturas permite que o material se incorpore exclusivamente nos pontos quânticos. A existência da família de pontos quânticos pequenos na imagem 4.3 a sugere que uma redistribuição de material, onde as ilhas maiores são alimentadas pelas menores, está presente mesmo entre famílias de estruturas coerentes. Sob esse aspecto, os pontos quânticos de $14 \mathrm{~nm}$ de altura atuam como as ilhas relaxadas, no sentido de drenar o material das ilhas menores para si. Porém, sendo o sistema totalmente coerente, esse efeito passa a ser favorável ao objetivo de se deslocar a faixa de emissões ópticas das amostras para a região de alto comprimento de onda. A seção seguinte lida com a caracterização óptica de amostras semelhantes às analisadas aqui, porém, cobertas por GaAs. 

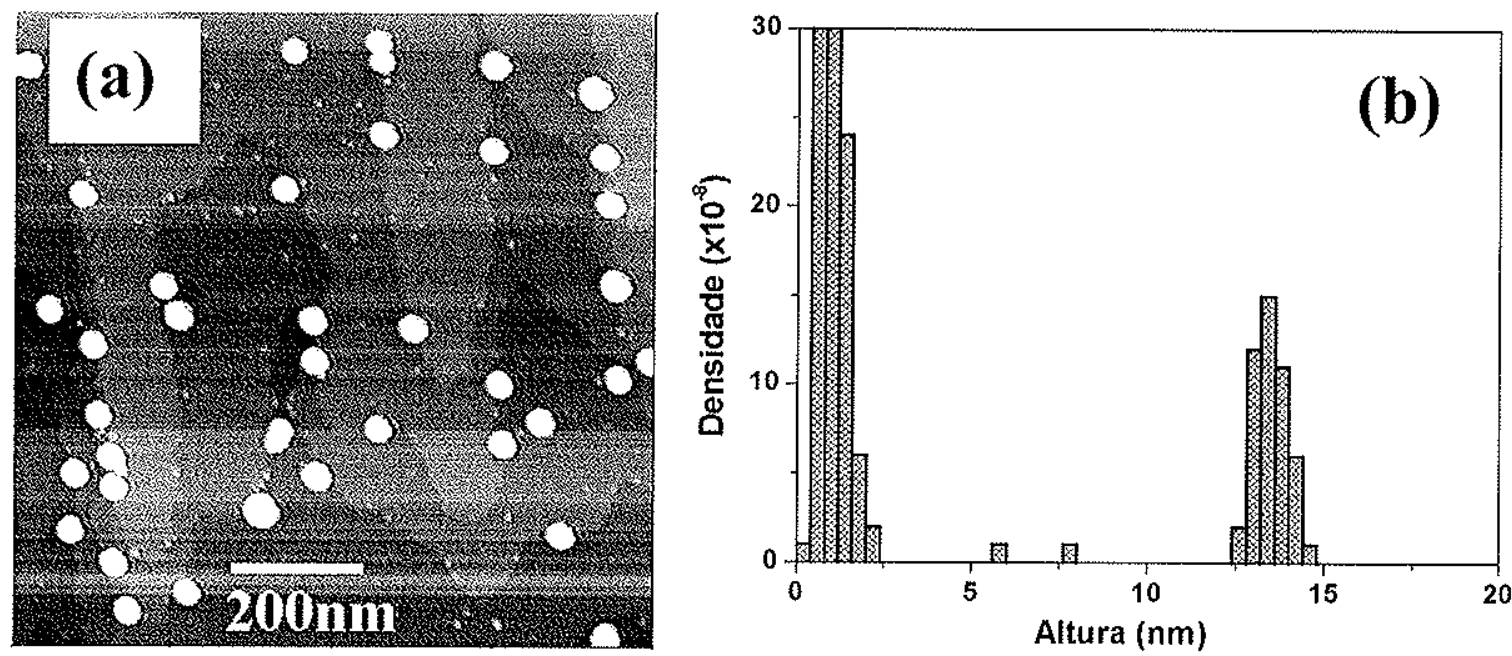

Figura 4.3 - Imagem AFM (a) e seu respectivo histograma de altura (b) da amostra crescida a $0,01 \mathrm{MC} / \mathrm{s}$ e $520^{\circ} \mathrm{C}$. Observa-se duas famílias de pontos quânticos, uma composta por estruturas com cerca de $14 \mathrm{~nm}$ de altura, promissoras para emissão óptica além de $1,3 \mu \mathrm{m}$, e uma segunda família, com pontos quânticos bem menores $(\sim 1-2 \mathrm{~nm})$.

\section{2 - Propriedades ópticas de pontos quânticos ativos em 1,4- $1,5 \mu \mathrm{m}$}

A detecção de pontos quânticos com $15 \mathrm{~nm}$ (figura 4.1) e 14nm (figura 4.3) de altura no crescimento em baixa taxa e alta temperatura cria a possibilidade de se estender a faixa de luminescência do sistema InAs/GaAs para além de 1,3um (300K). Afim de investigar a resposta óptica dessas estruturas, foram crescidas amostras nas mesmas condições que aquelas da seção anterior, porém com a camada de pontos quânticos coberta com um cap layer de 50nm de GaAs. A figura 4.4 mostra os espectros de PL a $100 \mathrm{~K}$ das amostras equivalentes àquelas da figura 4.1. Para melhor análise, as emissões observadas podem ser divididas em duas regiões, conforme indicado na figura 4.4. A região A é centrada em $1,20 \mu \mathrm{m}(\sim 1,28 \mu \mathrm{m}$ a $300 \mathrm{~K})$ nas amostras com 2,4MC (espectro a) e 3,2MC (espectro b), e em torno de $1,0 \mu \mathrm{m}$ na amostra de 4,0MC (espectro c). A presença de emissão para $2,4 \mathrm{MC}$ e

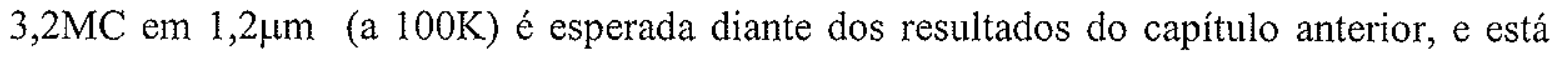
relacionada com os pontos quânticos com $10 \mathrm{~nm}$ de altura identificados nas imagens AFM da figura 4.1. As emissões em $1,44 \mu \mathrm{m} \quad(\sim 1,50 \mu \mathrm{m}$ a $300 \mathrm{~K})$ representam a região $\mathrm{B}$ dos 
espectros. Tais emissões representam a maior extensão já obtida em sinal de PL de amostras de pontos quânticos no sistema InAs/GaAs, e serão portanto o foco das discussões a partir de agora. O alcance dessa região de longo comprimento de onda foi possível em razão do crescimento dos pontos quânticos com 15-20nm de altura identificados nas imagens e histogramas das figuras 4.1 e 4.2, obtidos através da combinação de baixa taxa de deposição $(0,003 \mathrm{MC} / \mathrm{s})$ e alta temperatura de crescimento $\left(510^{\circ} \mathrm{C}\right)$. Além disso, uma taxa de crescimento elevada, de $0,8 \mathrm{MC} / \mathrm{s}$, para a deposição do cap layer $\left(\mathrm{a} 510^{\circ} \mathrm{C}\right.$ ) de GaAs foi empregada afim de se limitar as possíveis reduções de tamanho e composição sofridas pelas estruturas durante seu recobrimento. A obtenção de pontos quânticos com

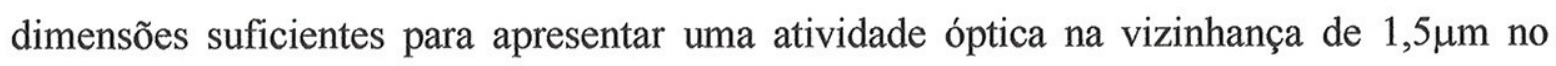
sistema InAs/GaAs representa uma importante contribuição para o estado da arte e, portanto, a natureza dessa emissão será discutida em maior detalhe utilizando a amostra com 4,0MC de InAs (espectro c da figura 4.4).

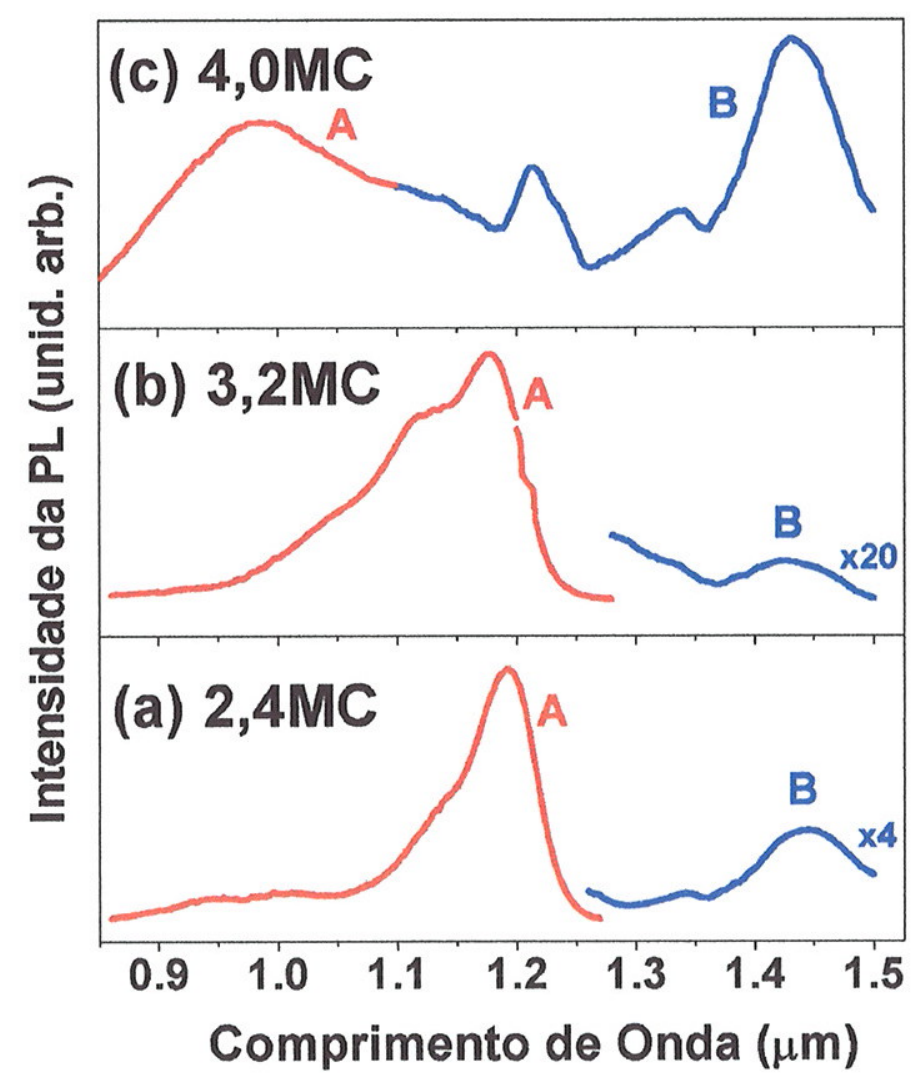

Figura 4.4 - Espectros de PL (100K) com densidade de potência de excitação de $150 \mathrm{Wcm}^{-2}$. Duas regiões de emissão são identificadas e estão relacionadas com as famílias de pontos quânticos identificadas nas respectivas imagens AFM da figura 4.1. 
A figura 4.5 mostra espectros de PL da região $\mathrm{B}$ da amostra de $4,0 \mathrm{MC}$ em função da densidade de potência de excitação (figura 4.5a). Pode ser observado que, em baixa excitação $\left(15 \mathrm{Wcm}^{-2}\right)$, o espectro é dominado por um único pico centrado em $1,44 \mu \mathrm{m}$ com largura à meia altura de apenas $28 \mathrm{meV}$. É possível, no entanto, perceber que mesmo nessa condição há um pequeno ombro em torno de $1,25 \mu \mathrm{m}$. Quando a densidade de potência de excitação é incrementada, duas outras emissões em mais alta energia são progressivamente acentuadas. $\mathrm{O}$ espectro de PL da figura $4.5 \mathrm{~b}$ mostra que, de fato, a emissão de mais baixa energia atinge $1,50 \mu \mathrm{m}$ a $300 \mathrm{~K}$. Não é possível interpretar facilmente os espectros da figura 4.5 como sendo estados de uma única família de pontos quânticos com $15 \mathrm{~nm}$ de altura (analogamente ao que foi feito com os pontos quânticos ativos em 1,3um no capítulo anterior), uma vez que não há um aparente acordo entre as distâncias entre picos e forma de linha de cada pico. É fácil perceber que o estado de mais baixa energia é em torno de 1,5 vezes mais largo que o estado seguinte em mais alta energia no espectro em $300 \mathrm{~K}$ (figura 4.5b). Diante dessas dificuldades é necessário um grau maior de investigação da natureza das emissões, sobretudo de sua conexão com os pontos quânticos de $15 \mathrm{~nm}$ de altura observados nas imagens AFM.
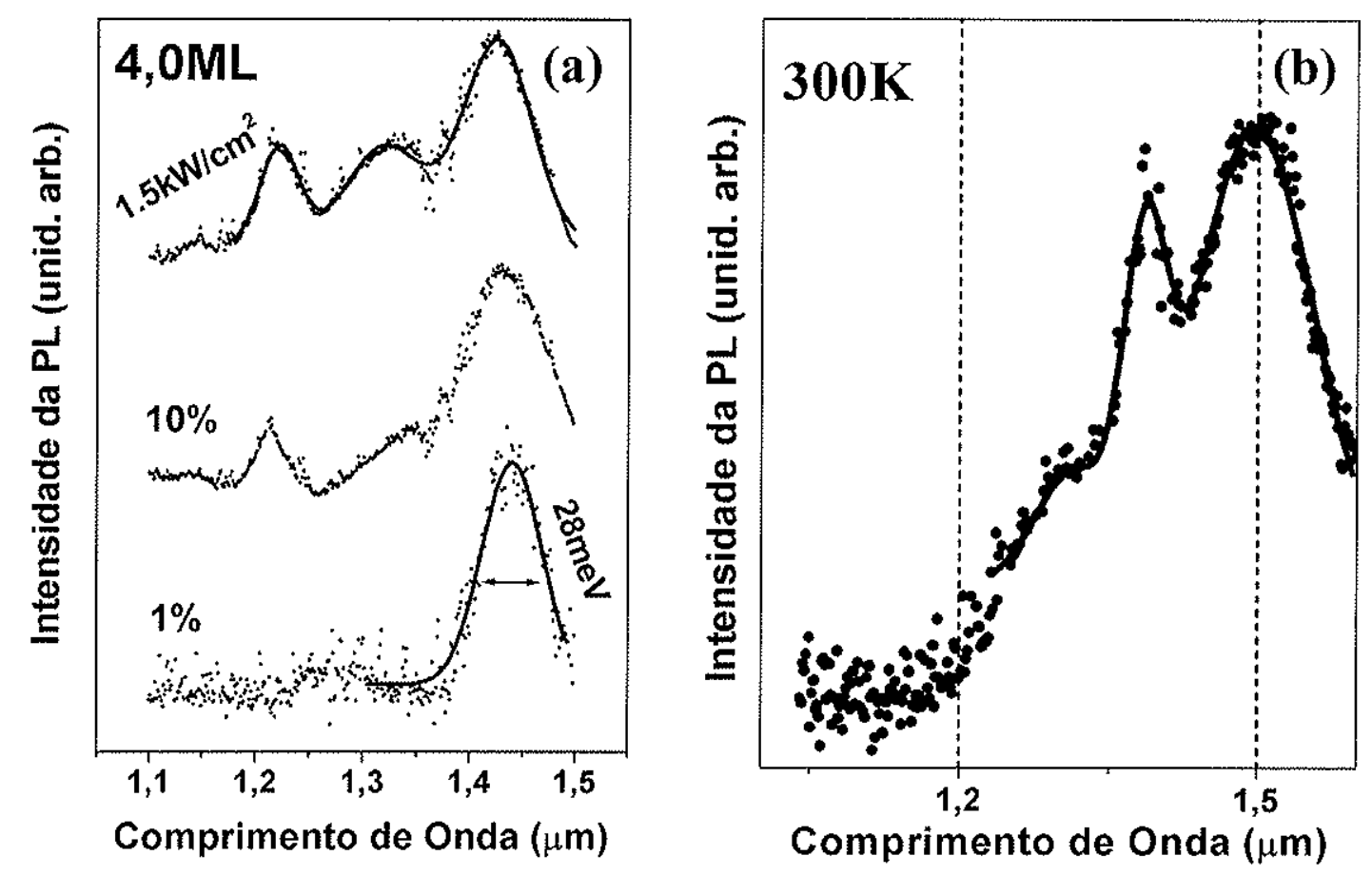

Figura 4.5 - Espectros de PL da amostra de 4,0MC de InAs em função da potência de excitação a $100 \mathrm{~K}$ (a) e a resposta óptica em $1,5 \mu \mathrm{m}$ a temperatura ambiente (b). 
Tem sido observado [45] que a homogeneidade de tamanho, forma e composição química pode ser fortemente favorecida através de tratamentos térmicos (tratamento térmico) nas amostras de pontos quânticos, resultando em estreitamento das emissões de PL e ganho de intensidade. A figura 4.6 mostra os espectros de PL a $77 \mathrm{~K}$ da amostra de 4,0MC de InAs após a realização de um tratamento térmico de 3 horas a $550^{\circ} \mathrm{C}\left(40^{\circ} \mathrm{C}\right.$ acima da temperatura de crescimento) em comparação com o espectro da mesma amostra antes do tratamento térmico. Observa-se um ganho de intensidade de cerca de três vezes na integral do sinal, e pelo menos cinco picos de emissão passam a ser visíveis após o tratamento térmico. $\mathrm{O}$ aumento na intensidade da PL é um efeito direto do tratamento térmico que tende a reduzir a densidade de centros de recombinação não radiativa presentes na camada de pontos quânticos. Um deslocamento de cerca de $50 \mathrm{meV}(\sim 0,1 \mu \mathrm{m})$ é observado entre os estados de mais baixa energia nos dois espectros. Esse efeito é atribuído à ativação térmica de trocas entre átomos de In dos pontos quânticos e átomos de Ga do cap layer. O efeito mais importante do tratamento térmico foi, no entanto, o de revelar múltiplas emissões com excelente resolução. Como já mencionado, a presença de vários estados é uma característica de amostras de pontos quânticos que pode ser usada para aprofundar o entendimento da natureza do espectro. Os espectros do canto superior esquerdo da figura 4.6 mostram a dependência dessas emissões em função da densidade de potência de excitação. Baseado no que foi discutido na seção 3.3 é pouco provável que os dois picos em mais baixa energia façam parte de uma mesma família de pontos quânticos.

A figura 4.7 mostra o espectro da amostra de 4,0MC de InAs (com tratamento térmico) excitada com uma potência moderada de $0,2 \mathrm{kWcm}^{-2}$ a $100 \mathrm{~K}$. Ajustes com curvas gaussianas foram usados para deconvoluir as emissões e auxiliar na interpretação desse complexo espectro. Como indicado na figura, cinco gaussianas são necessárias para o adequado ajuste do espectro. De modo semelhante ao que foi feito nas medidas de PL em função da densidade de potência de excitação da seção 3.3, o comportamento relativo das emissões deconvoluídas do espectro da figura 4.7 foi estudado em detallhe. Quando a potência de excitação é reduzida para patamares muito baixos $\left(\sim 4 \mathrm{Wcm}^{-2}\right)$ em medidas a $2 \mathrm{~K}$, apenas os picos 1 e 3 permanecem, conforme ilustrado no canto superior direito da figura 4.7, o que sugere que tais emissões estão associadas a potenciais de confinamento distintos. Há, no entanto, uma mistura de estados excitados provavelmente originados por 
mais que uma família de estruturas que torna a interpretação das medidas em função da potência muito difíceis de serem interpretadas. As emissões podem ser consideradas estreitas $(\sim 30 \mathrm{meV})$ e típicas de pontos quânticos crescidos no regime de baixa taxa de crescimento

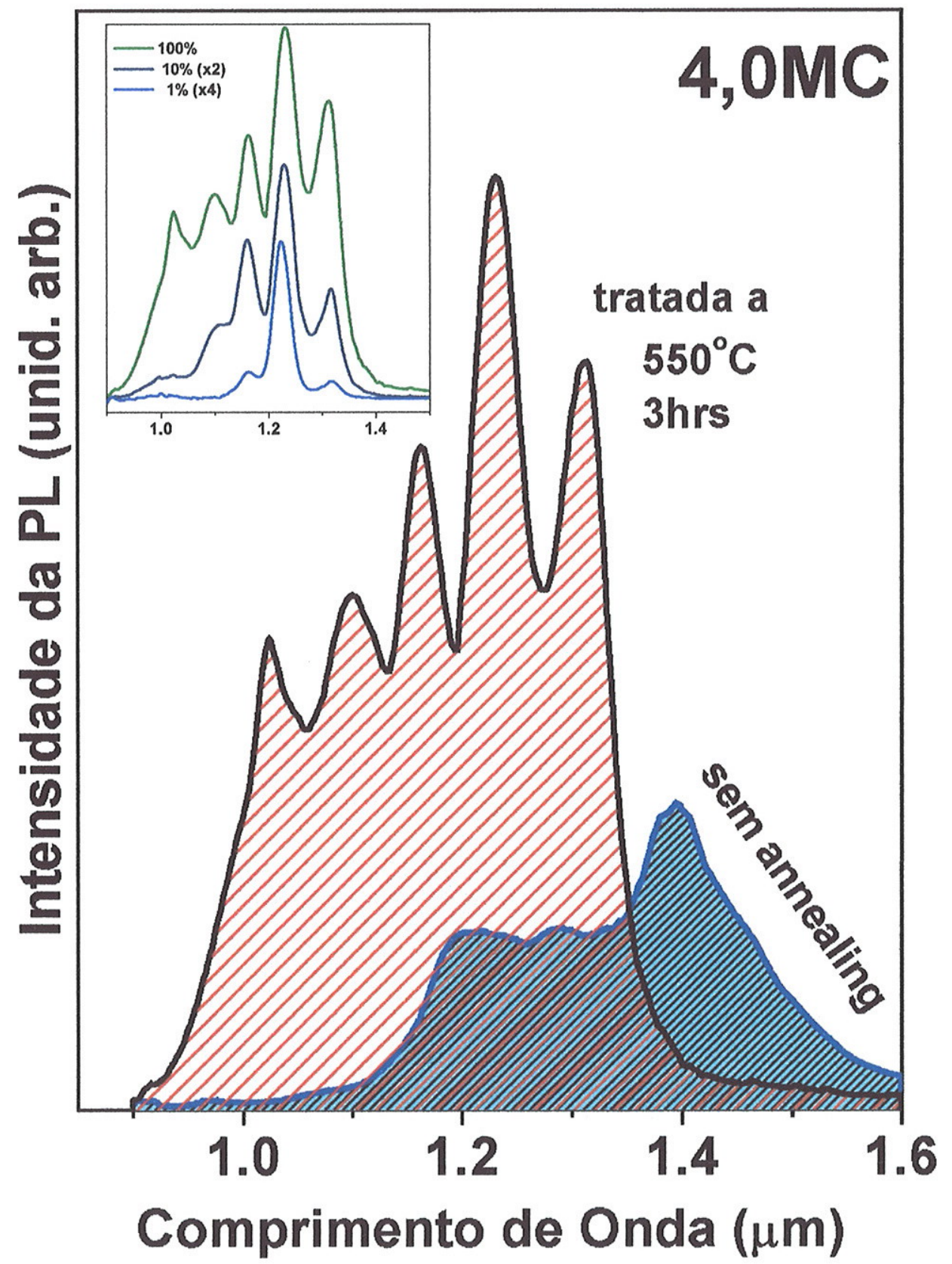

Figura 4.6 - Espectros de PL (77K) da amostra de 4,0MC antes e depois do tratamento térmico de 3 horas a $550^{\circ} \mathrm{C}$, mostrando os efeitos de aumento de intensidade e resolução de múltiplas emissões. Os espectros do canto superior esquerdo mostram o comportamento das emissões da amostra após tratamento térmico em função da densidade de potência de excitação. 


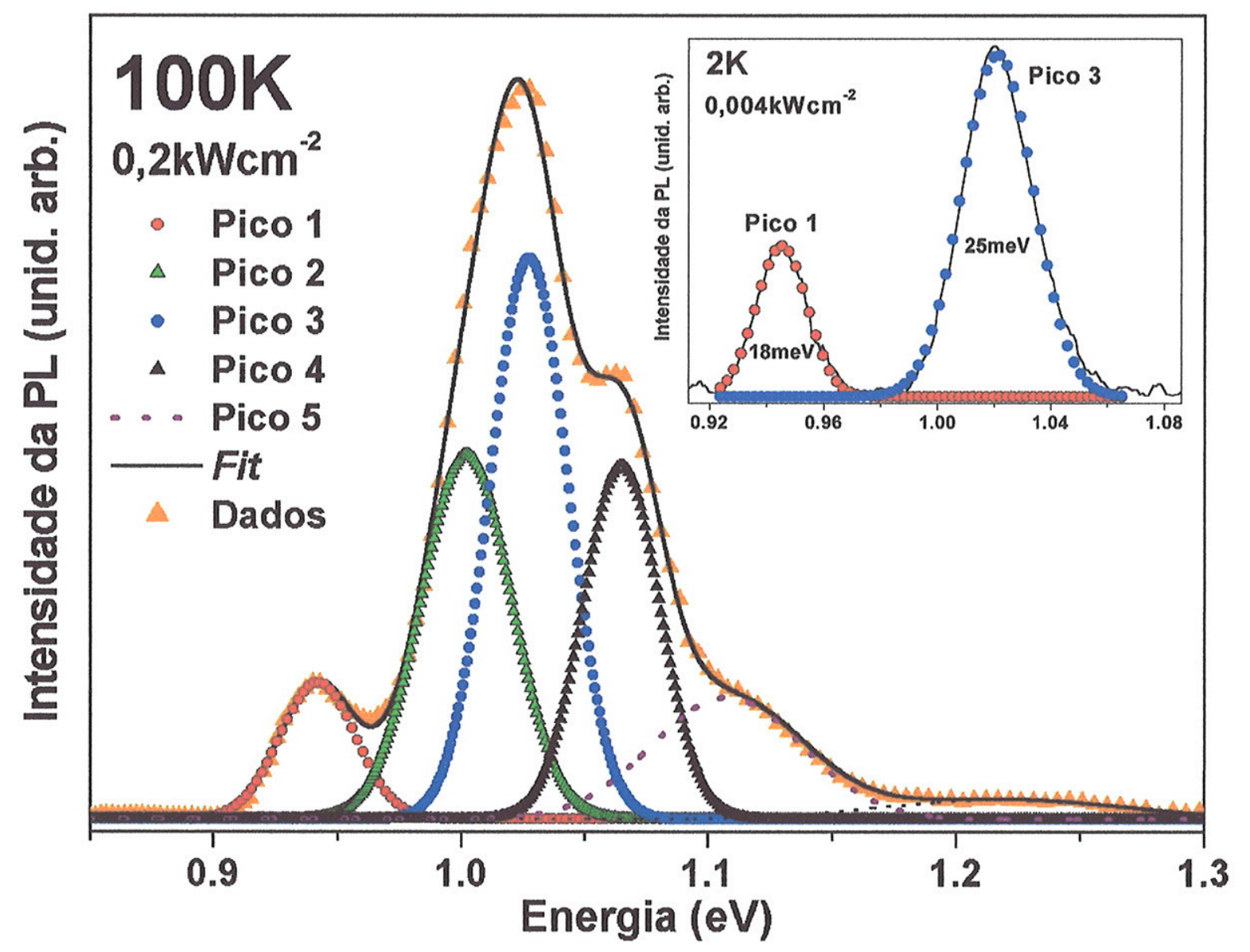

Figura 4.7 - Espectro de PL a 100K da amostra com 4,0MC (após tratamento térmico) onde aparecem cinco emissões deconvoluídas através de ajustes com curvas gaussianas. Quando a temperatura e a densidade de potência de excitação são reduzidas, o espectro se resume em duas emissões estreitas (canto superior direito).

A figura 4.8 mostra (em escala logarítmica) o comportamento da intensidade da PL dos quatro primeiros picos (a partir do lado de baixa energia) deconvoluídos do espectro da figura 4.7 em função da temperatura na faixa de $2 \mathrm{~K}$ a $300 \mathrm{~K}$. Pode ser observado que só há redução na intensidade das emissões a partir de cerca de $100 \mathrm{~K}$, quando os picos 1 e 2 começam a decrescer em intensidade. Essa estabilidade térmica das emissões é típica do potencial de confinamento dos pontos quânticos. Para comparação, pode-se observar o comportamento da intensidade da emissão associada ao buffer de GaAs, reportada no canto inferior direito da figura 4.8. O aumento de intensidade detectado para os picos 3 e 4, em torno de 130-150K mostra uma transferência de portadores a partir de outros potênciais de confinamento concorrentes, tais como os associados com os picos 1 e 2 . É muito 
interessante observar o comportamento da emissão do GaAs nessa mesma faixa de temperaturas onde a intensidade sofre um forte e abrupto incremento, sugerindo que os portadores são emitidos pelo aumento da temperatura para o continuum do GaAs e então parcialmente recapturados pelo potencial representado pelos picos 3 e 4 .

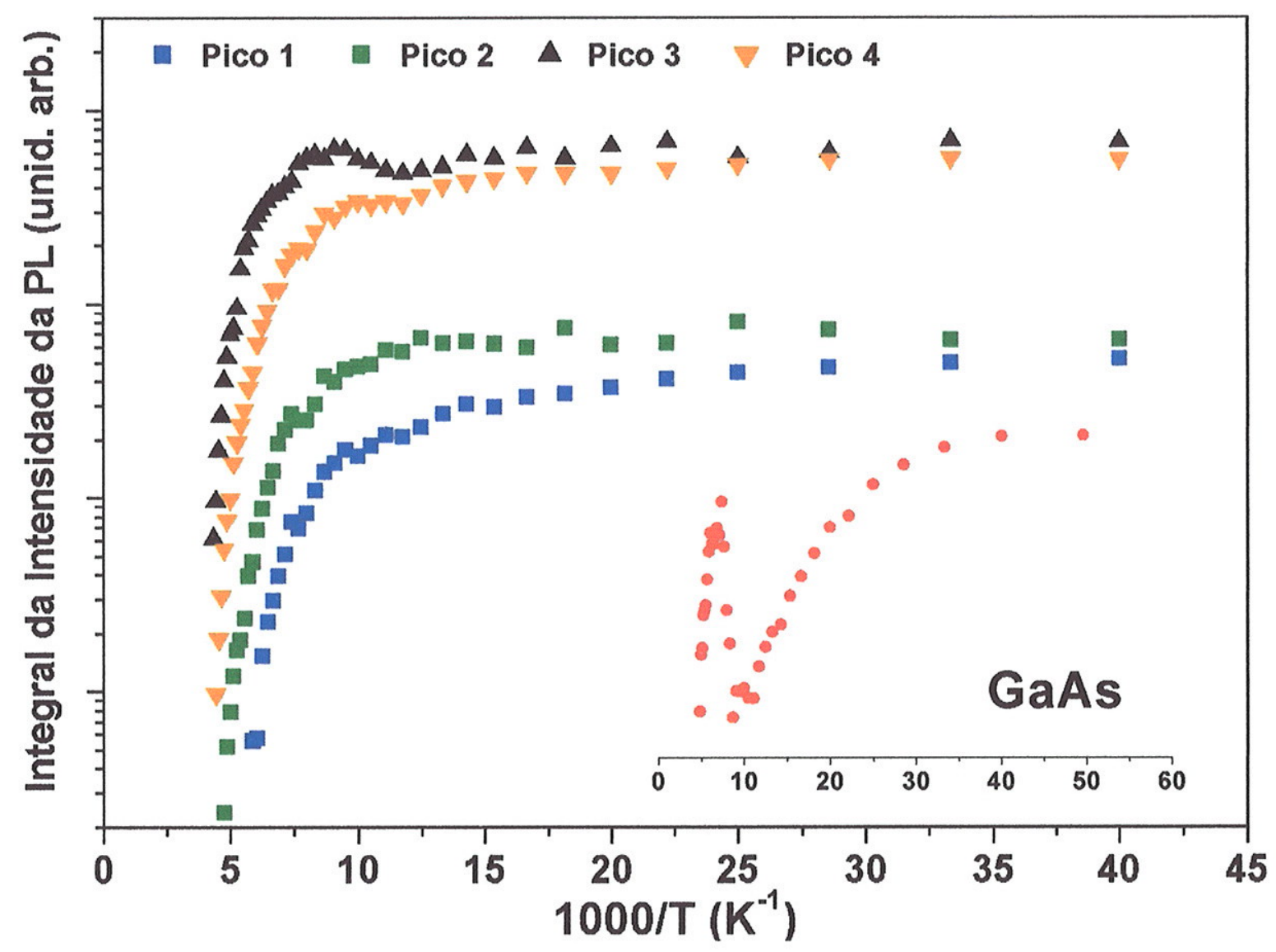

Figura 4.8 - Comportamento da intensidade da PL dos 4 primeiros picos de emissão detectados no espectro da figura 4.7. A transferência de portadores através do GaAs é evidenciada pela abrupta variação de sua emissão em torno de 150K (canto inferior direito).

A baixa densidade de pontos quânticos $\left(<1 \times 10^{9} \mathrm{~cm}^{-2}\right)$, a presença de ilhas relaxadas e a necessidade de tratamento térmico para o refinamento das emissões tornam a interpretação dos espectros da amostra de 4,0MC crescida a $0,003 \mathrm{MC} / \mathrm{s}$ e $510^{\circ} \mathrm{C}$ extremamente difícil. Por outro lado, a mostra crescida a $0,01 \mathrm{MC} / \mathrm{s}$ e $520^{\circ} \mathrm{C}$ mostra através da imagem AFM da figura 4.3 a presença de pontos quânticos semelhantes aos encontrados na amostra de 4,0MC (com $14 \mathrm{~nm}$ de altura), porém num cenário muito mais favorável, 
onde a densidade é cerca de 10 vezes maior e a formação de estruturas relaxadas foi severamente reduzida. A figura 4.9 mostra o espectro de PL dessa amostra a $2 \mathrm{~K}$ (figura 4.9a) em comparação com a amostra crescida na mesma taxa a $490^{\circ} \mathrm{C}$ (figura $4.9 \mathrm{~b}$ ), já discutida no capítulo 3 (figura 3.14). Nesse caso, não há qualquer complicação na interpretação das emissões ópticas que são qualitativamente idênticas àquelas discutidas no capítulo 3. Há porém um significativo ganho em sintonia em direção à região da banda $\mathrm{C}$ $(\sim 65 \mathrm{meV})$, colocando a emissão do estado fundamental em $1,3 \mu \mathrm{m}$ em baixa temperatura $(\sim 1,4 \mu \mathrm{m}$ a $300 \mathrm{~K})$, o que foi possível pelo crescimento de pontos quânticos ainda maiores que aqueles já obtidos no capítulo anterior. Esses resultados sugerem que as condições de crescimento usadas nessa amostra representam um caminho viável para o desafio de se sintonizar a emissão na vizinhança de $1,5 \mu \mathrm{m}$ no sistema $\mathrm{InAs} / \mathrm{GaAs}$ através do crescimento de pontos quânticos em baixa taxa de deposição.

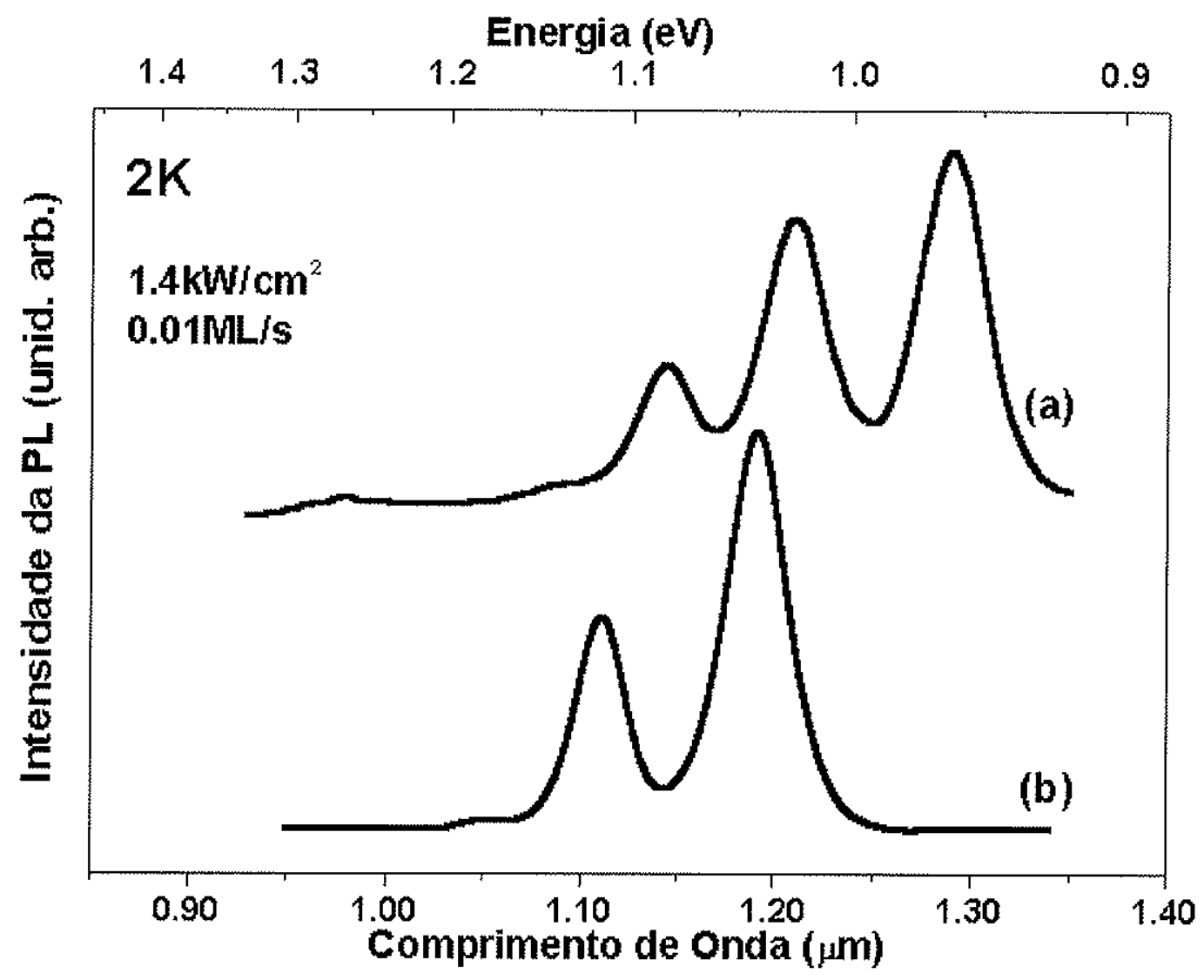

Figura 4.9 - Espectro de PL $(2 \mathrm{~K})$ da amostra com cap layer da figura 4.3, onde se evidencia o significativo (65meV) ganho em sintonia na direção de alto comprimento de onda. O espectro (b) refere-se à amostra crescida na mesma taxa, porém com a temperatura do substrato em $490^{\circ} \mathrm{C}$. 


\section{Capítulo 5}

\section{Considerações finais e conclusão}

Nesse capítulo serão apresentadas as conclusões do trabalho, bem com algumas considerações a respeito de atividades de pesquisa adicionais desenvolvidas ao longo da tese, que sugerem possíveis linhas de pesquisa para o aprofundamento do estudo visando uma aplicação prática das estruturas de pontos quânticos crescidos em baixa taxa. Ao final será apresentada a lista de trabalhos publicados durante a execução do projeto. 


\section{1 -Acoplamento vertical vs. baixa taxa de crescimento}

Há cerca de quatro anos, o método do acoplamento vertical de camadas sucessivas de pontos quânticos começou a ser sistematicamente estudado por muitos grupos como uma tentativa de se deslocar as emissões ópticas de pontos quânticos do sistema InAs/GaAs para as faixas de interesse na região de longo comprimento de onda. No início desse projeto, abordamos esse problema afim de investigar a viabilidade do acoplamento vertical para sintonizar as emissões em torno de $1,3 \mu \mathrm{m}$.

Para que se promova o acoplamento entre estados de pontos quânticos alinhados verticalmente, de modo que cada pilha de ilhas atue como um único ponto quântico, gerando uma estrutura com altura efetiva muito maior que aquela normalmente obtida em uma única camada de InAs, é necessário que as camadas sucessivas sejam espaçadas por um filme de GaAs muito fino. A figura 5.1 mostra os espectros de PL (2K) de um conjunto de amostras crescidas para se investigar a possibilidade de acoplamento vertical de níveis através do empilhamento de 2, 3 e 5 camadas sucessivas de pontos quânticos de InAs espaçadas por $5 \mathrm{~nm}$ de GaAs e crescidas a $0,05 \mathrm{MC} / \mathrm{s}$ e $490^{\circ} \mathrm{C}$. A caracterização morfológica das amostras sem cap layer mostrou que a primeira camada de pontos quânticos (amostra de referência) apresenta estruturas com densidade de $3 \times 10^{10} \mathrm{~cm}^{-2}$ e altura média em torno de 7,0nm. É possível observar na figura 5.1 que, ao contrário do esperado, o empilhamento de múltiplas camadas conduz a um blueshift das emissões em relação à amostra de referência, que possui uma única camada de pontos quânticos. Esse resultado mostra que mesmo se o acoplamento está presente, existe algum outro efeito atuando no sentido inverso, forçando as emissões a se deslocarem para menores comprimentos de onda. No começo do ano 2000 , Lipnski et al. [24] demonstraram que a proximidade entre as camadas de pontos quânticos sucessivas promove uma forte interação entre os campos de tensão cujo efeito é acentuar a troca de átomos de In dos pontos quânticos por átomos de Ga da camada espaçadora de GaAs, reduzindo assim a concentração de In nas ilhas e deslocando as emissões para alto comprimento de onda, como observado. 


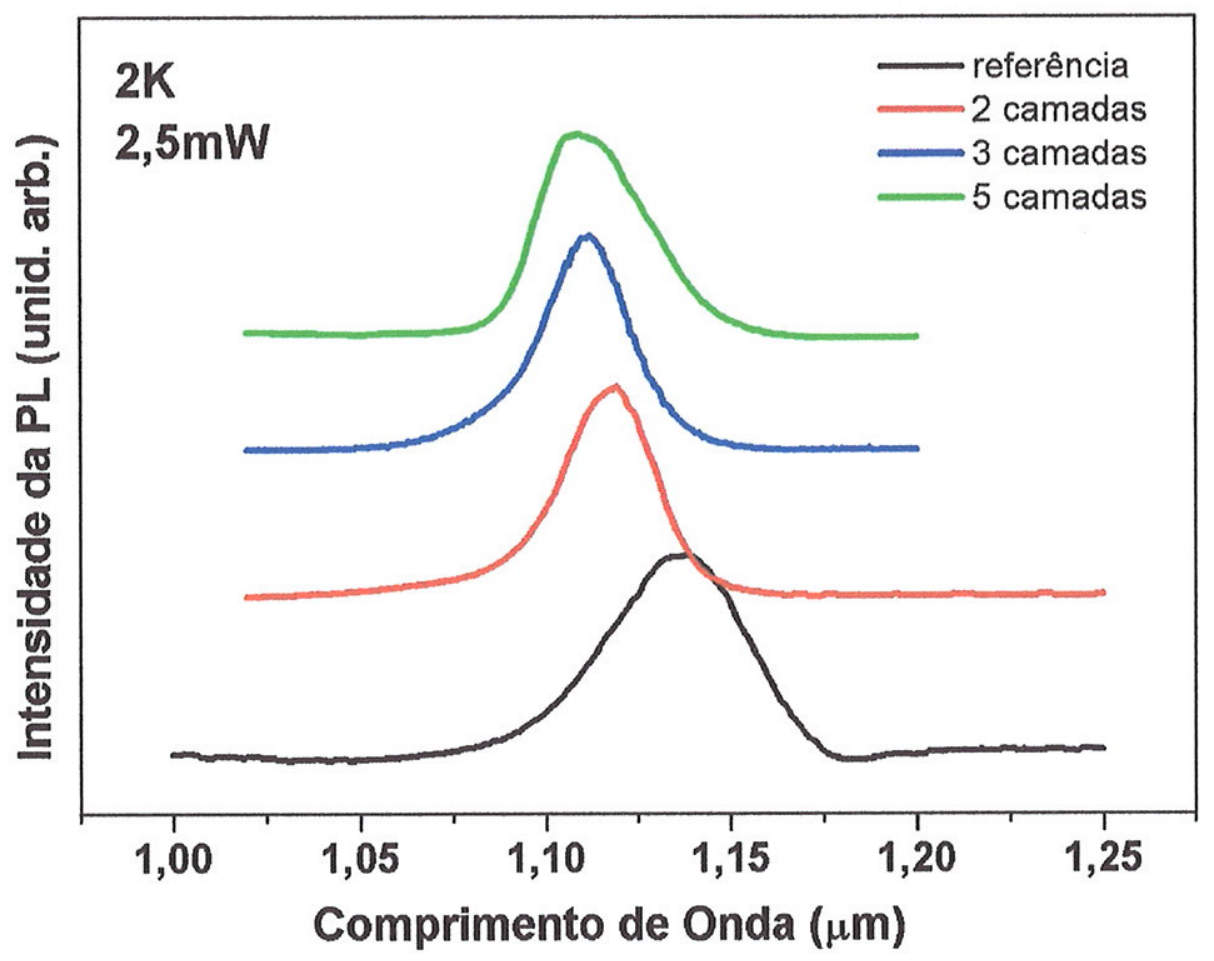

Figura 5.1 - Espectros de PL (2K) de amostras com 1, 2, 3 e 5 camadas de pontos quânticos sucessivas espaçadas por $5 \mathrm{~nm}$ de GaAs.

Em comparação com o crescimento de pontos quânticos em baixa taxa, o alinhamento vertical, caso fosse viável, representaria uma alternativa com uma vantagem inegável: maior densidade superficial de pontos quânticos. Conforme demonstrado nos capítulos anteriores, a redução da taxa de crescimento reduz também a densidade de estruturas em relação àquela que pode ser obtida no regime de taxa de crescimento mais elevada. Apesar disso, o acoplamento vertical como meio para se tentar sintonizar as emissões na faixa de $1,3 \mu \mathrm{m}$ parece ter sido totalmente abandonado atualmente. 


\section{2 - Controle da densidade de pontos quânticos crescidos em baixa taxa}

Apesar do estudo do acoplamento vertical como método de sintonia dos pontos quânticos na faixa de interesse ter falhado, a possibilidade de alinhamento vertical de ilhas, mesmo quando a distância é muito maior que a necessária para o acoplamento eletrônico, sugere um artifício que pode ser usado para se tentar controlar a densidade superficial de estruturas crescidas no regime de baixa taxa de deposição. A idéia se baseia em depositar a camada de pontos quânticos a baixa taxa sobre uma camada de ilhas crescidas com taxa convencional, mantendo uma separação da ordem de $10 \mathrm{~nm}$ de GaAs entre as duas camadas. Espera-se que essa distância seja suficiente para promover o alinhamento sem amplificar muito o efeito de intermixing In-Ga. Assim, como os pontos quânticos da camada inferior (camada semente) possuem uma densidade na faixa de $3-5 \times 10^{10} \mathrm{~cm}^{-2}$ e o espaçamento de GaAs é suficientemente pequeno para permitir o alinhamento vertical entre as camadas pela influência do campo de tensão da camada inferior, pode-se esperar um significativo aumento na densidade das ilhas crescidas mesmo com baixa taxa de deposição na segunda camada, caso seja mantida a correlação vertical. A figura 5.2 mostra imagens AFM de um conjunto de amostras elaborado para verificar esse efeito. A figura 5.2 a mostra a superfície de uma amostra com pontos quânticos crescidos a $0,003 \mathrm{MC} / \mathrm{s}$, exibindo uma densidade característica dessa condição de crescimento da ordem de $5 \times 10^{9} \mathrm{~cm}^{-2}$. A amostra usada como semente (figura $5.2 \mathrm{~b}$ ), crescida com uma taxa de $0,05 \mathrm{MC} / \mathrm{s}$, apresenta uma densidade da ordem de $3 \times 10^{10} \mathrm{~cm}^{-2}$. A figura $5.2 \mathrm{c}$ ilustra os pontos quânticos obtidos no regime de baixa taxa quando uma camada como a da figura $5.2 \mathrm{~b}$ foi usada como semente. Observa-se que, nessas condições, a densidade assemelha-se com a densidade da camada semente, o que demonstra a viabilidade do método. Um estudo mais sistemático, procurando otimizar as condições de cresicmento das duas camadas envolvidas bem como o completo monitoramento da resposta óptica necessita, no entanto, ser ainda conduzido para se certificar que a estratégia funciona para atingir o objetivo final. 

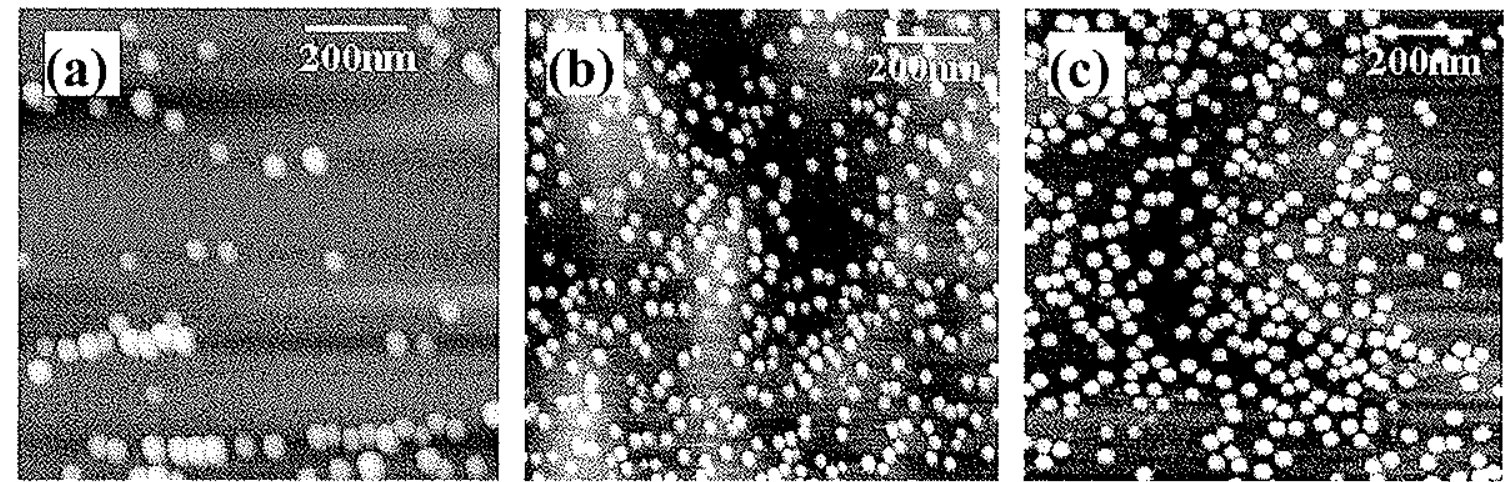

Figura 5.2 - Imagens AFM de uma camada de pontos quânticos obtidos no regime de baixa taxa (a), de uma camada crescida com taxa convencional (b), e de uma camada crescida com baixa taxa (c) tendo uma camada semente como a da figura (b).

\section{3 - O problema do cap layer}

Como demonstrado no capítulo 4, é possível encontrar condições de crescimento tais que pontos quânticos com 14-15nm de altura possam ser fabricados afim de obter-se uma luminescência na faixa de comprimento de onda da banda $C(\sim 1,5 \mu \mathrm{m})$. Quando se compara as respostas ópticas dos pontos quânticos das figuras $4.1 \mathrm{com}$ aquelas da figura 4.3, observa-se que, apesar das dimensões das ithas serem semelhantes, os primeiros emitem em 1,5 $\mu$ m enquanto a emissão de estado fundamental na outra amostra está em torno de $1,4 \mu \mathrm{m}$. Além da taxa de crescimento e temperatura usadas, uma diferença quanto ao crescimento do cap layer pode ser responsável por parte da diferença. O GaAs que cobre os pontos quânticos com emissão em $1,5 \mu \mathrm{m}$ foi depositado em uma taxa de $0,8 \mathrm{MC} / \mathrm{s}$ (relativamente alta para o crescimento de cap layers), enquanto que as estruturas com PL em 1,4 $\mathrm{mm}$ foram cobertas por GaAs crescido com cerca de 0,4MC/s. Como já discutido anteriormente, o processo de recobrimento dos pontos quânticos pode possuir um papel decisivo quanto às alterações morfológicas e químicas nas ilhas e, portanto, um estudo sistemático dos processos de capping deve ser necessariamente realizado para se extrair o ganho máximo em sintonia possível com o crescimento de pontos quânticos em baixa taxa. 


\section{4 - Conclusão do trabalho}

Essa tese se propôs a investigar sistematicamente a possibilidade de estender a atividade óptica do sistema InAs/GaAs para a região de longo comprimento de onda através do crescimento de pontos quânticos no regime de baixa taxa de deposição. Foram encontradas condições de crescimento capazes de gerar pontos quânticos com $10 \mathrm{~nm}$ de

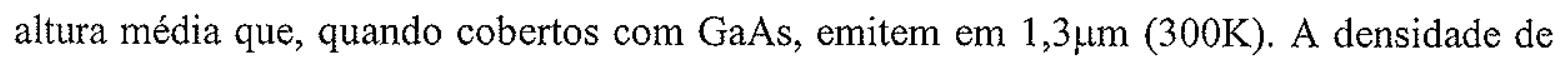
estruturas obtida $\left(1-2 \times 10^{10} \mathrm{~cm}^{-2}\right)$ com o crescimento a $0,01 \mathrm{MC} / \mathrm{s}$ e $490^{\circ} \mathrm{C}$ é cerca de 5 vezes maior que os resultados presentes na literatura, e o grau de homogeneidade alcançado permitiu que as emissões de PL fossem tão estreitas quanto os melhores resultados existentes atualmente. O estudo topográfico por AFM permitiu identificar as etapas envolvidas no crescimento dessas estruturas bem como os limites de incremento de tamanho esperado quando se manipula a taxa de crescimento e a quantidade de InAs depositado. A natureza das emissões ópticas envolvidas (estados excitados, deslocamento térmico, forma de linha, etc.) foram investigadas com algum detalhe.

Apesar da aparente saturação de tamanho máximo, e conseqüentemente do máximo redshift na emissão óptica, sugerir que dificilmente se poderia avançar ainda mais na sintonia rumo à banda em $1,5 \mu \mathrm{m}$, obtivemos resultados promissores nesse sentido através da elevação da temperatura de crescimento mantendo um compromisso com o efeito de reevaporação de material a partir da superfície. Com isso, alcançamos os maiores deslocamentos na direção dos longos comprimentos de onda já reportados para esse sistema quando apenas InAs e GaAs estão envolvidos (i.e. sem adição de outros materiais e/ou uso de ligas ternárias), e os maiores pontos quânticos de InAs, distribuídos com grande uniformidade, foram conseguidos.

Finalmente, os resultados obtidos nesse trabalho mostram que o crescimento MBE no regime de baixa taxa de deposição é capaz de produzir amostras de pontos quânticos promissoras para aplicações práticas nas bandas $\mathrm{O}$ e $\mathrm{C}$, que é onde reside boa parte da motivação para o estudo desse tipo de estrutura. 


\section{5 - Artigos publicados}

1- InAs/GaAs quantum dots optically active at $1.5 \mu \mathrm{m}$

M. J. da Silva, A. A. Quivy, S. Martini, T. E. Lamas, E. C. F. da Silva, J. R. Leite, Appl. Phys. Lett. 82, 2646 (2003);

2 - Low growth rate InAs/GaAs quantum dots for room-temperature luminescence over $1.3 \mu \mathrm{m}$

M. J. da Silva, S. Martini, T. E. Lamas, A. A. Quivy, E. C. F. da Silva, J. R. Leite, Microelec. J. 34, 631 (2003);

3 - Optical response at $1.3 \mu \mathrm{m}$ and $1.5 \mu \mathrm{m}$ with InAs quantum dots embedded in a pure GaAs matrix

M. J. da Silva, A. A. Quivy, S. Martini, T. E. Lamas, E. C. F. da Silva, J. R. Leite,

J. Cryst. Growth, 251, 181 (2003);

4 -- Anomalous blueshift in vertically coupled InAs/GaAs quantum dots using InGaAs strain-reducing layers

M. J. da Silva, A. A. Quivy,

Braz. J. Phys. 32, 290 (2002);

5 - Atomic-force microscopy study of self-assembled InAs quantum dots along their complete evolution cycle

M. J. da Silva, A. A. Quivy, P. P. González-Borrero, E. Marega Jr., J. R. Leite,

J. Cryst. Growth 241, 19 (2002);

6 - Study of the spontaneous alignment of InAs quantum dots along the surface steps as a function of the InAs coverage

M. J. da Silva, A. A. Quivy, P. P. González-Borrero, E. Marega Jr.,

Thin Solid Films 410, 188 (2002);

7 - Maximization of the InAs quantum-dot density through the growth of an intentionally non-homogeneous sample

M. J. da Silva, A. A. Quivy, P. P. González-Borrero, E. Marega Jr.,

J. Cryst. Growth 236, 41 (2002);

8 - Correlation between structural and optical properties of InAs quantum dots along their evolution

M. J. da Silva, A. A. Quivy, P. P. González-Borrero, N. T. Moshegov, E. Marega Jr.,

J. Cryst. Growth 227, 1025 (2001);

9 - Carrier kinetics in quantum dots through continuous wave photoluminescence modeling: A systematic study on a sample with surface dot density gradient

F. V. Sales, J. M. R. Cruz, S. W. da Silva, M. A. G. Soler, P. C. Morais, M. J. da Silva, A. A. Quivy, J. R. Leite,

J. Appl. Phys. 94, 1787 (2003); 
10 - Coupled rate equation modeling of self-assembled quantum dot photoluminescence F. V. de Sales, J. M. R. Cruz, S. W. da Silva, M. A. G. Soler, P. C. Morais, M. J. da Silva, A. A. Quivy, J. R. Leite, Microelc. J. 34, 705 (2003);

11 - Morphological and optical properties of p-type GaAs(001) layers doped with silicon T. E. Lamas, S. Martini, M. J. da Silva, A. A. Quivy, J. R. Leite, Microelec. J. 34, 701 (2003);

12 - Observation of the spectral dependence of the spatial photocarrier redistribution in InAs/GaAs quantum dots

F. V. de Sales, S. W. da Silva, J. M. R. Cruz, M. A. G. Soler, P. C. Morais, M. J. da Silva, A. A. Quivy, J. R. Leite,

Physica E 17, 120 (2003);

13 - CW photoluminescence determination of the capture cross-section of self-assembled InAs quantum dots

J. M. R. Cruz, F. V. de Sales, S. W. da Silva, M. A. G. Soler, P. C. Morais, M. J. da Silva, A. A. Quivy, J. R. Leite,

Physica E 17, 107 (2003);

14 - Photoexcited carrier diffusion in self-assembled InAs/GaAs quantum dots with different dot densities

A. F. G. Monte, F. V. de Sales, S. W. da Silva, M. A. G. Soler, J. M. R. Cruz, P. C. Morais, M. J. da Silva, A. A. Quivy, J. R. Leite,

Physica E 17, 122 (2003);

15 - Influence of the temperature on the carrier capture into self-assembled InAs/GaAs quantum dots

C. A. Duarte, E. C. F. da Silva, A. A. Quivy, M. J. da Silva, S. Martini, J. R. Leite, J. Appl. Phys. 93, 6279 (2003);

16 - Influence of indium segregation on the RHEED oscillations during the growth of InGaAs layers on a GaAs(001) surface

S. Martini, A. A. Quivy, T. E. Lamas, M. J. da Silva, E. C. F. da Silva, J. R. Leite, J. Cryst. Growth 251, 101 (2003);

17 - Influence of illumination on the quantum mobility of a two-dimensional electron gas in Si $\delta$ doped GaAs/In $0.15 G a_{0.85}$ As quantum wells

A. Cavalheiro, E. C. F. da Silva, A. A. Quivy, E. K. Takahashi, S. Martini, M. J. da Silva, E. A. Meneses, J. R. Leite,

J. Phys.: Cond. Matter 15, 121 (2003);

18 - Excitation Transfer through quantum dots measured by microluminescence: dependence on the quantum dot density 
F. V. de Sales, S. W. da Silva, A. F. G. Monte, M. A. G. Soler, J. M. R. Cruz, M. J. da Silva, A. A. Quivy, J. R. Leite, P. C. Morais, Phys. Stat. Sol. 187, 45 (2001);

\section{6 - Artigos submetidos}

1 - Large InAs/GaAs quantum dots with an optical response in the long-wavelength region M. J. da Silva, A. A. Quivy, S. Martini, T. E. Lamas, E. C. F. da Silva and J. R. Leite

Submetido para J. Phys. Cond. Matter (2003);

2 - Ex-situ investigation of indium segregation in InGaAs/GaAs quantum wells using high resolution $x$-ray diffraction

S. martini, A. A. Quivy, M. J. da Silva, T. E. Lamas, E. C. F. da Silva, J. R. Leite, E. Abramof,

Aceito para publicação no J. Appl. Phys. (2003);

3 - Smooth p-type GaAs(001) films grown by molecular-beam epitaxy using silicon as the dopant

T. E. lamas, A. A. Quivy, S. Martini, M. J. da Silva, J. R. Leite, Submetido para Thin Solid Films (2003); 


\section{Referências}

[1] N. W. Ashcroft e N. D. Mermin, Solid State Physiscs (Saunders College, 1975)

[2] L. V. Keldysh, Sov. Phys. Solid State 4, 2265 (1962)

[3] R. Davies e H. Hosack, J. Appl. Phys. 33, 864 (1963)

[4] R. Dinlge, W. Wiegman e C. H. Henry, Phys. Rev. Lett. 33, 827 (1974)

[5] A. I. Ekimov e A. A. Onuschenko, JETP Lett. 34, 345 (1981)

[6] A. Scherer e H. G. Craighead, Appl. Phys. Lett. 49, 1284 (1986)

[7] D. J. Eaglesham e M. Cerullo, Phys. Rev. Lett. 64, 1943 (1990)

[8] S. Guha, A. Madhukar e K. C. Rajkumar, Appl. Phys. Lett. 57, 2110 (1990)

[9] D. Leonard, M. Krishnamurthy, C. M. Reaves, S. P. Denbaars e P. M. Petroff, Appl.

Phys. Lett. 63, 3203 (1993)

[10] G. T. Liu, A. Stintz, H. Li, K. J. Malloy e L. F. Lester, Elec. Lett. 35, (1999)

[11] L. F. Lester, A. Stintz, H. Li, T. C. Newell, E. A. Pease, B. A. Fuchs e K. J. Malloy, IEEE 11, 931 (1999)

[12] P. B. Joyce, T. J. Krzyzewski, G. R. Bell, T. S. Jones, E. C. Le Ru e R. Murray, Phys. Rev. B 64, 235317 (2002)

[13] K. G. Günther, Z. Naturforsch. A. 13a, 1081 (1958).

[14] J. E. Davey, T., J.Pankey, Appl. Phys. 39, 1941 (1968).

[15] M. A. Herman, H. Sitter, Molecular Beam Epitaxy, Spring Series in Materials Science 7, (1996).

[16] A. Madhukar, S. V Ghaisas, CRC Critical Rev.in Sol. Stat. Phys. And Mat. Scie. 14, 1$130(1988)$

[17] Arthur, J. R.; Brown, T. R.; J. Vac. Sci. Technol. 12, 200, (1975).

[18] Foxon, C. T., Joyce, B. A., Surf. Sci., 50, 434, (1975).

[19] Foxon, C. T., Joyce B. A., Surf. Sci., 64, 293, (1977).

[20] D. J. Eaglesham, M. Cerullo, Phys. Rev. Lett., 64, 1943 (1990). 
[21] S. Guha, A. Madhukar, K. C. Rajkumar, Appl. Phys. Lett., 57, 2110 (1990).

[22] A. J. Durelli, E. A. Phillips, C. H. Tsao, Introduction to the theoretical and experimental analysis of stress and strain, McGraw-Hill (1958).

[23] J. Y. Tsao, Materials Fundamentals on Molecular Beam Epitaxy, Academic Press, (1993).

[24] J. Massies, N. Grandjean, Phys. Rev. Lett., 71, 1411 (1993).

[25] - Y. Nabetani, T. Ishikawa, S. Noda, " Sasaki, J. Appl. Phys. 76, 347 (1994).

[26] - A. L. Sperandio, Dissertação de Mestrado, Universidade de São Paulo (1998); M. J.

da Silva, Dissertação de Mestrado, Universidade de São Paulo (1999).

[27] - S. Martini, Dissertação de Doutorado, Universidade de São Paulo (2002).

[28] - Y. Arakawa, H. Sakaki, Appl. Phys. Lett. 40, 939 (1982)

[29] - D. J. Eaglesham, M. Cerullo, Phys. Rev. Lett. 64, 1943 (1990)

[30] - D. Leonard, M. Krishnamurthy, C. M. Reaves, S. P. Denbaars, P. M. Petroff, Appl.

Phys. Lett. 63, 3203 (1993)

[31] - A. Madhukar, Q. Xie, P. Chen, A. Konkar, Appl. Phys. Lett. 64, 2727 (1994)

[32] - R. Murray, S. Malik, P. Siverns, D. Childs, C. Roberts, B. Joyce, H. Davock, Jpn. J.

Appl. Phys. 38, 496 (1999)

[33] - G. S. solomon, J. A. Trezza, A. F. Marshall, J. S. Harris Jr., Aplpl. Phys.Lett., 76, $952(1996)$

[34] - M. J. da Silva, A. A Quivy, Braz. J. of Phys., 32, 290 (2002)

[35] - M. O. Lipnski, H. Schuler, O. G. Schmidt, K. Eberl, Appl. Phys. Lett. 77, 1789

(2000)

[36] - Y. Nakata, J. Crys. Growth, 208, 93 (200) 
[37] - P. B. Joyce, T. J. Krzyzewski, G. R. Bell, T. S. Jones, s. Malik, D. Childs, R.

Murray, Phys. Ver. B, 62, 10891 (2000).

[38] - K. Nishi, H. Saito, S. Sugou, J. Lee, Appl. Phys. Lett., 74, 1111 (1999)

[39] - M. J. da Silva, S. Martini, T. E. Lamas, A. A. Quivy, E. C. F. da Silva, J. R. Leite,

Mic. Journal, 34, 631 (2003).

[40] - H. Ishikawa, H. Shoji, Y. Nakata, K. Mukai, M. Sugawara, M. Egawa, N. Otsuka, Y.

Sugiyama, T. Futatsugi, and N. Yokoyama, J. Vac. Sci. Technol. A 16, 794 (1998)

[41] - M. Sugawara, Y. Nakata, K. Mukai, H. Shoji, Phys. Ver. B, 55, 13155 (1997)

[42] - D. I. Lubyshev, P. P. Gonzáles-Borrero, E. Marega Jr., E. Petitprez, N. La Scala, P.

Basmaji, Appl. Phys. Lett., 68, 205 (1996).

[43] - M. J. da Silva, A. A. Quivy, P. P. González-Borrero, E. Marega Jr., J. R. Leite, J.

Crys. Growth, 241, 19 (2002).

[44] - P. B. Joyce, T. J. Krzyzewski, G. R. Bell, T. S. Jones, E. C. Le Ru, R. Murray, Phys.

Rev. B, 64, 235317 (2001).

[45] - S. Fafard, Z. R. Wasilewski, C. Ni. Allen, D, Picard, M. Spanner, J. P. McCaffrey, P.

G. Piva, Phys. Rev. B, 59, 15368 (1999). 